\title{
Long-term observations of cloud condensation nuclei in the Amazon rain forest - Part 1: Aerosol size distribution, hygroscopicity, and new model parametrizations for $\mathrm{CCN}$ prediction
}

\author{
Mira L. Pöhlker ${ }^{1}$, Christopher Pöhlker ${ }^{1}$, Florian Ditas ${ }^{1}$, Thomas Klimach ${ }^{1}$, Isabella Hrabe de Angelis ${ }^{1}$, \\ Alessandro Araújo ${ }^{2}$, Joel Brito ${ }^{3, a}$, Samara Carbone ${ }^{3, b}$, Yafang Cheng ${ }^{1}$, Xuguang Chi ${ }^{1, c}$, Reiner Ditz ${ }^{1}$, \\ Sachin S. Gunthe ${ }^{4}$, Jürgen Kesselmeier ${ }^{1}$, Tobias Könemann ${ }^{1}$, Jošt V. Lavrič ${ }^{5}$, Scot T. Martin ${ }^{6}$, Eugene Mikhailov ${ }^{7}$, \\ Daniel Moran-Zuloaga ${ }^{1}$, Diana Rose ${ }^{8}$, Jorge Saturno ${ }^{1}$, Hang Su ${ }^{1}$, Ryan Thalman ${ }^{9, d}$, David Walter ${ }^{1}$, Jian Wang ${ }^{9}$, \\ Stefan Wolff ${ }^{1,10}$, Henrique M. J. Barbosa ${ }^{3}$, Paulo Artaxo ${ }^{3}$, Meinrat O. Andreae ${ }^{1,11}$, and Ulrich Pöschl ${ }^{1}$ \\ ${ }^{1}$ Multiphase Chemistry and Biogeochemistry Departments, Max Planck Institute for Chemistry, 55020 Mainz, Germany \\ ${ }^{2}$ Empresa Brasileira de Pesquisa Agropecuária (EMBRAPA), Trav. Dr. Enéas Pinheiro, Belém, PA, 66095-100, Brazil \\ ${ }^{3}$ Institute of Physics, University of São Paulo, São Paulo, 05508-900, Brazil \\ ${ }^{4}$ EWRE Division, Department of Civil Engineering, Indian Institute of Technology Madras, Chennai 600036, India \\ ${ }^{5}$ Department of Biogeochemical Systems, Max Planck Institute for Biogeochemistry, 07701 Jena, Germany \\ ${ }^{6}$ School of Engineering and Applied Sciences, Harvard University, Cambridge, MA 02138, USA \\ ${ }^{7}$ St. Petersburg State University, 7/9 Universitetskaya nab, St. Petersburg, 199034, Russia \\ ${ }^{8}$ Institute for Atmospheric and Environmental Research, Goethe University Frankfurt am Main, 60438 Frankfurt, Germany \\ ${ }^{9}$ Biological, Environmental \& Climate Sciences Department, Brookhaven National Laboratory, Upton, NY 11973, USA \\ ${ }^{10}$ Instituto Nacional de Pesquisas da Amazonia (INPA), Manaus, 69083-000, Brazil \\ ${ }^{11}$ Scripps Institution of Oceanography, University of California San Diego, La Jolla, CA 92037, USA \\ ${ }^{a}$ now at: Laboratory for Meteorological Physics, University Blaise Pascal, Clermont-Ferrand, France \\ b now at: Federal University of Uberlândia, Uberlândia-MG, 38408-100, Brazil \\ ${ }^{\mathrm{c}}$ now at: Institute for Climate and Global Change Research \& School of Atmospheric Sciences, Nanjing University, \\ Nanjing, 210093, China \\ dnow at: Department of Chemistry, Snow College, Richfield, UT 84701, USA
}

Correspondence to: Mira L. Pöhlker (m.pohlker@mpic.de)

Received: 16 June 2016 - Published in Atmos. Chem. Phys. Discuss.: 23 June 2016

Revised: 18 October 2016 - Accepted: 7 November 2016 - Published: 20 December 2016

\begin{abstract}
Size-resolved long-term measurements of atmospheric aerosol and cloud condensation nuclei $(\mathrm{CCN})$ concentrations and hygroscopicity were conducted at the remote Amazon Tall Tower Observatory (ATTO) in the central Amazon Basin over a 1-year period and full seasonal cycle (March 2014-February 2015). The measurements provide a climatology of CCN properties characteristic of a remote central Amazonian rain forest site.

The CCN measurements were continuously cycled through 10 levels of supersaturation $(S=0.11$ to $1.10 \%$ ) and span the aerosol particle size range from 20 to $245 \mathrm{~nm}$. The mean critical diameters of $\mathrm{CCN}$ activation range from
\end{abstract}

$43 \mathrm{~nm}$ at $S=1.10 \%$ to $172 \mathrm{~nm}$ at $S=0.11 \%$. The particle hygroscopicity exhibits a pronounced size dependence with lower values for the Aitken mode $\left(\kappa_{\text {Ait }}=0.14 \pm 0.03\right)$, higher values for the accumulation mode $\left(\kappa_{\mathrm{Acc}}=0.22 \pm 0.05\right)$, and an overall mean value of $\kappa_{\text {mean }}=0.17 \pm 0.06$, consistent with high fractions of organic aerosol.

The hygroscopicity parameter, $\kappa$, exhibits remarkably little temporal variability: no pronounced diurnal cycles, only weak seasonal trends, and few short-term variations during long-range transport events. In contrast, the $\mathrm{CCN}$ number concentrations exhibit a pronounced seasonal cycle, tracking the pollution-related seasonality in total aerosol concentra- 
tion. We find that the variability in the $\mathrm{CCN}$ concentrations in the central Amazon is mostly driven by aerosol particle number concentration and size distribution, while variations in aerosol hygroscopicity and chemical composition matter only during a few episodes.

For modeling purposes, we compare different approaches of predicting $\mathrm{CCN}$ number concentration and present a novel parametrization, which allows accurate $\mathrm{CCN}$ predictions based on a small set of input data.

\section{Introduction}

\subsection{Atmospheric aerosols and clouds}

In our current understanding of the Earth's climate system and its man-made perturbation, the multiscale and feedbackrich life cycles of clouds represent one of the largest uncertainties (Boucher et al., 2013; Stevens et al., 2016). Accordingly, the adequate and robust representation of cloud properties is an Achilles' heel in climate modeling efforts (Bony et al., 2015). Atmospheric aerosols are a key ingredient in the life cycle of clouds (known as aerosol indirect effect) as they affect their formation, development, and properties by acting as cloud condensation nuclei $(\mathrm{CCN})$ and ice nuclei (IN) (Lohmann and Feichter, 2005; Rosenfeld et al., 2008). Aerosol particles can originate from various natural and anthropogenic sources and span wide ranges of concentration, particle size, composition, as well as chemical and physical properties (Pöschl, 2005). Their activation into cloud droplets depends on their size, composition, and mixing state as well as the water vapor supersaturation (e.g., Köhler, 1936; Dusek et al., 2006; McFiggans et al., 2006; Andreae and Rosenfeld, 2008; Su et al., 2010). The microphysical link between clouds and aerosol has been the subject of manifold and long-term research efforts. On one hand, the cycling of $\mathrm{CCN}$ as well as their relationship to the aerosol population has been studied in a variety of field experiments worldwide (e.g., Gunthe et al., 2009; Rose et al., 2010; Jurányi et al., 2011; Paramonov et al., 2015). On the other hand, the knowledge obtained from the growing body of field data has been translated into different parametrization strategies that represent the cloud-aerosol microphysical processes in modeling studies (e.g., Nenes and Seinfeld, 2003; Petters and Kreidenweis, 2007; Su et al., 2010; Deng et al., 2013; Mikhailov et al., 2013).

\subsection{Amazon rain forest and its hydrological cycle}

The Amazon rain forest is a unique and important ecosystem for various reasons such as its high density and diversity of life, its role as major carbon storage, and its large recycling rate of energy and water in the Earth's hydrological cycle (Brienen et al., 2015; Gloor et al., 2015; Olivares et al., 2015; Yáñez-Serrano et al., 2015). In times of global change, the man-made disturbance and pressure on this ecosystem have strongly increased and have started a transition of the Amazon into an uncharted future (Davidson et al., 2012; Lawrence and Vandecar, 2015). In the context of atmospheric composition, the Amazon is unique since it represents one of the last terrestrial locations worldwide that allows - at least for part of the year - to investigate an relatively undisturbed state of the atmosphere in the absence of major anthropogenic pollution (Roberts et al., 2001; Andreae, 2007; Andreae et al., 2012; Hamilton et al., 2014).

Overall, the troposphere over the Amazon is defined by the alternation of a relatively clean wet season and a polluted dry season, as outlined in more detail in previous studies (e.g., Martin et al., 2010b; Andreae et al., 2012, 2015; Mishra et al., 2015). In this paper, we use the following classification of the Amazonian seasons ${ }^{1}$ : (i) the wet season typically spans February to May and shows the cleanest atmospheric state, (ii) the transition period from wet to dry season typically spans June and July, (iii) the dry season months August to November show the highest pollution levels, and (iv) the transition period from dry to wet season spans December and January (Andreae et al., 2015; Moran-Zuloaga et al., 2017).

A lively discussed aspect of the Amazonian hydrological cycle is the potential impact of changing aerosol regimes, which oscillate between polluted and pristine extremes, on the development of clouds and precipitation (e.g., Roberts et al., 2003; Andreae et al., 2004; Rosenfeld et al., 2008). A variety of pollution-induced changes in cloud properties, such as increased cloud drop concentrations with a corresponding decrease of their average size, intense competition for water vapor, and thus a deceleration of drop growth rates, suppression of supersaturation, reduced coalescence of smaller droplets, increased cloud depths as well as an invigoration of cloud dynamics and rain, are well documented (e.g., Koren et al., 2004, 2012; Freud et al., 2008).

Overall, the aforementioned observations indicate that increasing aerosol concentrations can have substantial impacts on spatial and temporal rainfall patterns in the Amazon (e.g., Martins et al., 2009a; Reutter et al., 2009). In view of the globally increasing pollution levels and the ongoing deforestation in the Amazon, pollution-triggered perturbations of the hydrological cycle are discussed as potential major threats to the Amazonian ecosystem, its forest structure, stability, and integrity (e.g., Coe et al., 2013; Junk, 2013).

\footnotetext{
${ }^{1}$ The Amazonian seasons are mostly defined meteorologically with respect to precipitation data (Fu et al., 2001; Fernandes et al., 2015). Note that in this study we use a slightly different definition of the seasons in the central Amazon based on meteorological and aerosol data to emphasize the seasonality in aerosol sources and prevalence. For example, the "meteorological wet season" typically has its core period in February (maximum in precipitation), whereas the "pollution-defined wet season" has its core period in April/May (e.g., minimum in carbon monoxide (CO) and black carbon (BC) concentrations) (Andreae et al., 2015).
} 


\subsection{Previous CCN measurements in the Amazon}

Ground-based and airborne CCN measurements have been conducted in a number of field campaigns in the Amazon Basin as outlined below in chronological order, constituting the baseline and context for the present study.

1998: Roberts and coworkers (Roberts et al., 2001; Roberts et al., 2002) conducted the first $\mathrm{CCN}$ measurements in the Amazon in the context of the LBA/CLAIRE-98 campaign (ground-based, Balbina site, March and April 1998) and pointed out that under clean conditions the CCN concentration $N_{\mathrm{CCN}}(S)$ (at a certain supersaturation $S$ ) in the "green ocean" Amazon is surprisingly similar to conditions in the maritime "blue ocean" atmosphere. Regarding the low natural $N_{\mathrm{CCN}}(S)$, which is dominated by mostly organic particles, they further suggested that cloud and precipitation properties may react sensitively to pollution-induced increases of the total aerosol load.

1999: In the context of the LBA-EUSTACH campaign in 1999, ground-based CCN measurements at three different sites in the Amazon Basin were conducted (Andreae et al., 2002; Roberts et al., 2003). This was the first study on $\mathrm{CCN}$ properties and cloud dynamics under the influence of strong biomass burning emissions in the Amazon.

2001: In the follow-up study LBA/CLAIRE-2001 in July 2001, ground-based (Balbina site) and airborne measurements (around Manaus) were conducted. For the ground-based study, Rissler et al. (2004) combined a hygroscopicity tandem differential mobility analyzer (HTDMA) with CCN measurements, focusing on the CCNrelevant water-soluble fraction in the particles, and provided a CCN closure and parametrization for model approaches. In addition, an airborne analysis of the aerosol and $\mathrm{CCN}$ properties was conducted, focusing on the contrast between the Amazonian background air and the Manaus plume (Kuhn et al., 2010).

2002: Subsequently, in the course of the LBA-SMOCC2002 campaign in southern Brazil during major biomass burning episodes (Rondônia state, September and October 2002), ground-based and airborne CCN measurements were performed (Vestin et al., 2007; Martins et al., 2009b). A major finding of this study was that the $\mathrm{CCN}$ efficiency of natural biogenic and man-made pyrogenic (cloud-processed) aerosols is surprisingly similar (Andreae et al., 2004). Furthermore, $N_{\mathrm{CCN}}(0.5 \%)$ was found as a valuable predictor for the required cloud depth of warm rain formation, which is an important property for cloud dynamics (Freud et al., 2008).

2008: During the AMAZE-08 campaign (ground-based, ZF2 site, February and March 2008), the first size- resolved $\mathrm{CCN}$ measurements in the Amazon were conducted (Gunthe et al., 2009; Martin et al., 2010a). These studies report that aerosol particles in the Aitken and accumulation modes, which represent the CCN-relevant size range, predominantly contain organic constituents and thus have comparably low hygroscopicity levels. The observed hygroscopicity parameter $\kappa$ ranges between 0.1 and 0.2 , which corresponds to the typical hygroscopicity of secondary organic aerosol (SOA) (Andreae and Rosenfeld, 2008).

2010/11: During several short observational periods, Almeida et al. (2014) measured total CCN concentrations around the city of Fortaleza in northeast Brazil. The selected measurement locations receive wind from changing directions. Accordingly, the response of the $\mathrm{CCN}$ population to marine, urban, and rural air masses was investigated.

2013: Recently, Whitehead et al. (2016) reported results from further short-term, size-resolved CCN and HTDMA measurements that were conducted north of Manaus (ground-based, ZF2 site, July 2013) as part of the Brazil-UK network for investigation of Amazonian atmospheric composition and impacts on climate (BUNIAACIC) project. The results of this study agree well with Gunthe et al. (2009).

2014/15: As part of the international field campaign observation and modeling of the green ocean Amazon (GoAmazon2014/5), size-resolved CCN measurements were conducted at three sites in and around Manaus: the Amazon Tall Tower Observatory (ATTO) site (T0a, pristine rain forest), which is discussed in the present study, the T2 site (in Manaus, urban environment), and the T3 site (rural site in the Manaus plume) (Martin et al., 2016; Thalman et al., 2017). All three size-resolved CCN measurements in the context of GoAmazon2014/5 took place in close collaboration. Moreover, $\mathrm{CCN}$ measurements were conducted onboard the G-1 aircraft during the GoAmazon2014/5 intensive observation periods IOP1 and IOP2 (Martin et al., 2016).

2014: Furthermore, as part of the German-Brazilian ACRIDICON (Wendisch et al., 2016) and CHUVA (Machado et al., 2014) projects, airborne CCN measurements were made over the entire Amazon Basin (September 2014). The results of this study are currently being analyzed for an upcoming publication and represent an ideal complement to the long-term data of the present study.

In addition to the aforementioned $\mathrm{CCN}$ measurements, some further studies relied on HTDMA measurements to probe the aerosol hygroscopicity and particle growth factors below $100 \%$ relative humidity $(\mathrm{RH})$, which can be used 
to extrapolate the $\mathrm{CCN}$ activity in supersaturation regimes (Zhou et al., 2002; Rissler et al., 2006).

\subsection{Aims and scope of this study}

All of the previously published CCN measurements in the Amazon have been conducted over relatively short time periods of up to several weeks. In addition, size-resolved CCN measurements are still sparse in the Amazon region. In this study, we present the first continuous, long-term, and sizeresolved CCN data set from the Amazon Basin, which spans a full seasonal cycle and therefore represents the $\mathrm{CCN}$ properties during contrasting seasonal conditions.

The focus of this study is on presenting major trends and characteristics of the $\mathrm{CCN}$ population in the Amazon Basin. Thus, our study contributes to a global inventory of $\mathrm{CCN}$ properties, representing this unique and climatically important ecosystem. We extract key CCN properties and parameters that help to include CCN predictions in the Amazon region into future modeling studies. Based on our data set, different parametrization strategies for $\mathrm{CCN}$ prediction are compared and discussed. Moreover, we present a novel and generalized $\mathrm{CCN}$ parametrization, which allows efficient modeling of $\mathrm{CCN}$ concentrations based on a minimal set of basic aerosol properties.

This paper represents part 1 of a comprehensive analysis of the CCN cycling in the central Amazon. It covers the overall trends and presents annually averaged CCN parameters as well as characteristic differences in the CCN population between the Amazonian seasons. A companion paper (Part 2) provides in-depth analyses of particularly interesting events through short-term case studies and aims for a more emission- and process-related understanding of the CCN variability (M. L. Pöhlker et al., 2017a).

\section{Methods}

\subsection{Measurement site and period}

The measurements reported in this study were conducted at the ATTO site $\left(02^{\circ} 08.602^{\prime} \mathrm{S}, 59^{\circ} 00.033^{\prime} \mathrm{W}\right.$; $130 \mathrm{~m}$ a.s.l. $)$, which is located in an untouched rain forest area in the central Amazon, about $150 \mathrm{~km}$ northeast of the city of Manaus, Brazil. An overview of the atmospheric, geographic, and ecological conditions at the ATTO site has been published recently by Andreae et al. (2015), where a detailed description of the aerosol setup for the long-term measurements can be found. The instrumentation for CCN measurements is part of a broad aerosol measurement setup, which also covers aerosol size and concentration, absorptivity, scattering, fluorescence, as well as chemical composition (Andreae et al., 2015). The aerosol inlet is located at a height of $60 \mathrm{~m}$, which is about $30 \mathrm{~m}$ above the forest canopy. The sample air is dried by silica gel diffusion dryers at the main inlet, which keeps the $\mathrm{RH}$ below $40 \%$. For the CCN setup, a second diffusion dryer decreases the RH even further to $<20 \%$, which ensures reliable hygroscopicity measurements.

The CCN measurements are ongoing since the end of March 2014. This study covers the measurement period from the end of March 2014 to February 2015, representing almost a full seasonal cycle. Also, the measurement period overlaps with the international large-scale field campaign GoAmazon2014/5 that was conducted in and around the city of Manaus from 1 January 2014 through 31 December 2015. During GoAmazon2014/5, comprehensive CCN measurements were conducted at different sites (see Sect. 1.3) (Martin et al., 2016). The ATTO site served as a clean background (T0a) site during GoAmazon2014/5. Furthermore, the measurement period of this study encompasses the GermanBrazilian ACRIDICON-CHUVA field measurement campaign in September 2014 (Machado et al., 2014; Wendisch et al., 2016), where (non-size-resolved) $\mathrm{CCN}$ measurements at multiple supersaturation levels were performed onboard the high-altitude and long-range research aircraft (HALO) flying over the Amazon Basin.

\subsection{Size-resolved CCN measurements}

The number concentration of $\mathrm{CCN}$ was measured with a continuous-flow streamwise thermal gradient $\mathrm{CCN}$ counter (CCNC, model CCN-100, DMT, Boulder, CO, USA) (Roberts and Nenes, 2005; Rose et al., 2008b). The inlet flow rate of the $\mathrm{CCNC}$ was $0.5 \mathrm{~L} \mathrm{~min}^{-1}$ with a sheath-to-aerosol flow ratio of 11 . The water pump was operated at a rate of $4 \mathrm{~mL} \mathrm{~h}^{-1}$ corresponding to the CCNC setting of "low" liquid flow. The supersaturation $(S)$ of the CCNC was cycled through 10 different $S$ values between 0.11 and $1.10 \%$ (see Table 1), which are defined by controlled temperature gradients inside the CCNC column. Particles with a critical supersaturation $\left(S_{\mathrm{c}}\right) \leq S$ in the column are activated and form water droplets. Droplets with diameters $\geq 1 \mu \mathrm{m}$ are detected by an optical particle counter (OPC) at the exit of the column.

Size-resolved CCN activation curves (for nomenclature, see Sect. 2.3) were measured based on the concept of Frank et al. (2006), following the procedures in Rose et al. (2008a) and Krüger et al. (2014) by combining the CCNC with a differential mobility analyzer (DMA, model M, Grimm Aerosol Technik, Ainring, Germany). The DMA was operated with a sheath-to-aerosol flow ratio of 5. The DMA selects particles with a certain diameter $(D)$ in the size range of 20 to $245 \mathrm{~nm}$ (sequence of $D$ value has been optimized for every $S$ ), which are then passed into the two instruments: (i) the CCNC system and (ii) a condensation particle counter (CPC, model 5412, Grimm Aerosol Technik), which measures the number concentration of aerosol particles with selected $D\left(N_{\mathrm{CN}}(D)\right)$, while the CCNC measures the number concentration of $\mathrm{CCN}$ with selected $D$ for the given $S\left(N_{\mathrm{CCN}}(S, D)\right)$. The cycle through a full CCN activation curve $\left(N_{\mathrm{CCN}}(S, D) / N_{\mathrm{CN}}(D)\right)$ for one $S$ level took $\sim 28 \mathrm{~min}$, including $\sim 40$ s equilibration time for every new $D$, and $\sim 2$ min equilibration time 
Table 1. Characteristic CCN parameters as a function of the supersaturation $S$, averaged over the entire measurement period: midpoint activation diameter $D_{a}(S)$, hygroscopicity parameter $\kappa\left(S, D_{a}\right)$, width of CCN activation curve $\sigma(S)$, heterogeneity parameter $\sigma(S) / D_{a}(S)$, maximum activated fraction $\operatorname{MAF}(S), \mathrm{CCN}$ number concentration $N_{\mathrm{CCN}}(S)$, total particle concentration $(>10 \mathrm{~nm}) N_{\mathrm{CN}, 10}$, CCN efficiencies $N_{\mathrm{CCN}}(S) / N_{\mathrm{CN}, 10}$, and number of data points $n . S$ is shown as set value \pm the experimentally derived deviation in $S$. All other values are given as arithmetic mean \pm 1 standard deviation. All values are provided for ambient conditions (temperature $\sim 28^{\circ} \mathrm{C}$; pressure $\sim 100 \mathrm{kPa}$ ).

\begin{tabular}{|c|c|c|c|c|c|c|c|c|c|}
\hline $\begin{array}{c}S \\
(\%)\end{array}$ & $\begin{array}{c}D_{a}(S) \\
(\mathrm{nm})\end{array}$ & $\kappa\left(S, D_{a}\right)$ & $\begin{array}{l}\sigma(S) \\
(\mathrm{nm})\end{array}$ & $\sigma(S) / D_{a}(S)$ & $\operatorname{MAF}(S)$ & $\begin{array}{c}N_{\mathrm{CCN}}(S) \\
\left(\mathrm{cm}^{-3}\right)\end{array}$ & $\begin{array}{l}N_{\mathrm{CN}, 10} \\
\left(\mathrm{~cm}^{-3}\right)\end{array}$ & $N_{\mathrm{CCN}}(S) / N_{\mathrm{CN}, 10}$ & $n$ \\
\hline $0.11 \pm 0.01$ & $172 \pm 12$ & $0.22 \pm 0.05$ & $45 \pm 11$ & $0.26 \pm 0.06$ & $0.93 \pm 0.10$ & $275 \pm 219$ & $1100 \pm 776$ & $0.24 \pm 0.10$ & 1071 \\
\hline $0.15 \pm 0.02$ & $136 \pm 10$ & $0.22 \pm 0.05$ & $42 \pm 10$ & $0.31 \pm 0.06$ & $0.97 \pm 0.05$ & $457 \pm 384$ & $1093 \pm 770$ & $0.39 \pm 0.13$ & 1086 \\
\hline $0.20 \pm 0.02$ & $117 \pm 9$ & $0.21 \pm 0.05$ & $35 \pm 10$ & $0.30 \pm 0.07$ & $0.98 \pm 0.04$ & $571 \pm 482$ & $1096 \pm 775$ & $0.48 \pm 0.15$ & 1087 \\
\hline $0.24 \pm 0.03$ & $105 \pm 8$ & $0.19 \pm 0.05$ & $29 \pm 8$ & $0.28 \pm 0.07$ & $0.99 \pm 0.04$ & $652 \pm 550$ & $1098 \pm 778$ & $0.55 \pm 0.16$ & 1078 \\
\hline $0.29 \pm 0.03$ & $98 \pm 7$ & $0.17 \pm 0.04$ & $27 \pm 8$ & $0.27 \pm 0.08$ & $1.01 \pm 0.05$ & $719 \pm 601$ & $1103 \pm 784$ & $0.60 \pm 0.17$ & 1069 \\
\hline $0.47 \pm 0.04$ & $77 \pm 5$ & $0.13 \pm 0.03$ & $17 \pm 6$ & $0.22 \pm 0.07$ & $1.03 \pm 0.04$ & $883 \pm 744$ & $1101 \pm 799$ & $0.74 \pm 0.18$ & 1008 \\
\hline $0.61 \pm 0.06$ & $63 \pm 4$ & $0.14 \pm 0.03$ & $15 \pm 5$ & $0.23 \pm 0.07$ & $0.97 \pm 0.03$ & $900 \pm 719$ & $1089 \pm 791$ & $0.78 \pm 0.14$ & 922 \\
\hline $0.74 \pm 0.08$ & $57 \pm 4$ & $0.13 \pm 0.03$ & $14 \pm 6$ & $0.24 \pm 0.09$ & $0.96 \pm 0.03$ & $941 \pm 730$ & $1108 \pm 809$ & $0.82 \pm 0.12$ & 984 \\
\hline $0.92 \pm 0.11$ & $49 \pm 4$ & $0.13 \pm 0.03$ & $12 \pm 6$ & $0.24 \pm 0.11$ & $0.96 \pm 0.04$ & $987 \pm 742$ & $1117 \pm 814$ & $0.86 \pm 0.10$ & 995 \\
\hline $1.10 \pm 0.08$ & $43 \pm 3$ & $0.13 \pm 0.03$ & $11 \pm 5$ & $0.25 \pm 0.10$ & $0.95 \pm 0.03$ & $1013 \pm 747$ & $1120 \pm 792$ & $0.88 \pm 0.08$ & 952 \\
\hline
\end{tabular}

for every new $S$ level. The completion of a full measurement cycle comprising CCN activation curves for $12-13 \mathrm{D}$ values (number of $D$ depends on $S$ ) and 10 different $S$ levels took $\sim 4.5 \mathrm{~h}$. The entire $\mathrm{CCN}$ system (including the CCNC, DMA, and CPC) was controlled by a dedicated LabVIEW (National Instruments, Munich, Germany) routine.

The $S$ levels of the CCNC system were calibrated periodically (March, May, and September 2014) using ammonium sulfate $\left(\left(\mathrm{NH}_{4}\right)_{2} \mathrm{SO}_{4}\right.$, Sigma Aldrich, St. Louis, MO, USA) particles generated in an aerosol nebulizer (TSI Inc., Shoreview, MN, USA). The calibration procedure was conducted according to Rose et al. (2008b). All three calibrations gave consistent results and thus confirmed that the $S$ cycling in the $\mathrm{CCNC}$ was very stable and reliable throughout the entire measurement period.

All concentration data presented here are given for ambient conditions. During the entire measurement period, no significant fluctuations in temperature $\left(\sim 28^{\circ} \mathrm{C}\right)$ and pressure $(\sim 100 \mathrm{kPa})$ were observed in the air-conditioned laboratory container.

\subsection{Data analysis, error analysis, and nomenclature of CCN key parameters}

The theoretical background and related $\mathrm{CCN}$ analysis procedures are comprehensively described elsewhere (Petters and Kreidenweis, 2007; Rose et al., 2008a). For the present study, the following corrections were applied to the data set. (i) The CCN activation curves were corrected for systematic deviations in the counting efficiency of the CCNC and CPC according to Rose et al. (2010). (ii) Usually, the double-charge correction of the CCN activation curve is conducted according to Frank et al. (2006). For this study, we developed the following alternative approach, which reconstructs the CCN efficiency curves based on data from an independent scanning mobility particle sizer (SMPS, TSI model
3080 with CPC 3772 operating with standard TSI software) at the ATTO site. The activation curve for every $D$ can be described by the following equation:

$$
\frac{\sum_{i} N_{\mathrm{CCN}}\left(S, D_{i}\right)}{\sum_{i} N_{\mathrm{CN}}\left(D_{i}\right)}=\frac{\sum_{i} f\left(D_{i}\right) \cdot s\left(D_{i}\right) \cdot a\left(S, D_{i}\right)}{\sum_{i} f\left(D_{i}\right) \cdot s\left(D_{i}\right)} .
$$

The index $i$ represents the charge of the particles (typically $1 \leq i \leq 4$ ). The left side of the equation is the measured (noncorrected) ratio of $\mathrm{CCN}$ to condensation nuclei $(\mathrm{CN})$ for one selected $D$ and $S$. The parameter $s\left(D_{i}\right)$ is the multi-chargecorrected particle number size distribution inverted from the SMPS measurements at $D_{i}$ with its different charge states. The parameter $f\left(D_{i}\right)$ is the corresponding fraction of particles with the charge $i$. The function $a\left(S, D_{i}\right)$ accounts for the activated fraction of $s\left(D_{i}\right)$ at a given supersaturation $S$. We describe $a\left(S, D_{i}\right)$ as a cumulative Gaussian function. Using a nonlinear least-squares fit method (Levenberg-Marquardt) together with the knowledge of $s\left(D_{i}\right)$ and $f\left(D_{i}\right)$, the parameters of the function $a\left(S, D_{i}\right)$ can be optimized to get an optimal fit of the measured CCN activation curve for a given $S$. The function $a(S, D)$ is the cumulative Gaussian function after the fit, which describes the multi-charge-corrected CCN activation curve and has been used as a basis for the further analysis. Because the information on multiple charged particles also contributes to the fit results, this approach is superior to previously used methods, where this information is neglected. Based on $a(S, D)$, the critical diameter $\left(D_{a}(S)\right.$, where $50 \%$ of the particles are activated) is used to retrieve the effective hygroscopicity parameter $\left(\kappa\left(S, D_{a}\right)\right)$ according to the $\kappa$-Köhler model (Petters and Kreidenweis, 2007). A detailed description of the calculation can be found in Petters and Kreidenweis (2007), Rose et al. (2010), and Mikhailov et al. (2009). 
The CCN size distribution $\left(N_{\mathrm{CCN}}(S, D)\right)$ was calculated by

$N_{\mathrm{CCN}}(S, D)=s(D) \cdot a(S, D)$.

In this equation, $s(D)$ represents the particle number size distribution of the SMPS at $D(10 \leq D \leq 450 \mathrm{~nm})$.

The CCN efficiencies $\left(N_{\mathrm{CCN}}(S) / N_{\mathrm{CN}, 10}\right.$; for nomenclature, see end of Sect. 2.3) have been calculated based on the integral concentration of $\mathrm{CN}$ with lower size cutoff $D_{\text {cut }}=10 \mathrm{~nm}\left(N_{\mathrm{CN}, 10}\right)^{2}$ and $\mathrm{CCN}\left(N_{\mathrm{CCN}}(S)\right)$ as

$\frac{N_{\mathrm{CCN}}(S)}{N_{\mathrm{CN}, 10}}=\frac{\int_{D} N_{\mathrm{CCN}}(S, D) \cdot \mathrm{d} D}{\int_{D} s(D) \cdot \mathrm{d} D}$.

In addition to $D_{a}(S)$, the maximum activated fraction $(\operatorname{MAF}(S))$ can be obtained from $a(S, D)$. $\operatorname{MAF}(S)$ typically equals unity, except for completely hydrophobic particles (i.e., fresh soot). The third parameter that can be derived from $a(S, D)$ is the width of the CCN activation curve $\sigma(S)$, which strongly depends on $D_{a}(S)$. The ratio between $\sigma(S)$ and $D_{a}(S)\left(\sigma(S) / D_{a}(S)\right)$ is called heterogeneity parameter and can be used as an indicator for the chemical and geometric diversity of the aerosol particles.

The error in $S$ was calculated based on the uncertainty according to the commonly used calibration procedure (Rose et al., 2008b). Overall, the error $\Delta S$ of $S$ equals approximately $10 \%$; however, in the following analysis, we have used the specific $\Delta S$ values for every $S$ (see Table 1). The uncertainty of the selected $D$ of the DMA $(\Delta D)$ was obtained as the mean width of the Gaussian fit of polystyrene latex (PSL) beads and equals $5.3 \mathrm{~nm}$. For $N_{\mathrm{CCN}}(S, D)$ and $N_{\mathrm{CN}}(D)$, the standard error of the counting statistic was used. By Gaussian error propagation we determined $\Delta\left(N_{\mathrm{CCN}}(S, D) / N_{\mathrm{CN}}(D)\right)$ and then repeated the data analysis for the upper and lower bounds $(1 \pm \Delta) \times\left(N_{\mathrm{CCN}}(D, S) / N_{\mathrm{CN}}(D)\right)$. The resulting relative errors of the values $N_{\mathrm{CCN}}(S), N_{\mathrm{CN}, 10}$, and $N_{\mathrm{CCN}}(S) / N_{\mathrm{CN}, 10}$ do not depend on $S$ and equal $6 \%$. The errors of $D_{a}(S)$ and $\kappa\left(S, D_{a}\right)$ depend on $S$ and can be described as

$\Delta D_{a}(S)=D_{a}(S) \cdot(S \cdot 0.07+0.03)$

$\Delta \kappa\left(S, D_{a}\right)=\kappa\left(S, D_{a}\right) \cdot(S \cdot 0.17+0.10)$.

Throughout this study, we observed a slight systematic deviation of the results for the supersaturation $S=0.47 \%$. This effect can be seen, for example, in $\operatorname{MAF}(0.47 \%)$ values exceeding unity in Fig. 1 and $N_{\mathrm{CCN}}(0.47 \%, D) / N_{\mathrm{CN}}(D)$ values exceeding unity in Fig. 5. The effect persists even after applying all aforementioned corrections to the data and is most pronounced during the dry season. Yet, since we did not find any evidence of these data being erroneous, we decided to keep them in the study.

\footnotetext{
${ }^{2}$ Note that $N_{\mathrm{CN}, 10}$ usually corresponds to the total CPCdetectable aerosol particle number concentration for the characteristic size distribution at the ATTO site because the particle population in the nucleation-mode range (i.e., $<10 \mathrm{~nm}$ ) is negligibly small.
}

The use of certain terms in the context of CCN measurements is not uniform in the literature. For clarity, we summarize the key parameters and terms applied in this study as follows: (i) the value $N_{\mathrm{CCN}}(S, D) / N_{\mathrm{CN}}(D)$ is called CCN activated fraction, while (ii) $N_{\mathrm{CCN}}(S, D) / N_{\mathrm{CN}}(D)$ plotted against $D$ is called $\mathrm{CCN}$ activation curve; (iii) $N_{\mathrm{CCN}}(S)$ plotted against $S$ is called $\mathrm{CCN}$ spectrum; (iv) $N_{\mathrm{CCN}}(S) / N_{\mathrm{CN}, D_{\text {cut }}}$ at a certain $S$ level is called CCN efficiency; (v) $N_{\mathrm{CCN}}(S) / N_{\mathrm{CN}, D_{\text {cut }}}$ plotted against $S$ is called $\mathrm{CCN}$ efficiency spectrum.

\subsection{Aerosol mass spectrometry}

In addition to the $\mathrm{CCN}$ measurements, aerosol chemical speciation monitor (ACSM, Aerodyne Research Inc., Billerica, MA, USA) measurements are being performed at the ATTO site (Andreae et al., 2015). The ACSM routinely characterizes nonrefractory submicron aerosol species such as organics, nitrate, sulfate, ammonium, and chloride ( $\mathrm{Ng}$ et al., 2011). Particles are focused by an aerodynamic lens system into a narrow particle beam, which is transmitted through three successive vacuum chambers. In the third chamber, the particle beam is directed into a hot tungsten oven $\left(600^{\circ} \mathrm{C}\right)$ where the particles are flash vaporized, ionized with a $70 \mathrm{eV}$ electron impact ionizer, and detected with a quadrupole mass spectrometer. In this study, a time resolution of $30 \mathrm{~min}$ was used. The measurements provide a total mass concentration of the chemical composition of the aerosol particles. Further details about the ACSM can be found in Ng et al. (2011).

\subsection{Carbon monoxide measurements}

Carbon monoxide (CO) measurements are conducted continuously at the ATTO site using a G1302 analyzer (Picarro Inc. Santa Clara, CA, USA). The experimental setup from the point of view of functioning and performance is a duplication of the system described in Winderlich et al. (2010).

\section{Results and discussion}

\subsection{Time series of $\mathrm{CCN}$ parameters for the entire measurement period}

Over the entire measurement period from 25 March 2014 to 5 February 2015 we recorded size-resolved CCN activation curves at 10 different levels of water vapor supersaturation $S$ with an overall time resolution of approximately $4.5 \mathrm{~h}$. A total of $10253 \mathrm{CCN}$ activation curves were fitted and analyzed to obtain parameters of CCN activity as detailed above (Sect. 2.3). Table 1 serves as a central reference in the course of this study and summarizes the annual mean values and standard deviations of the following key parameters, resolved by $S: D_{a}(S), \kappa\left(S, D_{a}\right), \sigma(S), \sigma(S) / D_{a}(S)$, $\operatorname{MAF}(S), N_{\mathrm{CCN}}(S), N_{\mathrm{CN}, 10}$, and $N_{\mathrm{CCN}}(S) / N_{\mathrm{CN}, 10}$. In Fig. 1 , some of these $\mathrm{CCN}$ key parameters are presented as time se- 


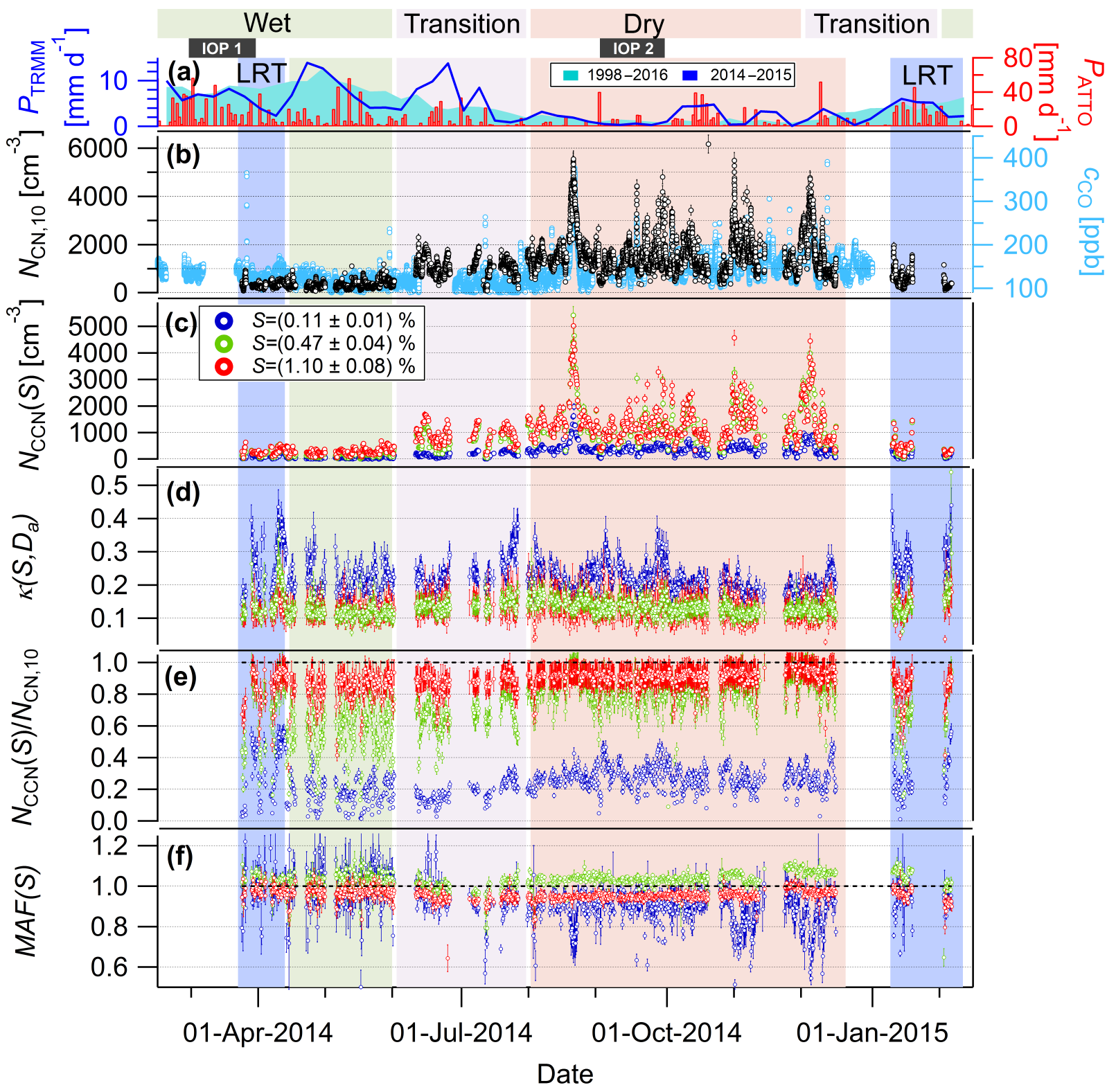

Figure 1. Seasonal trends in time series of precipitation rate $P$, total aerosol concentration $N_{\mathrm{CN}, 10}$, carbon monoxide mole fraction ( $c_{\mathrm{CO}}$ ), and CCN key parameters for three selected supersaturations $S$ for the entire measurement period (shown in original time resolution). (a) Precipitation rates from tropical rainfall measuring mission (TRMM) $P_{\text {TRMM }}$ and in situ measurements at the ATTO site $P_{\text {ATTO }}$. The $P_{\text {TRMM }}$ seasonal cycles are derived from an area upwind of the ATTO site $\left(59.5^{\circ} \mathrm{W}, 2.4^{\circ} \mathrm{N}, 54.0^{\circ} \mathrm{W}, 3.5^{\circ} \mathrm{S}\right)$, covering a long-term period from $1 \mathrm{Jan}$ uary 1998 to 30 June 2016 (aqua shading), and the period of the CCN measurements from 1 March 2014 to 28 February 2015 (blue line). (b) Time series of pollution tracers $N_{\mathrm{CN}, 10}$ and $c_{\mathrm{CO}}$. (c) $\mathrm{CCN}$ concentrations $N_{\mathrm{CCN}}(S)$, (d) hygroscopicity parameter $\kappa\left(S, D_{a}\right)$, (e) $\mathrm{CCN}$ efficiencies $N_{\mathrm{CCN}}(S) / N_{\mathrm{CN}, 10}$, and (f) maximum activated fraction $\operatorname{MAF}(S)$. Three different types of shading represent (i) the seasonality in the Amazon atmosphere according to Andreae et al. (2015) (wet vs. dry seasons with transition periods, illustrated at the top of the graph), (ii) periods of IOP1 and IOP2 during GoAmazon2014/5, (iii) seasonal periods of interest in context of the present study as defined in Sect. 3.3 (shading in background of time series).

ries over the entire measurement period to provide a general overview of their temporal evolution and variability. Concentration time series of the pollution tracers $N_{\mathrm{CN}, 10}$ and $\mathrm{CO}$ are added to illustrate the pollution seasonality at the ATTO site.
Figure 1a presents precipitation data from satellite and in situ measurements at the ATTO site to illustrate the meteorological seasonality for the measurement period. The precipitation rates in the Amazon Basin can show pronounced 
anomalies due to teleconnections with the Atlantic and/or Pacific sea surface temperatures (SSTs) (Fu et al., 2001; Fernandes et al., 2015). The most prominent example here is the El Niño-Southern Oscillation (ENSO) and its various impacts on the Amazonian ecosystem (e.g., Asner et al., 2000; Ronchail et al., 2002). For the measurement period, the Oceanic Niño Index (ONI) ranged between -0.4 and $0.6^{\circ} \mathrm{C}$, confirming that only towards the end of the measurement period a slightly positive anomaly was observed. ${ }^{3}$ In Fig. 1a, satellite data from the tropical rainfall measurement mission (TRMM) are presented for the area around the ATTO site. The TRMM data are provided for an extended time period (January 1998 until June 2016) and, for comparison, for the CCN measurement period (March 2014 until February 2015). This comparison shows that the 2014/15 precipitation rates do not deviate substantially from the 18 year average data, and thus further confirms that the measurement period can be regarded as a typical year with typical seasons and no pronounced hydrological anomalies.

Figure $1 \mathrm{~b}$ displays the characteristic seasonal cycle in $N_{\mathrm{CN}, 10}$ and the $\mathrm{CO}$ mole fraction $\left(c_{\mathrm{CO}}\right)$. Both pollution tracers reach their maxima during the dry season $\left(N_{\mathrm{CN}, 10}=1400 \pm 710 \mathrm{~cm}^{-3} ; c_{\mathrm{CO}}=144 \pm 45 \mathrm{ppb}\right)$, whereas the lowest values are observed during the wet season $\left(N_{\mathrm{CN}, 10}=285 \pm 131 \mathrm{~cm}^{-3} ; c_{\mathrm{CO}}=117 \pm 12 \mathrm{ppb}\right)$ (given as mean \pm 1 standard deviation). An obvious feature of the dry season months is the occurrence of rather short and strong peaks (reaching up to $N_{\mathrm{CN}, 10}=\sim 5000 \mathrm{~cm}^{-3}$; $c_{\mathrm{CO}}=\sim 400 \mathrm{ppb}$ ) on top of elevated background pollution levels. The pronounced peaks originate from biomass burning plumes, which impact the ATTO site for comparatively short periods (a few hours up to several days). Selected events are discussed in detail in M. L. Pöhlker et al. (2017a). Figure 1c shows that $N_{\mathrm{CCN}}(S)$ follows the same overall trends. A rather close correlation between $N_{\mathrm{CCN}}(S)$ and $N_{\mathrm{CN}, 10}$ as well as $N_{\mathrm{CCN}}(S)$ and $c_{\mathrm{CO}}$ can be observed, as pointed out in previous studies (Andreae, 2009; Kuhn et al., 2010). Figure $1 \mathrm{~d}$ displays the $\kappa\left(S, D_{a}\right)$ time series for three exemplary $S$ levels. It shows that the $\kappa\left(S, D_{a}\right)$ values, which provide indirect information of the particles' chemical composition, are remarkably stable throughout the year (see also standard deviations of $\kappa\left(S, D_{a}\right)$ in Table 1). This illustrates that the dry season maximum in $N_{\mathrm{CCN}}(S)$ is mainly related to the overall increase in $N_{\mathrm{CN}, 10}$, and not to substantial variations in aerosol composition and therefore $\kappa\left(S, D_{a}\right)$. The levels of the three $\kappa\left(S, D_{a}\right)$ time series, with their corresponding $D_{a}(S)$, provide a first indication that $\kappa\left(S, D_{a}\right)$ shows a clear size dependence, as further discussed in Sect. 3.2. The pro-

\footnotetext{
${ }^{3}$ For the ONI data and specific information on the reference area and time frame, refer to National Oceanic and Atmospheric Administration (NOAA)/National Weather Service, 2016. Historical El Niño/La Niña episodes (1950-present) are available at http://www.cpc.ncep.noaa.gov/products/analysis_ monitoring/ensostuff/ensoyears.shtml (last access: 1 October 2016).
}

nounced (but rather rare) "spikes" in $\kappa\left(S, D_{a}\right)$ (i.e., in April and August) as well as various other specific events in this time series are analyzed in detail in the companion Part 2 paper (M. L. Pöhlker et al., 2017a). Figure 1e gives an overview of the CCN efficiencies $N_{\mathrm{CCN}}(S) / N_{\mathrm{CN}, 10}$ (for three $S$ levels) and its seasonal trends. This representation shows continuously high fractions of cloud-active particles for higher $S$ (e.g., $\left.N_{\mathrm{CCN}}(1.10 \%) / N_{\mathrm{CN}, 10}>0.9\right)$ throughout the entire measurement period with almost no seasonality. For intermediate $S$, such as $0.47 \%$, the values of $N_{\mathrm{CCN}}(0.47 \%) / N_{\mathrm{CN}, 10}$ range from 0.6 to 0.9 and reveal a noticeable seasonal cycle, with the highest levels during the dry season. Furthermore, $N_{\mathrm{CCN}}(0.11 \%) / N_{\mathrm{CN}, 10}$ is mostly below 0.4 , with clear seasonal trends. These observations can be explained by the characteristic aerosol size distribution at the ATTO site (Andreae et al., 2015), which (i) is dominated by particles in the Aitken (annually averaged peak $D_{\text {Ait }}$ at $\sim 70 \mathrm{~nm}$ ) and accumulation modes (annually averaged peak $D_{\text {Acc }}$ at $\sim 150 \mathrm{~nm}$ ), (ii) shows a sparse occurrence of nucleation-mode particles $(<30 \mathrm{~nm})$, and (iii) reveals a clear seasonality in the relative abundance of Aitken and accumulation modes (see Sect. 3.3 and Fig. 6). Thus, the higher dry season abundance of accumulation-mode particles, which are more prone to act as $\mathrm{CCN}$, results in higher $N_{\mathrm{CCN}}(S) / N_{\mathrm{CN}, 10}$ levels, particularly at lower $S$.

Analogous $N_{\mathrm{CCN}}(S) / N_{\mathrm{CN}}$ results from other continental background sites have been published previously: for example, Levin et al. (2012) reported $N_{\mathrm{CCN}}(0.97 \%) / N_{\mathrm{CN}}=0.4-0.7$, $N_{\mathrm{CCN}}(0.56 \%) / N_{\mathrm{CN}}=0.25-0.5$, and $N_{\mathrm{CCN}}(0.14 \%) / N_{\mathrm{CN}}$ $<0.15$ for a semi-arid Rocky Mountain site. Jurányi et al. (2011) reported $N_{\mathrm{CCN}}(1.18 \%) / N_{\mathrm{CN}, 16}=0.6-$ $0.9, \quad N_{\mathrm{CCN}}(0.47 \%) / N_{\mathrm{CN}, 16}=0.2-0.6, \quad$ and $N_{\mathrm{CCN}}(0.12 \%) / N_{\mathrm{CN}, 16}<0.25$ for the high alpine Jungfraujoch site. At both locations, the $\mathrm{CCN}$ efficiencies tend to be lower than the corresponding results at the ATTO site, which can be explained by the frequent occurrence of new particle formation (NPF) and the related abundance of ultrafine particles (with sizes well below $D_{a}(S)$ ) at these sites (Boulon et al., 2010; Ortega et al., 2014). The activated fractions at the Rocky Mountain and Jungfraujoch sites have a stronger seasonality than those at ATTO, probably inversely related to the seasonal cycle in NPF. Overall, we state that the activated fractions in the central Amazon, due the absence of significant ultrafine particle $(<30 \mathrm{~nm})$ populations, tend to be constantly higher than in other continental background locations (Paramonov et al., 2015). The absence of "classical" NPF (Kulmala et al., 2004) and the corresponding lack of ultrafine particles is a unique property of the Amazon atmosphere resulting in the uniquely high $\mathrm{CCN}$ efficiencies. A systematic study on the abundance, properties, and seasonality of the sparse nucleation-mode bursts in the central Amazon is the subject of an upcoming study. 


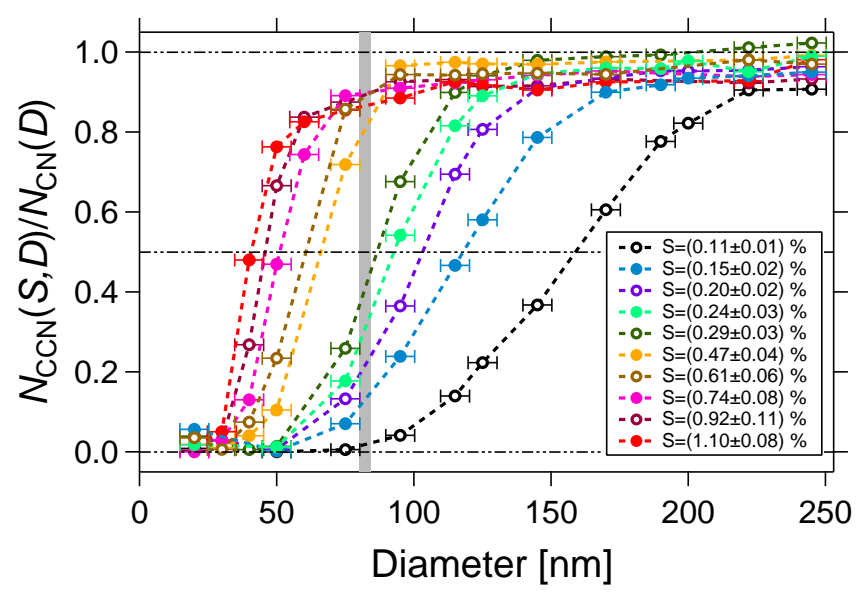

Figure 2. CCN activation curves for all measured $S$ levels $(S=0.11-1.10 \%)$, averaged over the entire measurement period. Data points represent arithmetic mean values. For $N_{\mathrm{CCN}}(S, D) / N_{\mathrm{CN}}(D)$, the standard error is plotted, which is very small (due to the large number of scans with comparatively small variability) and therefore not perceptible in this representation. For the diameter, $D$, the error bars represent the experimental error as specified in Sect. 2.3. The grey vertical band represents the position of the Hoppel minimum (including error range) for the annual mean number size distribution (compare to Fig. 3). Dashed lines provide visual orientation and indicate 0,50 , and $100 \%$ activation. The value at $50 \%$ activation is used for calculation of the hygroscopicity parameter $\kappa\left(S, D_{a}\right)$. The lines connecting the data points merely serve as visual orientation.

The $\operatorname{MAF}(S)$ time series in Fig. 1f represents a valuable additional parameter to determine the abundance of "poor" $\mathrm{CCN}$ (i.e., aerosol particles that are not activated into $\mathrm{CCN}$ within the tested $S$ range). For higher $S$ (i.e., $S>0.11 \%$ ), $\operatorname{MAF}(S)$ is close to unity over the whole year. In contrast, $\operatorname{MAF}(0.11 \%)$ fluctuates around unity during the wet season months; however, it drops below unity during the biomassburning-impacted dry season and subsequent transition period. For some episodes, $\operatorname{MAF}(S)$ shows very pronounced dips, as further discussed in the Part 2 study (M. L. Pöhlker et al., 2017a).

\subsection{Annual means of CCN activation curves and hygroscopicity parameter}

Figure 2 displays the annual mean $\mathrm{CCN}$ activation curves for all $S$ levels. Thus, it represents an overall characterization of the particle activation behavior, which means that for decreasing $S$ levels the activation diameter, $D_{a}(S)$, increases. In other words, every $S$ corresponds to a certain (and to some extent typical) $D_{a}(S)$ range, where particles start to become activated (see Table 1). As an example, relatively high $S$ conditions $(0.47-1.10 \%)$ yield substantial activation already in the Aitken-mode range, while low $S$ levels (0.11-0.29\%) correspond to activation of larger particles, mostly in the ac- cumulation mode. Note that $S$ levels in convective clouds rarely exceed $1.0 \%$, but that in the presence of precipitation higher $S$ values are possible (Cotton and Anthes, 1989). The step from the activation curves at $S=0.47 \%$ to $S=0.29 \%$ relates to the position of the characteristic Hoppel minimum (at $97 \mathrm{~nm}$ for the annual mean size distribution; see Table 2) between Aitken and accumulation mode in the bimodal size distribution. Thus, the step to $S=0.47 \%$ represents the onset of significant activation in the Aitken-mode size range.

A different representation of these observations is displayed in Fig. 3, which shows the bimodally fitted (bimodal logarithmic normal distribution, $\left.R^{2}=0.99\right)$ annual mean $N_{\mathrm{CN}}(D)$ size distribution. In this annual average representation, the Aitken-mode maximum is located at $D_{\text {Ait }}=69 \pm 1 \mathrm{~nm}$, the accumulation-mode maximum at $D_{\text {Acc }}=149 \pm 2 \mathrm{~nm}$, and both are separated by the Hoppel minimum (compare to Table 2) (Hoppel et al., 1996). Furthermore, Fig. 3 clearly shows that different $\kappa\left(S, D_{a}\right)$ values are retrieved for the Aitken $\left(\kappa_{\text {Ait }}=0.14 \pm 0.03\right)$ vs. the accumulation-mode size range $\left(\kappa_{\mathrm{Acc}}=0.22 \pm 0.03\right)$. This indicates that Aitken- and accumulation-mode particles have different hygroscopicities and thus different chemical compositions. In this case, Aitken-mode particles tend to be more predominantly organic (close to $\kappa=0.1$ ) than the accumulation-mode particles, which tend to contain more inorganic species (i.e., ammonium, sulfates, potassium) (Prenni et al., 2007; Gunthe et al., 2009; Wex et al., 2009; C. Pöhlker et al., 2012). The enhanced hygroscopicity in the accumulation mode is a well-documented observation for various locations worldwide, which is thought to result from the cloud processing history of this aerosol size fraction (e.g., Paramonov et al., 2013, 2015). For the Amazon Basin, our observed size dependence of $\kappa\left(S, D_{a}\right)$ agrees well with the values reported by Gunthe et al. (2009) and Whitehead et al. (2016).

The arithmetic mean hygroscopicity parameter at the ATTO site for all sizes $\left(43 \mathrm{~nm}<D_{a}<172 \mathrm{~nm}\right)$ and for the entire measurement period is $\kappa_{\text {mean }}=0.17 \pm 0.06$. For comparison, Gunthe et al. (2009) reported $\kappa_{\text {mean }}=0.16 \pm 0.06$ (for the early wet season 2008). The observed standard deviation is rather small, which reflects the low variability of $\kappa_{\text {mean }}$ throughout the year (see Fig. 1b).

No perceptible diurnal trend in $\kappa_{\text {mean }}$ is present in the annually averaged data. This is because the ATTO site is not (strongly) influenced by aerosol compositional changes that follow pronounced diurnal cycles (i.e., input of anthropogenic emissions). A consequence of this finding is that the overall hygroscopicity of the aerosol at the ATTO site (as a representative measurement station of the central Amazon) is well represented in model studies by using $\kappa_{\text {mean }}=0.17 \pm 0.06$ (see also Sect. 3.5.4). Previous longterm CCN observations from alpine, semi-arid, and boreal background sites have similarly shown that diurnal cycles in $\kappa\left(S, D_{a}\right)$ (or the related $\left.D_{a}(S)\right)$ tend to be rather small or even 
Table 2. Properties (position $x_{0}$, integral number concentration $N_{\mathrm{CN}}$, width $\sigma$ ) of Aitken and accumulation modes from the double lognormal fit (compare to $R^{2}$ ) of the total particle size distributions. Values are given as annual means and subdivided into seasonal periods of interest as specified in Sect. 3.3 (compare also to Fig. 6). In addition, values for the position of the Hoppel minimum $D_{\mathrm{H}}$ as well as estimated average peak supersaturation in cloud $S_{\text {cloud }}\left(D_{\mathrm{H}}, \kappa\right)$ are listed. The errors represent the uncertainty of the fit parameters. The error in $S_{\text {cloud }}\left(D_{\mathrm{H}}, \kappa\right)$ is the experimentally derived error in $S$.

\begin{tabular}{|c|c|c|c|c|c|c|c|c|}
\hline Season & Mode & $\begin{array}{c}N_{\mathrm{CN}} \\
\left(\mathrm{cm}^{-3}\right)\end{array}$ & $\kappa$ & $\begin{array}{c}x_{0} \\
(\mathrm{~nm})\end{array}$ & $\sigma$ & $R^{2}$ & $\begin{array}{c}D_{\mathrm{H}} \\
(\mathrm{nm})\end{array}$ & $\begin{array}{c}S_{\text {cloud }}\left(D_{\mathrm{H},}, \kappa\right) \\
(\%)\end{array}$ \\
\hline Year & $\begin{array}{l}\text { Aitken } \\
\text { accumulation }\end{array}$ & $\begin{array}{l}397 \pm 31 \\
906 \pm 29\end{array}$ & $\begin{array}{l}0.13 \pm 0.03 \\
0.22 \pm 0.05\end{array}$ & $\begin{array}{c}69 \pm 1 \\
149 \pm 2\end{array}$ & $\begin{array}{l}0.44 \pm 0.02 \\
0.57 \pm 0.01\end{array}$ & 0.99 & $97 \pm 2$ & $0.29 \pm 0.03$ \\
\hline LRT & $\begin{array}{l}\text { Aitken } \\
\text { accumulation }\end{array}$ & $\begin{array}{c}231 \pm 8 \\
232 \pm 10\end{array}$ & $\begin{array}{l}0.14 \pm 0.04 \\
0.28 \pm 0.08\end{array}$ & $\begin{array}{c}67 \pm 1 \\
172 \pm 1\end{array}$ & $\begin{array}{l}0.63 \pm 0.01 \\
0.51 \pm 0.01\end{array}$ & 0.99 & $109 \pm 2$ & $0.23 \pm 0.02$ \\
\hline Wet & $\begin{array}{l}\text { Aitken } \\
\text { accumulation }\end{array}$ & $\begin{array}{l}246 \pm 9 \\
145 \pm 8\end{array}$ & $\begin{array}{l}0.13 \pm 0.02 \\
0.21 \pm 0.05\end{array}$ & $\begin{array}{c}70 \pm 1 \\
170 \pm 2\end{array}$ & $\begin{array}{l}0.53 \pm 0.01 \\
0.42 \pm 0.01\end{array}$ & 0.99 & $112 \pm 2$ & $0.22 \pm 0.02$ \\
\hline Transition & $\begin{array}{l}\text { Aitken } \\
\text { accumulation }\end{array}$ & $\begin{array}{l}405 \pm 24 \\
668 \pm 24\end{array}$ & $\begin{array}{l}0.14 \pm 0.02 \\
0.24 \pm 0.04\end{array}$ & $\begin{array}{c}65 \pm 1 \\
135 \pm 1\end{array}$ & $\begin{array}{l}0.42 \pm 0.01 \\
0.53 \pm 0.01\end{array}$ & 0.99 & $92 \pm 2$ & $0.34 \pm 0.03$ \\
\hline Dry & $\begin{array}{l}\text { Aitken } \\
\text { accumulation }\end{array}$ & $\begin{array}{c}483 \pm 49 \\
1349 \pm 47\end{array}$ & $\begin{array}{l}0.13 \pm 0.03 \\
0.21 \pm 0.04\end{array}$ & $\begin{array}{c}71 \pm 2 \\
150 \pm 2\end{array}$ & $\begin{array}{l}0.42 \pm 0.03 \\
0.58 \pm 0.01\end{array}$ & 0.99 & $97 \pm 2$ & $0.29 \pm 0.03$ \\
\hline
\end{tabular}

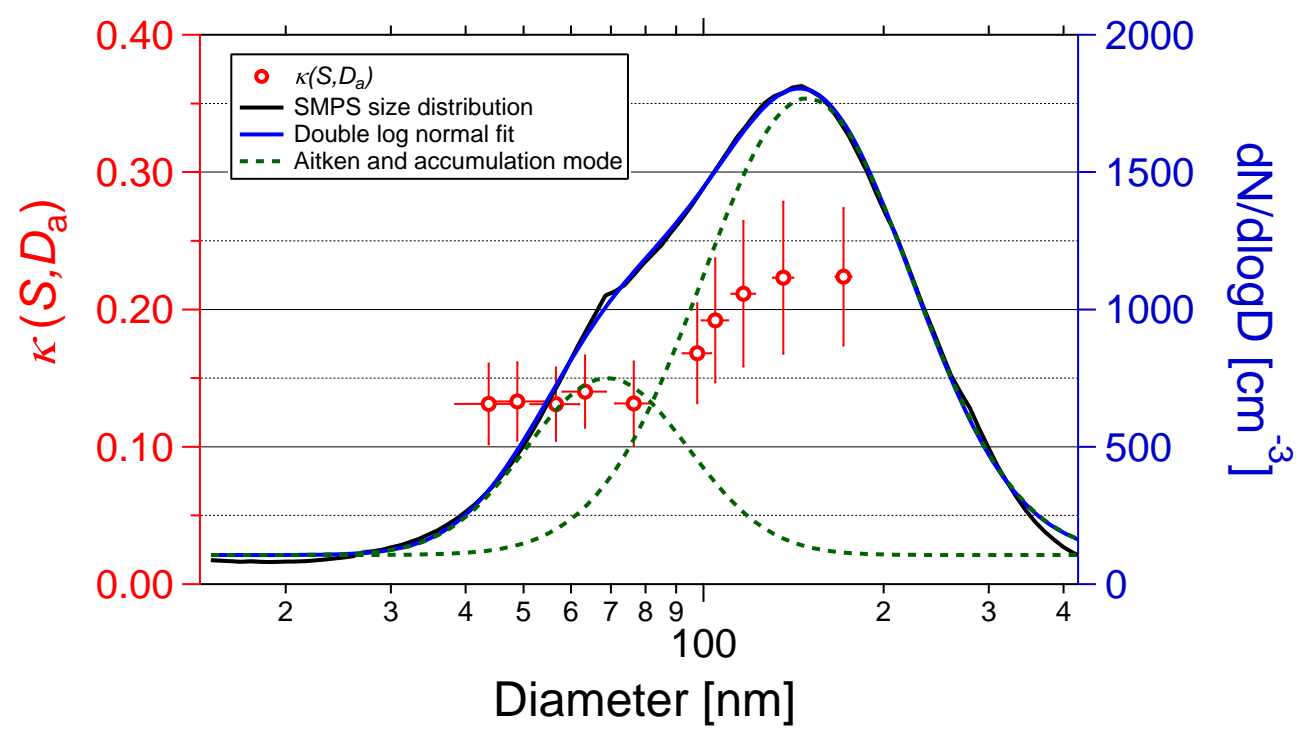

Figure 3. Size dependence of the hygroscopicity parameter $\kappa\left(S, D_{a}\right)$ averaged over the entire measurement period. Values of $\kappa\left(S, D_{a}\right)$ for every $S$ level are plotted against their corresponding midpoint activation diameter $D_{a}(S)$ (left axis). For $\kappa\left(S, D_{a}\right)$, the error bars represent 1 standard deviation. For $D_{a}(S)$, the experimentally derived error is shown. In addition, the average number size distribution for the entire measurement period is shown (right axis). Dashed green lines represent the average Aitken and accumulation modes. The standard error of the number size distribution is indicated as grey shading, which is very small and therefore hardly perceptible in this representation due to the large number of scans with comparatively small variability. Distinctly different $\kappa\left(S, D_{a}\right)$ levels can be observed for the Aitken and accumulation modes with lower variability in the Aitken than in the accumulation mode.

absent (Jurányi et al., 2011; Levin et al., 2012; Paramonov et al., 2013).

Figure 4 combines the annually averaged size distributions of $N_{\mathrm{CN}}(D)$ as well as $N_{\mathrm{CCN}}(S, D)$ for all $S$ levels. These curves result from multiplying the $N_{\mathrm{CN}}(D)$ size distribution with the CCN activation curves in Fig. 2 and clearly visualize the inverse relationship of $D_{a}(S)$ and $S$. Following the previous discussion of Fig. 2, $S$ ranging between 0.11 and $0.29 \%$ mostly activates accumulation-mode particles, while $S$ ranging between 0.47 and $1.10 \%$ activates the accumulation mode plus a substantial fraction of Aitken-mode particles. For the highest supersaturation $(S=1.10 \%)$ that was used in this study, almost the entire $N_{\mathrm{CN}}(D)$ size distribution is being activated into $\mathrm{CCN}$, which (regarding the very 


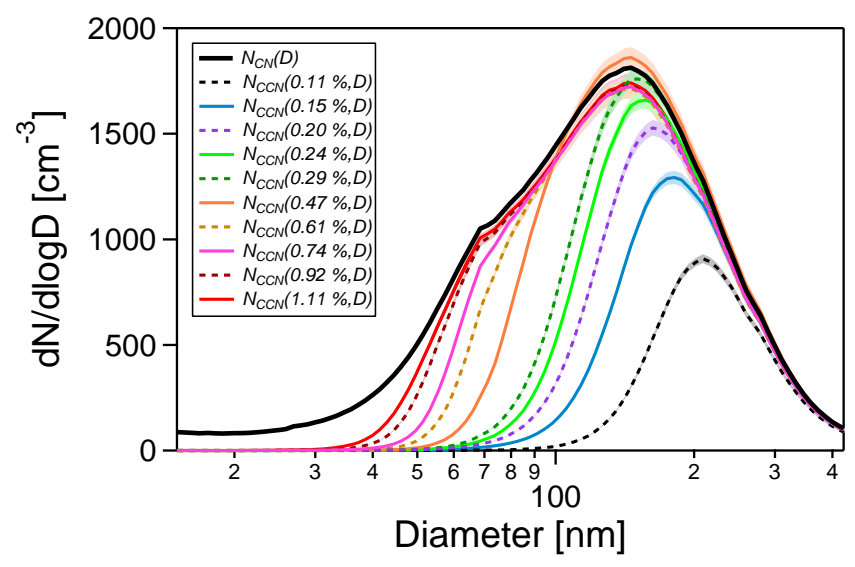

Figure 4. Number size distributions of total aerosol particles, $N_{\mathrm{CN}}(D)$, and of cloud condensation nuclei, $N_{\mathrm{CCN}}(S, D)$, at all 10 supersaturation levels $(S=0.11-1.10 \%)$ averaged over the entire measurement period. The $N_{\mathrm{CCN}}(S, D)$ size distributions were calculated by multiplying the average $N_{\mathrm{CN}}(D)$ size distributions (in Fig. 3) with the average $\mathrm{CCN}$ activation curves in (Fig. 2).

sparse occurrence of particles $<30 \mathrm{~nm}$ ) explains the high $N_{\mathrm{CCN}}(1.10 \%) / N_{\mathrm{CN}, 10}$ levels in Fig. $1 \mathrm{~d}$.

\subsection{Seasonal differences in $\mathrm{CCN}$ properties at the ATTO site}

Within the seasonal periods in the central Amazon as defined in Sect. 1.2, we have subdivided the annual data set into the following four periods of interest, which represent the contrasting aerosol conditions and/or sources. (a) The first half of the wet seasons 2014 and 2015 received substantial amounts of long-range transport (LRT) aerosol: mostly African dust, biomass smoke, and fossil fuel emissions (Ansmann et al., 2009; Salvador et al., 2016). Here, the corresponding period of interest will be called LRT season and covers 24 March to 13 April 2014 and 9 January to 10 February 2015. (b) In the late wet season 2014, all pollution indicators approached background conditions. Thus, the period from 13 April to 31 May 2014 will be treated as the clean wet season in this study. (c) The months June to July represent the transition period from wet to dry season and will be called "transition wet to dry". (d) The period of interest that covers the dry season with frequent intrusion of biomass burning smoke ranges from August to December 2014.

Figure 5 shows the CCN activation curves for all $S$ levels, subdivided into the four seasonal periods of interest. Although the plots for the individual seasons appear to differ only subtly, e.g., in $D_{a}(S)$ position and curve width, there is one major difference: the variable shape of the activation curve for the smallest $S=0.11 \%$. Particularly, the behavior of $\operatorname{MAF}(0.11 \%)$ shows clear seasonal differences. It reaches unity during the wet season, whereas it levels off below unity for the LRT, transition, and particularly for the dry season periods. The fraction of non-activated particles with $D \leq 245 \mathrm{~nm}$ at $S=0.11 \%$ is $\sim 10 \%$ during the transition period and $\sim 20 \%$ during the dry season. Interestingly, this effect is only observed for $S=0.11 \%$, whereas $\operatorname{MAF}(>0.11 \%)$ reaches unity throughout the entire year. An explanation for this observation could be the intrusion of relatively fresh biomass burning aerosol plumes during the transition period and dry season, which contain a fraction of comparatively inefficient $\mathrm{CCN}$. Soot is probably a main candidate here; however, fresh soot should also significantly reduce the $\operatorname{MAF}(S)$ for higher $S$ levels (Rose et al., 2010). Thus, we speculate that probably "semi-aged" soot particles may be an explanation for the observed activation behavior.

Figure 6 corresponds to Fig. 3 and subdivides the annual mean $\kappa\left(S, D_{a}\right)$ size distribution $\left(\kappa\left(S, D_{a}\right)\right.$ plotted against all measured $\left.D_{a}(S)\right)$ as well as the annual mean $N_{\mathrm{CN}}(D)$ size distribution into their seasonal counterparts. The particle size distributions were fitted with a bimodal logarithmic normal distribution and the corresponding results are listed in detail in Table 2. The differences in the characteristic size distributions for the individual seasons clearly emerge: in addition to the strong variations in total particle number concentration (see Fig. 1), the accumulation mode overwhelms the Aitken mode during the dry season, while accumulation and Aitken modes occur at comparable strength under wet season conditions. In other words, during the dry season, Aitken-mode particles account on average for about $26 \%$ of the total aerosol population $\left(N_{\mathrm{CN} \text {,Ait }}=483 \pm 49 \mathrm{~cm}^{-3}\right.$ vs. $N_{\mathrm{CN}, \text { Acc }}=1349 \pm 47 \mathrm{~cm}^{-3}$ ), whereas during the wet season, the Aitken mode accounts for about $62 \%$ $\left(N_{\mathrm{CN}, \text { Ait }}=246 \pm 9 \mathrm{~cm}^{-3}\right.$ vs. $\left.N_{\mathrm{CN}, \text { Acc }}=145 \pm 8 \mathrm{~cm}^{-3}\right)(\mathrm{see}$ Table 2). The size distribution of the transition period from wet to dry season represents an intermediate state between the wet and dry season "extremes". Furthermore, the comparison between wet season conditions with and without LRT influence reveals comparable distributions. However, a slight increase in the accumulation mode during LRT conditions indicates the presence of dust, smoke, pollution, and aged sea spray on top of the biogenic aerosol population during pristine periods (M. L. Pöhlker et al., 2017a).

The Hoppel minimum $D_{\mathrm{H}}$ (Hoppel et al., 1996) between the Aitken and accumulation modes ${ }^{4}$ also shows seasonal variations with its largest values around $110 \mathrm{~nm}$ in the wet season and its smallest values around $95 \mathrm{~nm}$ in the dry season (compare to Fig. 5 and Table 2). Following Krüger et al. (2014), the observed $D_{\mathrm{H}}$ can be used to determine an effective average cloud peak supersaturation $S_{\text {cloud }}\left(D_{\mathrm{H}, \kappa)}\right.$.

\footnotetext{
${ }^{4}$ The position of $D_{\mathrm{H}}$ was determined as the intersection of the fitted and normalized modes (monomodal fits for Aitken and accumulation mode were normalized to equal area). The normalization is necessary for a precise localization of $D_{\mathrm{H}}$ because large differences in Aitken- and accumulation-mode strength (e.g., for the dry season conditions) cause biased $D_{\mathrm{H}}$ as the intersection of both modes is shifted towards the smaller mode.
} 

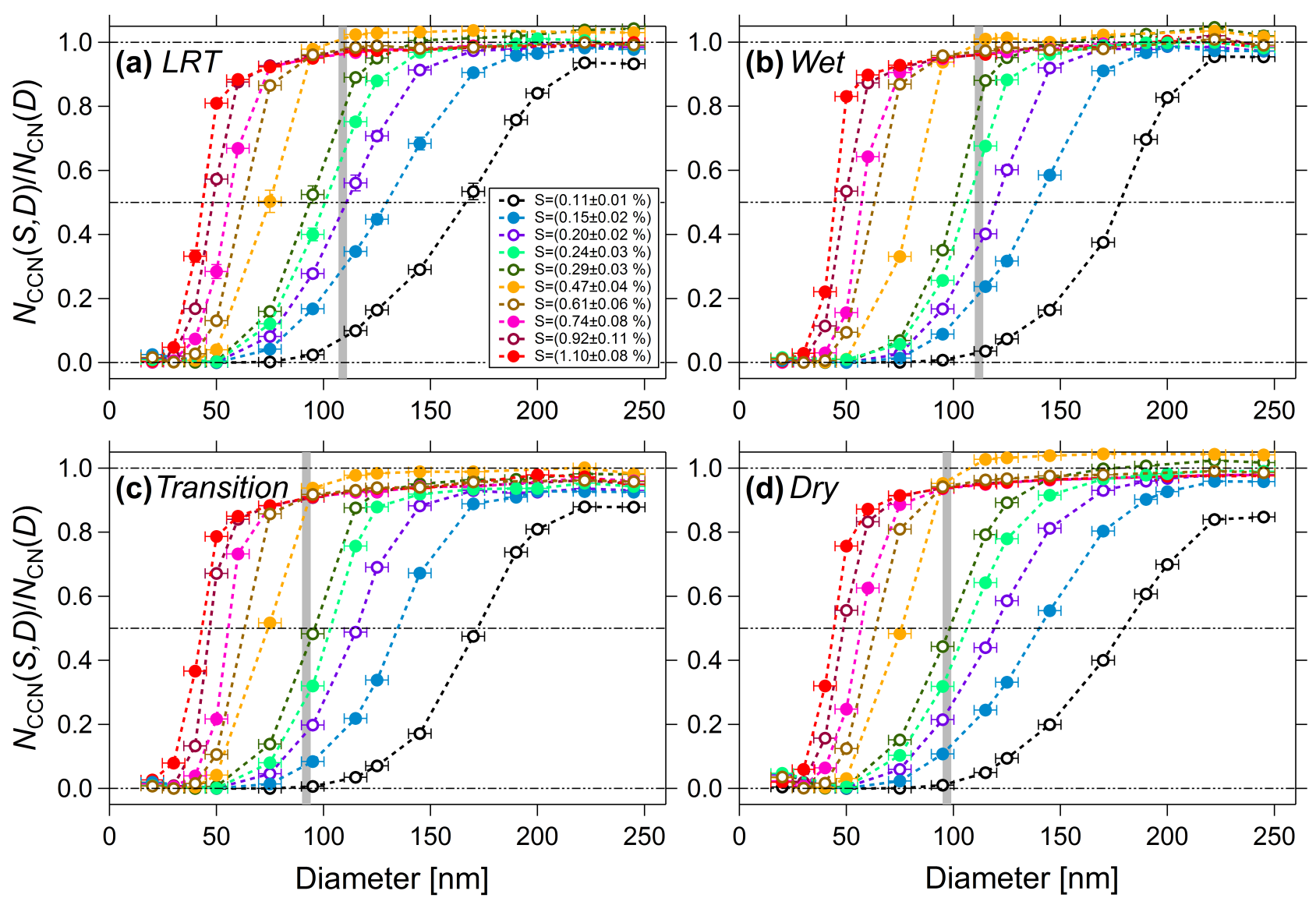

Figure 5. CCN activation curves for all measured $S$ levels $(S=0.11-1.10 \%)$, subdivided into seasonal periods of interest as specified in Sect. 3.3. Data points represent arithmetic mean values. For $N_{\mathrm{CCN}}(S, D) / N_{\mathrm{CN}}(D)$, the standard error is plotted, which is very small (due to the large number of scans with comparatively small variability) and therefore not perceptible in this representation. For the diameter, $D$, the error bars represent the experimental error as specified in Sect. 2.3. The grey vertical bands represent the (seasonal) position of the Hoppel minima (including error range; compare to Table 2). Dashed horizontal lines provide visual orientation and indicate 0,50 , and $100 \%$ activation. The $50 \%$ activation diameter is used for calculation of the hygroscopicity parameter $\kappa\left(S, D_{a}\right)$. The lines connecting the data points merely serve as visual orientation.

Cloud development and dynamics are highly complex processes in which aerosol particles are activated at different supersaturations. In the context of this study, $S_{\text {cloud }}\left(D_{\mathrm{H}}, \kappa\right)$ is used as a mean cloud supersaturation and serves as an overall reference value; however, it does not reflect the complex development of $S$ inside a cloud. Based on our data, $S_{\text {cloud }}\left(D_{\mathrm{H}}, \kappa\right)$ is estimated as a value around $0.29 \%$ during dry season conditions and around $0.22 \%$ during wet season conditions (Table 2). This indicates that $S_{\text {cloud }}\left(D_{\mathrm{H}}, \kappa\right)$ levels tend to be noticeable lower during wet season cloud development compared to the dry season scenario. A plausible cause for the comparatively small $D_{\mathrm{H}}$ and high $S_{\text {cloud }}\left(D_{\mathrm{H}}, \kappa\right)$ in the dry season could be invigorated updraft regimes in the convective clouds. This invigoration could be caused by the stronger solar heating during the dry season and/or the increased aerosol load under biomass-burning-impacted conditions, as suggested previously (Andreae et al., 2004; Rosenfeld et al., 2008). As outlined in Sect. 1.1, aerosol particle size, concentration, and hygroscopicity as well as cloud supersaturation represent key parameters for a detailed understanding of cloud properties. Figure 6 provides reference values for all these parameters, resolved by seasons and thus provides comprehensive insight into the Amazonian cloud properties.

Comparing the seasonal $\kappa\left(S, D_{a}\right)$ size distributions in Fig. 6 , it is obvious that the (seasonally averaged) $\kappa_{\text {Ait }}$ values in the Aitken-mode size range are surprisingly stable between 0.13 and 0.14 throughout the whole year. This indicates that the Aitken-mode aerosol population was persistently dominated by almost pure organic particles throughout the seasons. In contrast, noticeable seasonal differences were observed for (seasonally averaged) $\kappa_{\text {Acc }}$ values in the accumulation-mode size range, with mean values ranging from around 0.21 to 0.28 . This indicates that the accumulation mode also comprises high contents of organic materials, however, with elevated amounts of inorganic ingredi- 


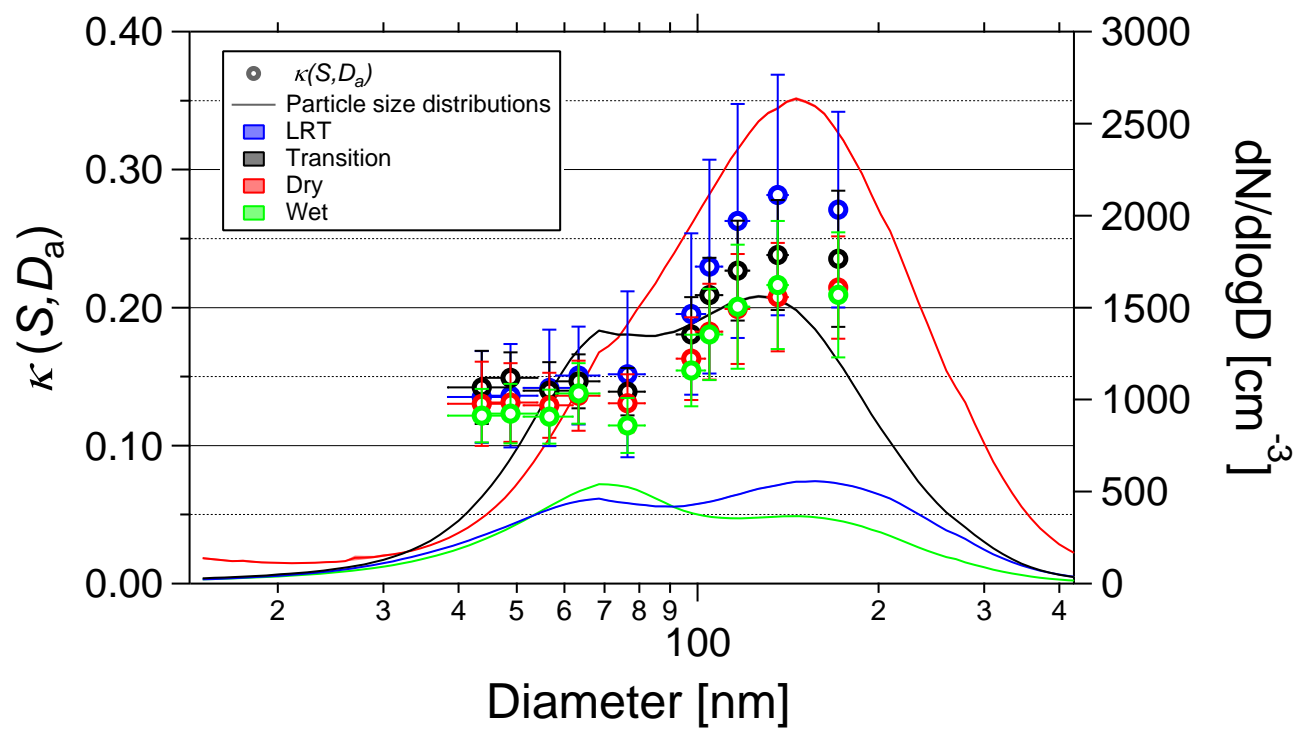

Figure 6. Size dependence of the hygroscopicity parameter $\kappa\left(S, D_{a}\right)$ subdivided into seasonal periods of interest (color coding) as specified in Sect. 3.3. Values of $\kappa\left(S, D_{a}\right)$ for every $S$ level are plotted against their corresponding midpoint activation diameter $D_{a}(S)$ (left axis). For $\kappa\left(S, D_{a}\right)$, the error bars represent 1 standard deviation. For $D_{a}(S)$, the experimentally derived error is shown. In addition, the average number size distributions for the seasonal periods of interest are shown (right axis). The standard error of the number size distributions is indicated as shading, which is very small and therefore hardly perceptible in this representation due to the large number of scans with comparatively small variability. A clear size dependence and seasonal trends in $\kappa\left(S, D_{a}\right)$ levels can be observed. The averaged number size distributions show very pronounced seasonal differences.

ents (i.e., sulfate, ammonium, and potassium). In the size range around $D_{\mathrm{H}}$, which separates the (apparently) chemically distinct aerosol populations of Aitken and accumulation modes, a step-like increase in $\kappa\left(S, D_{a}\right)$ is observed. The highest seasonally averaged $\kappa\left(S, D_{a}\right)$ values (up to 0.28$)$ are observed during intrusion of dust, marine sulfate, and seasalt-rich LRT plumes. Note that short-term peaks in $\kappa\left(S, D_{a}\right)$ can be even higher; see case studies in Part 2 (M. L. Pöhlker et al., 2017a). In the absence of LRT, the $\kappa_{\text {Acc }}$ values are also rather stable for most of the year and range between 0.21 and 0.24 . Overall, a remarkable observation is the high similarity between the wet and dry season $\kappa\left(S, D_{a}\right)$ size distributions, while many other aerosol parameters undergo substantial seasonal variations (Andreae et al., 2015).

The $\kappa\left(S, D_{a}\right)$ levels reported here agree well with the corresponding results in the previous Amazonian CCN studies by Gunthe et al. (2009) and Whitehead et al. (2016), which range between 0.1 and 0.4 , with a mean around $0.16 \pm 0.06$. In a wider context, our results also agree well with previous long-term measurements at other continental background locations (i.e., alpine, semi-arid, and boreal sites) (Jurányi et al., 2011; Levin et al., 2012; Paramonov et al., 2013; Mikhailov et al., 2015). Comparing these four sites with each other, the following observations can be made. (i) $\kappa_{\text {Ait }}$ tends to be smaller than $\kappa_{\text {Acc }}$ at all four background locations. (ii) At the alpine, semi-arid, and boreal sites, $\kappa\left(S, D_{a}\right)$ undergoes a rather gradual increase from the Aitken- to the accumulation-mode size range (Paramonov et al., 2013, and references therein), whereas this increase appears to be steeper (step-like) in the Amazon. This can clearly be seen in the present study (e.g., Fig. 3) as well as in Gunthe et al. (2009) and Whitehead et al. (2016). (iii) Particularly in the vegetated environments (i.e., tropical, boreal, and semiarid forests), $\kappa_{\text {Ait }}$ mostly ranges between 0.1 and 0.2 , suggesting that the Aitken-mode particles predominantly comprise organic constituents. Furthermore, $\kappa_{\text {Ait }}$ shows a remarkably small seasonality for these locations. (iv) The $\kappa_{\text {Acc }}$ levels show a much wider variability throughout the seasons for all locations.

Figure 7 presents the diurnal cycles in $\kappa_{\text {mean }}$ for the four seasonal periods of interest. No perceptible diurnal trends in $\kappa_{\text {mean }}$ can be observed for any of the seasons. The only observable difference is an increased variability of $\kappa_{\text {mean }}$ during the LRT season (see error bars in Fig. 7a). This can be explained by the episodic character of LRT intrusions, which causes an "alternating pattern" of clean periods with background conditions and periods of elevated concentrations of LRT aerosol (M. L. Pöhlker et al., 2017a). For comparison, the diurnal cycles in $N_{\mathrm{CN}}$ concentration have been added to Fig. 7, which confirm the absence of strong diurnal variations in the aerosol population. 

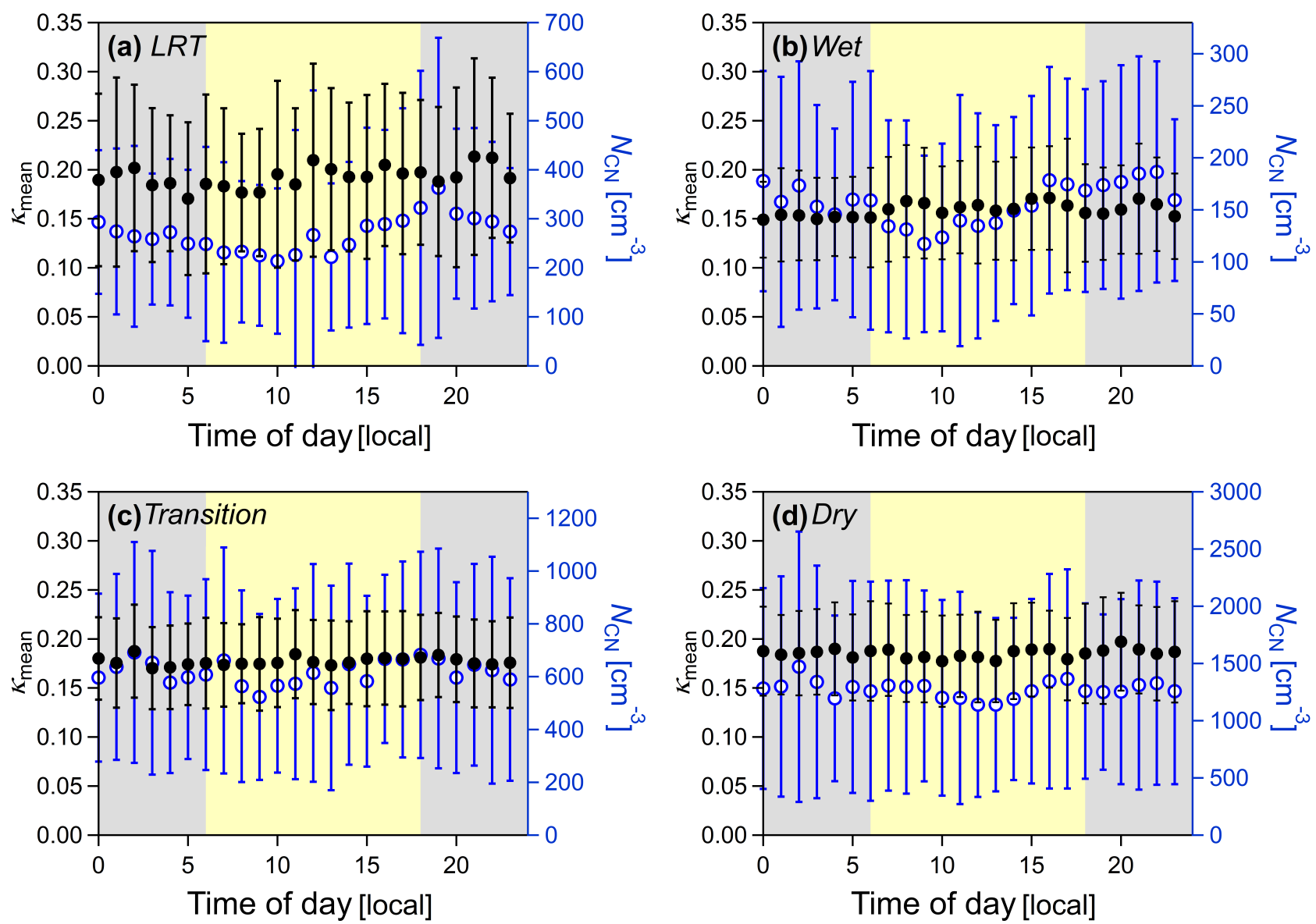

Figure 7. Diurnal cycles in hygroscopicity parameter, $\kappa_{\text {mean }}$, and total aerosol number concentration, $N_{\mathrm{CN}}$, subdivided into seasonal periods of interest as specified in Sect. 3.3. No diurnal trend is detectable throughout the year. Note that the range of 1 standard deviation of $\kappa_{\text {mean }}$ around the mean is surprisingly small given that long seasonal time periods and data from all $S$ levels have been averaged. The only perceptible difference is a larger scattering during a period with LRT influence (a). Grey and yellow shading indicate night and day.

\subsection{Aerosol chemical composition and effective hygroscopicity}

Continuous ACSM measurements are being conducted at the ATTO site since March 2014, providing online and nonsize-resolved information on the chemical composition of the non-refractory aerosol (Andreae et al., 2015). Here, we compare the ACSM data on the aerosol's chemical composition with the CCNC-derived $\kappa\left(S, D_{a}\right)$ values. This analysis focuses on the dry season months, when ACSM and CCNC were operated in parallel. ${ }^{5}$ Note that the ACSM covers a size range from 75 to $650 \mathrm{~nm}$ ( $\mathrm{Ng}$ et al., 2010), while the sizeresolved $\mathrm{CCN}$ measurements provide information only up to particle sizes of about $170 \mathrm{~nm}$. Since the ACSM records the size-integrated masses of defined chemical species (organics,

\footnotetext{
${ }^{5}$ Although the ACSM measurements were started in March 2014, instrumental issues during the initial months caused some uncertainty for the corresponding data. Thus, for this study, we focus only on the data period August to December 2014, when the instrumental issues were resolved.
}

nitrate, sulfate, ammonium, and chloride), the results tend to be dominated by the fraction of larger particles with comparatively high masses (i.e., in the accumulation-mode size range) and are influenced less by the fraction of small particles with comparatively low masses (i.e., in the Aitken-mode size range). Thus, in order to increase the comparability between ACSM and CCNC, we have chosen the lowest $S$ level ( $S=0.11 \pm 0.01 \%)$, which represents the largest measured $D_{a}(S)\left(D_{a}(S)=172 \pm 12 \mathrm{~nm}\right)$.

In Fig. 8 , the $\kappa\left(0.11 \%, D_{a}\right)$ values are plotted against the ACSM-derived organic mass fraction $\left(f_{\text {org }}\right)$. The data were fitted with (i) a linear fit and (ii) a bivariate regression according to Cantrell (2008). A linear fit approach was used by Gunthe et al. (2009) to determine the effective hygroscopicity parameters $\kappa_{\text {org }}=0.1$ of biogenic Amazonian SOA $\left(f_{\text {org }}=1\right)$ and $\kappa_{\text {inorg }}=0.6$ for the inorganic fraction $\left(f_{\text {org }}=0\right)$. For the present data set, the same procedure results in an acceptable coefficient of determination $\left(R^{2}=0.66\right)$. We estimated the effective hygroscopicity parameters $\kappa_{\text {org }}=0.12 \pm 0.01$ and $\kappa_{\text {inorg }}=0.61 \pm 0.01$ based 


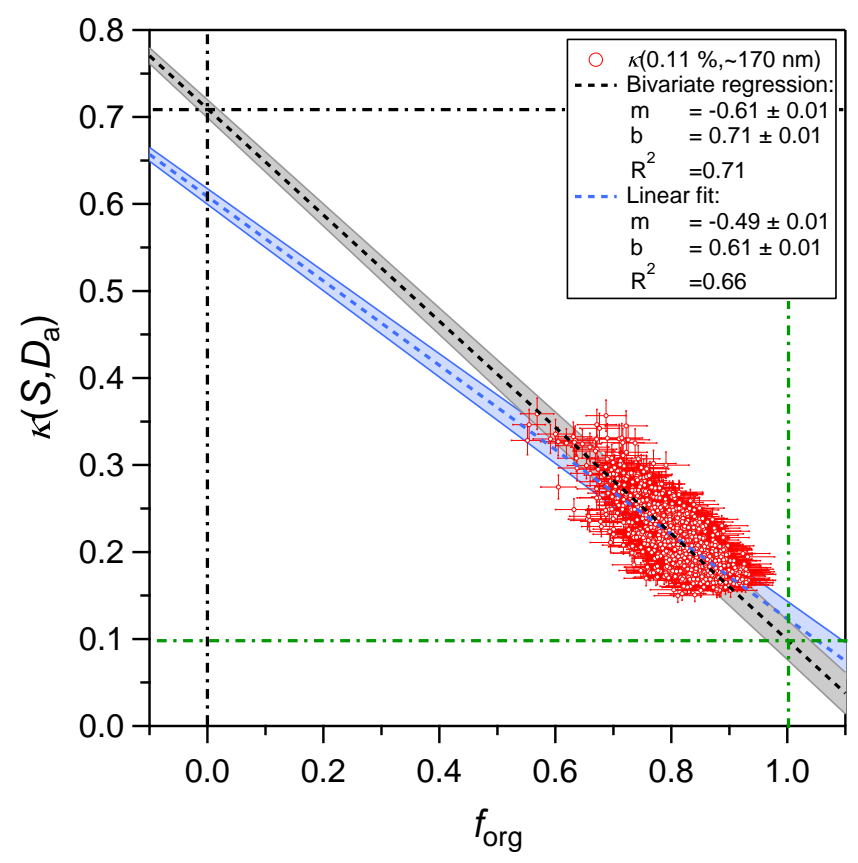

Figure 8. Correlation between $\kappa(0.11 \%, \sim 170 \mathrm{~nm})$ and the organic mass fraction, $f_{\text {org }}$, determined by the ACSM during the dry season months. The data were fitted by a linear and a bivariate regression fit. Shading of the fit lines shows the standard error of the fit. The error bars of the data markers represent the experimental error, which is estimated as $5 \%$ for $f_{\text {org }}$ and $10 \%$ for $\kappa(0.11 \%, \sim 170 \mathrm{~nm})$.

on the linear fit and extrapolation to $f_{\text {org }}=1$ and $f_{\text {org }}=0$, respectively. This is in good agreement with previous studies (King et al., 2007; Engelhart et al., 2008; Gunthe et al., 2009; Rose et al., 2011). However, a drawback of the linear fitting approach is the fact that swapping $f_{\text {org }}$ and $\kappa\left(0.11 \%, D_{a}\right)$ on the axes will change the results.

Therefore, we also applied the bivariate regression fit, which takes into account that both parameters, $f_{\text {org }}$ and $\kappa\left(0.11 \%, D_{a}\right)$, have an experimental error. For the bivariate regression, an error of $5 \%$ in $f_{\text {org }}$ and an error of $10 \%$ in $\kappa\left(0.11 \%, D_{a}\right)$ were used. A coefficient of determination of $R^{2}=0.71$ was obtained for the bivariate regression, which is slightly better than for the linear fit. Based on the bivariate regression, we estimated effective hygroscopicity parameters $\kappa_{\text {org }}=0.10 \pm 0.01$ and $\kappa_{\text {inorg }}=0.71 \pm 0.01$ for the organic and inorganic fractions, respectively.

\subsection{CCN parametrizations and prediction of $\mathrm{CCN}$ number concentrations}

Cloud-resolving models at all scales - spanning from large eddy simulations (LESs) to global climate models (GCMs) require simple and efficient parametrizations of the complex microphysical basis to adequately reflect the spatiotemporal CCN cycling (Cohard et al., 1998; Andreae, 2009). Previously, several different approaches to predict $\mathrm{CCN}$ concen- trations have been suggested (Andreae, 2009; Gunthe et al., 2009; Rose et al., 2010; Deng et al., 2013). Any parametrization strategy seeks, on one hand, an efficient combination of a minimal set of input data and, on the other hand, a good representation of the atmospheric $\mathrm{CCN}$ population.

The detailed analysis in this study has shown that the $\mathrm{CCN}$ population in the central Amazon is mainly defined by comparatively stable $\kappa\left(S, D_{a}\right)$ levels, due to the predominance of organic aerosol particles, and rather pronounced seasonal trends in aerosol number size distribution. Particularly, the remarkably stable $\kappa\left(S, D_{a}\right)$ values suggest that the Amazonian $\mathrm{CCN}$ cycling can be parametrized rather precisely for efficient prediction of $\mathrm{CCN}$ concentrations. In the following paragraphs, we apply the following $\mathrm{CCN}$ parametrization strategies to the present data set and explore their strengths and limitations:

i. CCN prediction based on the correlation between $N_{\mathrm{CCN}}(0.4 \%)$ and $N_{\mathrm{CN}}$, called the $\Delta N_{\mathrm{CCN}}(0.4 \%) / \Delta N_{\mathrm{CN}}$ parametrization here;

ii. $\mathrm{CCN}$ prediction based on the correlation between $N_{\mathrm{CCN}}(S)$ and $c_{\mathrm{CO}}$, called the $\Delta N_{\mathrm{CCN}}(S) / \Delta c_{\mathrm{CO}}$ parametrization here;

iii. CCN prediction based on analytical fit functions of experimentally obtained $\mathrm{CCN}$ spectra, called $\mathrm{CCN}$ spectra parametrization;

iv. CCN prediction based on the $\kappa$-Köhler model, called $\kappa$ Köhler parametrization; and

v. CCN prediction based on a novel and effective parametrization built on $\mathrm{CCN}$ efficiency spectra, called $\mathrm{CCN}$ efficiency spectra parametrization.

The prediction accuracy for the individual strategies is summarized in Table 3.

\subsection{1 $\Delta N_{\mathrm{CCN}}(0.4 \%) / \Delta N_{\mathrm{CN}}$ parametrization}

Andreae (2009) analyzed CCN data sets from several contrasting field sites worldwide and found significant relationships between the satellite-retrieved aerosol optical thickness (AOT) and the corresponding $N_{\mathrm{CCN}}(0.4 \%)$ levels as well as between the total aerosol number concentration $N_{\mathrm{CN}}$ and $N_{\mathrm{CCN}}(0.4 \%)$. The obtained ratio $N_{\mathrm{CCN}}(0.4 \%) / N_{\mathrm{CN}}=0.36 \pm 0.14-$ in other words, the globally averaged CCN efficiency at $S=0.4 \%$ - can be used to predict $\mathrm{CCN}$ concentrations. The corresponding results for the present data set are displayed in Fig. 9a and show a surprisingly tight correlation, given that a globally obtained $N_{\mathrm{CCN}}(0.4 \%) / N_{\mathrm{CN}}$ ratio has been used. However, Fig. 9a also shows a systematic underestimation of the predicted CCN concentration $N_{\mathrm{CCN}, \mathrm{p}}(0.4 \%)$, which can be explained by the comparatively high activated fractions in the Amazon (e.g., $N_{\mathrm{CCN}}(0.47 \%) / N_{\mathrm{CN}, 10}$ ranging from 0.6 to 0.9 ; 


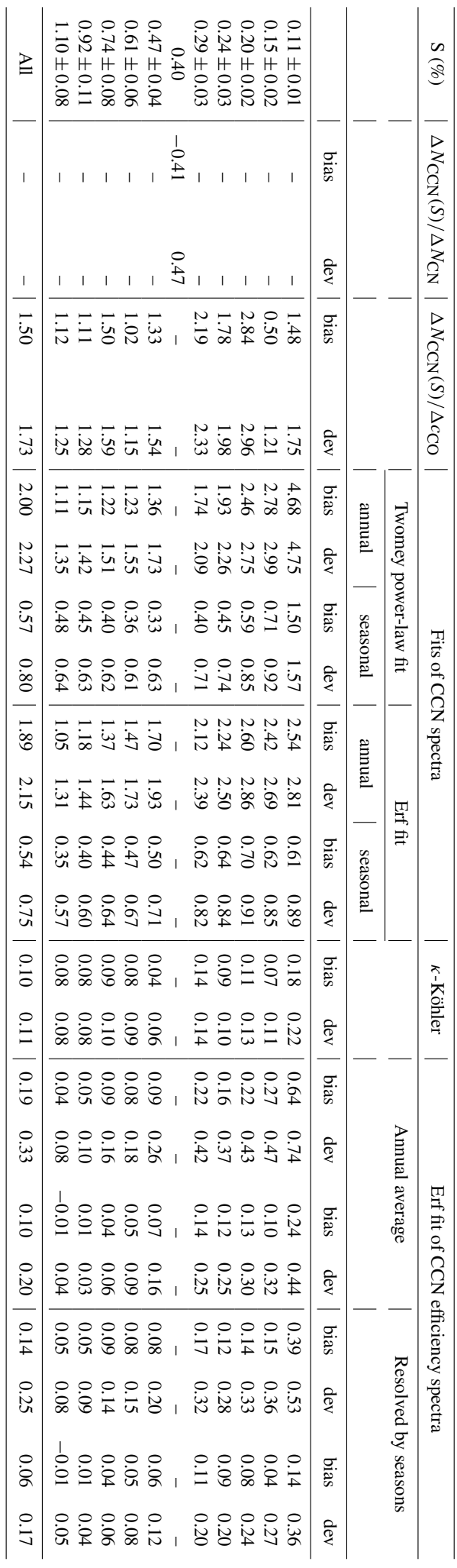

see Fig. 1). Activated fractions in other locations worldwide tend to be lower due to the (more persistent) abundance of nucleation-mode particles, as discussed in Sect. 3.1.

In Sect. 3.5.5, we will show that our novel parametrization is an extension of this approach: the $N_{\mathrm{CCN}}(0.4 \%) / N_{\mathrm{CN}}$ parametrization refers to a globally averaged CCN efficiency at one specific $S$, while the CCN efficiency spectra parametrization is based on an analytical description of CCN efficiencies across the entire (relevant) $S$ range and has been determined specifically for the central Amazon.

\subsection{2 $\Delta N_{\mathrm{CCN}}(S) / \Delta c_{\mathrm{CO}}$ parametrization}

Experimentally obtained excess $N_{\mathrm{CCN}}(S)$ to excess $c_{\mathrm{CO}}$ ratios can be used to calculate $N_{\mathrm{CCN}, \mathrm{p}}(S)$. Kuhn et al. (2010) determined $\Delta N_{\mathrm{CCN}}(0.6 \%) / \Delta c_{\mathrm{CO}}=\sim 26 \mathrm{~cm}^{-3} \mathrm{ppb}^{-1}$ for biomass burning plumes and $\Delta N_{\mathrm{CCN}}(0.6 \%) / \Delta c_{\mathrm{CO}}=$ $\sim 49 \mathrm{~cm}^{-3} \mathrm{ppb}^{-1}$ for urban emissions in the area around Manaus, Brazil. Lawson et al. (2015) investigated biomass burning emissions in Australia and found $\Delta N_{\mathrm{CCN}}(0.5 \%) / \Delta c_{\mathrm{CO}}=9.4 \mathrm{~cm}^{-3} \mathrm{ppb}^{-1}$. In the context of the present study, we have calculated $\Delta N_{\mathrm{CCN}}(S) / \Delta c_{\mathrm{CO}}$ for a strong biomass burning event in August 2014. This event and its impact on the CCN population is the subject of a detailed discussion in the companion Part 2 paper (M. L. Pöhlker et al., 2017a). Here, we use the $\Delta N_{\mathrm{CCN}}(S) / \Delta c_{\mathrm{CO}}$ ratios from the companion paper to obtain a $\mathrm{CCN}$ prediction. The observed $\Delta N_{\mathrm{CCN}}(S) / \Delta c_{\mathrm{CO}}$ ratios range between $6.7 \pm 0.5 \mathrm{~cm}^{-3} \mathrm{ppb}^{-1}$ (for $S=0.11 \%$ ) and values around $18.0 \pm 1.3 \mathrm{~cm}^{-3} \mathrm{ppb}^{-1}$ (for higher $S$ ) (see summary in Table 4). Since biomass burning is the dominant source of pollution in the central Amazon, these biomass-burningrelated $\Delta N_{\mathrm{CCN}}(S) / \Delta c_{\mathrm{CO}}$ ratios in Table 4 were used to calculate $N_{\mathrm{CCN}, \mathrm{p}}(S)$ for the present data set. The corresponding results in Fig. 9b show a reasonable correlation for highly polluted conditions $\left(N_{\mathrm{CN}}>2000 \mathrm{~cm}^{-3}\right)$ and a poor correlation for cleaner states $\left(N_{\mathrm{CN}}<2000 \mathrm{~cm}^{-3}\right)$. This behavior can be explained by the fact that the high concentrations in $\mathrm{CCN}$ and $\mathrm{CO}$ originate from frequent biomass burning plumes during the Amazonian dry season (see Fig. 1). Thus, they can be assigned to the same sources with rather defined $\Delta N_{\mathrm{CCN}}(S) / \Delta c_{\mathrm{CO}}$ ratios (Andreae et al., 2012). During the contrasting cleaner periods, $\mathrm{CN}$ and $\mathrm{CO}$ originate from a variety of different sources, which are often not related and therefore explain the poor correlation for clean to semi-polluted conditions. Overall, Fig. $9 \mathrm{~b}$ indicates that the quality of CO-based $\mathrm{CCN}$ prediction is rather poor, due to the complex interplay of different sources. The overall deviation between $N_{\mathrm{CCN}, \mathrm{p}}(S)$ and $N_{\mathrm{CCN}}(S)$ for this approach is about $170 \%$ (Table 3 ). 

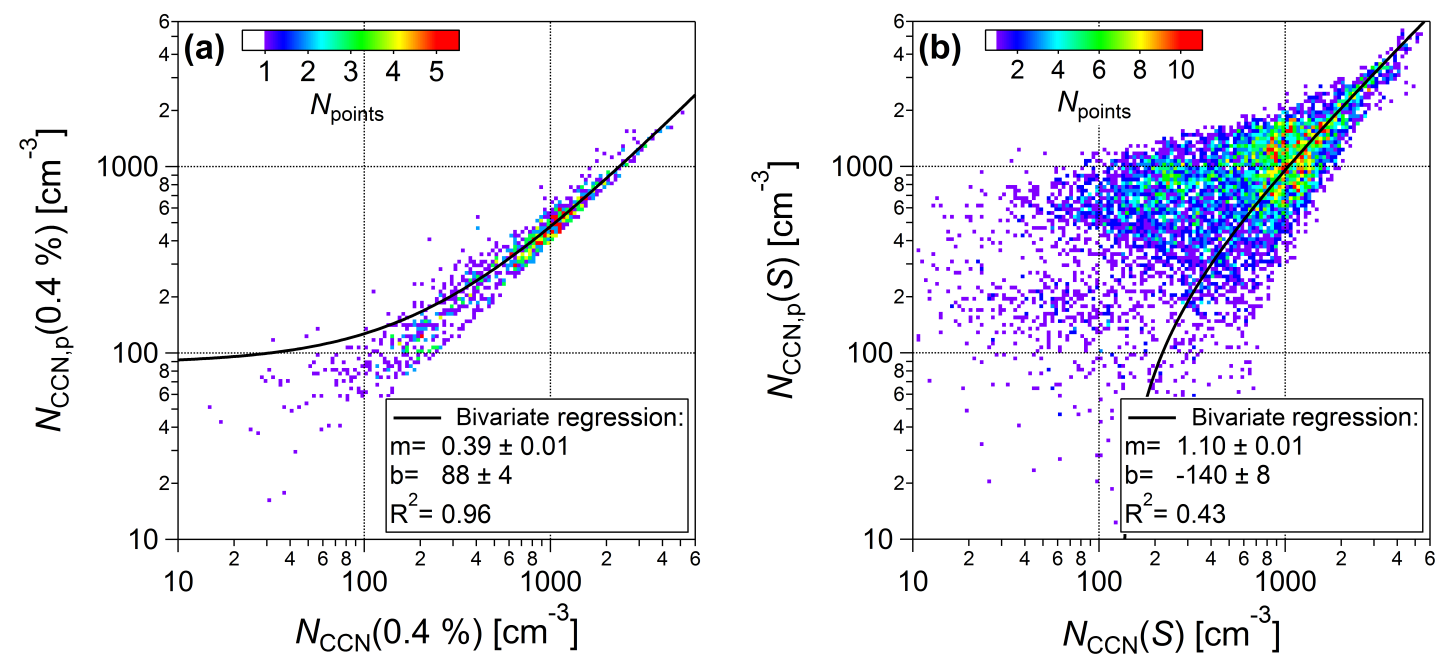

Figure 9. Predicted vs. measured $\mathrm{CCN}$ number concentrations calculated from (a) observed ratio $N_{\mathrm{CCN}}(0.4 \%) / N_{\mathrm{CN}}=0.36$ in $\mathrm{An}$ dreae (2009) and (b) observed (biomass-burning-related) excess CCN to excess CO ratios in M. L. Pöhlker et al. (2017a). The color code shows the number of data points falling into the pixel area, following Jurányi et al. (2011). The black line represents a bivariate regression fit of the data.

Table 4. Excess $N_{\mathrm{CCN}}(S)$ to excess $c_{\mathrm{CO}}$ ratios $\Delta N_{\mathrm{CCN}}(S) / \Delta c_{\mathrm{CO}}$ for the individual $S$ levels during peak period of the strong biomass burning event in August 2014. This event is analyzed in detail through a case study in the companion Part 2 paper (M. L. Pöhlker et al., 2017a). The values $\Delta N_{\mathrm{CCN}}(S) / \Delta c_{\mathrm{CO}}$ were obtained from bivariate regression fit of scatterplots between $N_{\mathrm{CCN}}(S)$ and $c_{\mathrm{CO}}$ for individual $S$ levels (Andreae et al., 2012). The parameter $N_{\mathrm{CCN}}(S)$ in this table represents the $y$ axis intercept of the linear regression of $N_{\mathrm{CCN}}$ vs. $c_{\mathrm{CO}}$ at $c_{\mathrm{CO}}=0 \mathrm{ppb}$ and is, therefore, negative (see M. L. Pöhlker et al., 2017a).

\begin{tabular}{cccc}
\hline$S(\%)$ & $\Delta N_{\mathrm{CCN}}(S) / \Delta c_{\mathrm{CO}}\left(\mathrm{cm}^{-3} \mathrm{ppb}^{-1}\right)$ & $N_{\mathrm{CCN}}(S)\left(\mathrm{cm}^{-3}\right)$ & $R^{2}$ \\
\hline $0.11 \pm 0.01$ & $6.7 \pm 0.5$ & $-603 \pm 125$ & 0.86 \\
$0.15 \pm 0.02$ & $13.6 \pm 1.4$ & $-1447 \pm 354$ & 0.68 \\
$0.20 \pm 0.02$ & $14.3 \pm 0.8$ & $-1128 \pm 208$ & 0.90 \\
$0.24 \pm 0.03$ & $16.8 \pm 1.0$ & $-1460 \pm 261$ & 0.86 \\
$0.29 \pm 0.03$ & $17.4 \pm 1.3$ & $-1378 \pm 296$ & 0.83 \\
$0.47 \pm 0.04$ & $20.1 \pm 1.7$ & $-1675 \pm 425$ & 0.84 \\
$0.61 \pm 0.06$ & $17.9 \pm 1.3$ & $-1206 \pm 332$ & 0.88 \\
$0.74 \pm 0.08$ & $16.5 \pm 1.3$ & $-933 \pm 329$ & 0.88 \\
$0.92 \pm 0.11$ & $18.1 \pm 1.4$ & $-1265 \pm 355$ & 0.85 \\
$1.10 \pm 0.08$ & $17.5 \pm 1.3$ & $-1096 \pm 328$ & 0.87 \\
\hline
\end{tabular}

\subsubsection{Classical and improved CCN spectra parametrization}

The total number of particles that are activated at a given $S$ is regarded as one of the central parameters in cloud formation and evolution (Andreae and Rosenfeld, 2008). Thus, CCN spectra $\left(N_{\mathrm{CCN}}(S)\right.$ plotted against $\left.S\right)$ are a widely and frequently used representation in various studies to summarize the observed $N_{\mathrm{CCN}}(S)$ values over the cloud-relevant $S$ range for a given time period and location (Twomey and Wojciechowski, 1969; Roberts et al., 2002; Rissler et al., 2004; Freud et al., 2008; Gunthe et al., 2009; Martins et al., 2009b). Different analytical fit functions of the experimental CCN spectra have been proposed and are used as parametrization schemes for $N_{\mathrm{CCN}}(S)$ in modeling studies (e.g., Cohard et al., 1998; Khain et al., 2000; Pinsky et al., 2012; Deng et al., 2013).

In the context of the present study, the annual mean Amazonian CCN spectrum is shown in Fig. 10. As an analytical representation of the experimental data, we have used Twomey's empirically found (classical) power-law fit function (Twomey, 1959):

$N_{\mathrm{CCN}}(S)=N_{\mathrm{CCN}}(1 \%) \cdot\left(\frac{S}{1 \%}\right)^{k}$,

which yields a reasonable coefficient of determination of $R^{2}=0.88$ (Fig. 10a). Besides the annual mean spectrum, we also conducted a Twomey fit for the seasonally resolved CCN spectra (not shown) and summarized the resulting fit parameters in Table 5. The obtained fit parameters (e.g., for the an- 


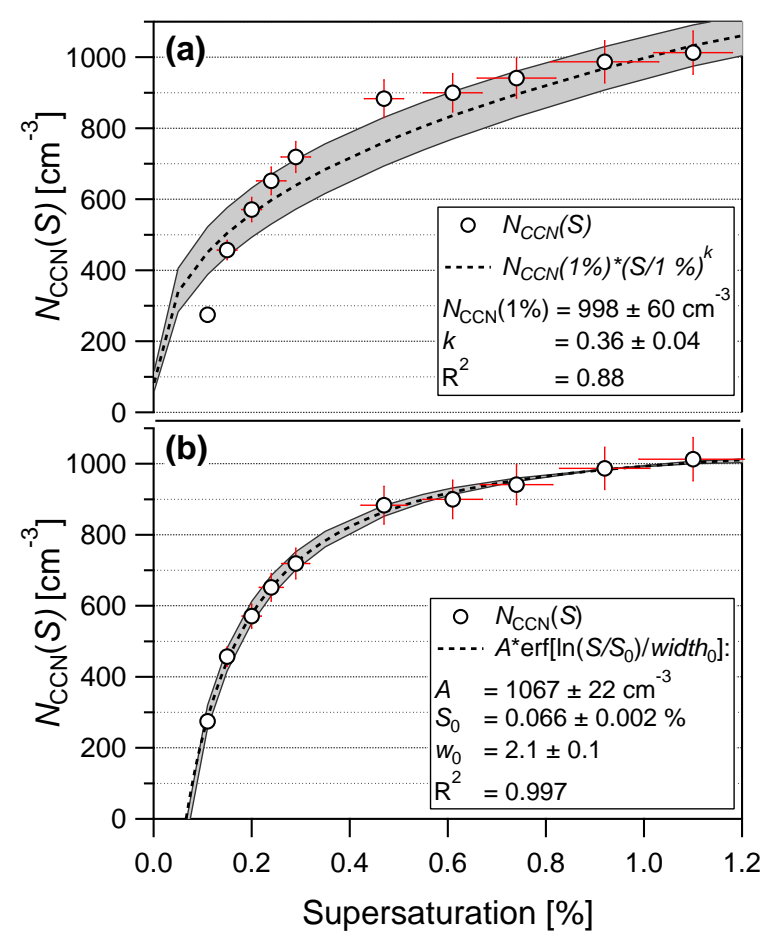

Figure 10. CCN spectrum (circular markers) averaged over the entire measurement period and fitted with the classical Twomey power-law fit (a) and an alternative error function fit (b). Error bars at the markers represent the measurement error in $S$ and standard error in $N_{\mathrm{CCN}}(S)$. The dashed line is a fit function with grey shading as uncertainty of the fit.

Table 5. Twomey fit parameters describing CCN spectra $N_{\mathrm{CCN}}(S)$ vs. $S$ as parametrization input data (compare to Figs. 10 and $11 \mathrm{a}, \mathrm{c}$ ). Fit parameters are provided for annually averaged $\mathrm{CCN}$ spectra and resolved by seasons.

\begin{tabular}{lccc}
\hline Time period & $N_{\mathrm{CCN}}(1 \%)\left(\mathrm{cm}^{-3}\right)$ & $k$ & $R^{2}$ \\
\hline Annual & $998 \pm 60$ & $0.36 \pm 0.04$ & 0.88 \\
Wet season & $289 \pm 7$ & $0.57 \pm 0.03$ & 0.98 \\
LRT period & $378 \pm 9$ & $0.38 \pm 0.03$ & 0.94 \\
Transition & $970 \pm 40$ & $0.49 \pm 0.05$ & 0.94 \\
Dry season & $1469 \pm 78$ & $0.36 \pm 0.06$ & 0.86 \\
\hline
\end{tabular}

nual mean CCN spectrum) $N_{\mathrm{CCN}}(1 \%)=998 \mathrm{~cm}^{-3}$ (sometimes also called $c$ ) and $k=0.36$ agree with results from previous measurements that are summarized by Martins et al. (2009b). The power-law function has become a widely used parametrization due to its simplicity (Cohard et al., 1998). However, because it is based on strong assumptions and not related to the physical basis of the fitted data, it has certain drawbacks, such as the poor representation of $N_{\mathrm{CCN}}(S)$ at small $S$ (i.e., $<0.2 \%$ ), as well as the fact that for larger $S$ (i.e., $>1.2 \%$ ) it does not converge against $N_{\mathrm{CN}}$, which is, for physical reasons, the upper limit.
Table 6. Erf fit parameters describing CCN spectra $N_{\mathrm{CCN}}(S)$ vs. $S$ as parametrization input data (compare to Figs. 10 and $11 \mathrm{~b}, \mathrm{~d}$ ). Fit parameters are provided for annually averaged CCN spectra and resolved by seasons.

\begin{tabular}{lcccc}
\hline Time period & $A\left(\mathrm{~cm}^{-3}\right)$ & $S_{0}(\%)$ & $w_{0}$ & $R^{2}$ \\
\hline Annual & $1067 \pm 22$ & $0.07 \pm 0.01$ & $2.1 \pm 0.1$ & 0.99 \\
Wet season & $340 \pm 30$ & $0.08 \pm 0.01$ & $2.9 \pm 0.2$ & 0.97 \\
LRT period & $532 \pm 72$ & $0.04 \pm 0.01$ & $4.5 \pm 1.0$ & 0.98 \\
Transition & $1180 \pm 37$ & $0.07 \pm 0.01$ & $3.0 \pm 0.2$ & 0.99 \\
Dry season & $1430 \pm 24$ & $0.07 \pm 0.01$ & $1.8 \pm 0.1$ & 0.99 \\
\hline
\end{tabular}

As an alternative, an error function fit - which is used in this context for the first time - represents the data much better (Fig. 10b). The proposed error function (erf)

$N_{\mathrm{CCN}}(S)=A \cdot \operatorname{erf}\left(\frac{\ln \left(\frac{S}{S_{0}}\right)}{w_{0}}\right)$

is related to the physical basis of the fitted data and yields a high coefficient of determination $\left(R^{2}=0.997\right)$. Mathematically, this erf represents an integration of a log-normal $N_{\mathrm{CN}}(D)$ size distribution. Analogously, the $N_{\mathrm{CCN}}(D)$ spectrum represents the cumulative distribution of the relative $N_{\mathrm{CN}}(D)$ distribution (compare to Fig. 4). A double-erf fit would be even more appropriate for the bimodal Amazon $N_{\mathrm{CN}}(D)$ distribution (compare to Fig. 6 and discussion in Sect. 3.5.5). However, the single-erf fit proposed above proved to be (already) a very good analytical representation as underlined by the high coefficient of determination $\left(R^{2}>0.99\right)$. The erf fit reflects the physically expected saturation behavior of aerosol activation for high $S$ and thus converges against a limit of $A=1067 \pm 22 \mathrm{~cm}^{-3}$, which matches well with the mean total number concentration of $N_{\mathrm{CN}, 10}=1097 \pm 66 \mathrm{~cm}^{-3}$. The erf fit (if not forced through the origin) transects the abscissa at $S_{0}=0.066 \%$. Therefore, the erf fit cannot describe the CCN activation behavior for low $S(\leq 0.07 \%)$, which is also an experimentally unaccessible $S$ range. For this approach, we also summarized the corresponding fit parameters for the annual mean $\mathrm{CCN}$ spectrum and the seasonally resolved cases in Table 6 .

Figure 11a and b show the corresponding $N_{\mathrm{CCN}, \mathrm{p}}(S)$ vs. $N_{\mathrm{CCN}}(S)$ scatterplots based on the annual mean CCN spectrum using the Twomey and erf fits. ${ }^{6}$ In general, parametrizations based on CCN spectra yield a mean state based on average concentrations (see fit parameters in Fig. 10 as well as Tables 5 and 6) and ignore the temporal variability of the aerosol abundance (Martins et al., 2009a; Rose et al., 2010; Jurányi et al., 2011). Upon closer inspection, Table 3 shows that the erf fit allows somewhat better predictions (e.g., deviation of power-law fit about $227 \%$ vs. $215 \%$ for erf fit

\footnotetext{
${ }^{6}$ The horizontal lines in the scatterplots result from the fact that constant $N_{\mathrm{CCN}, \mathrm{p}}(S)$ values are obtained for the different $S$ levels.
} 

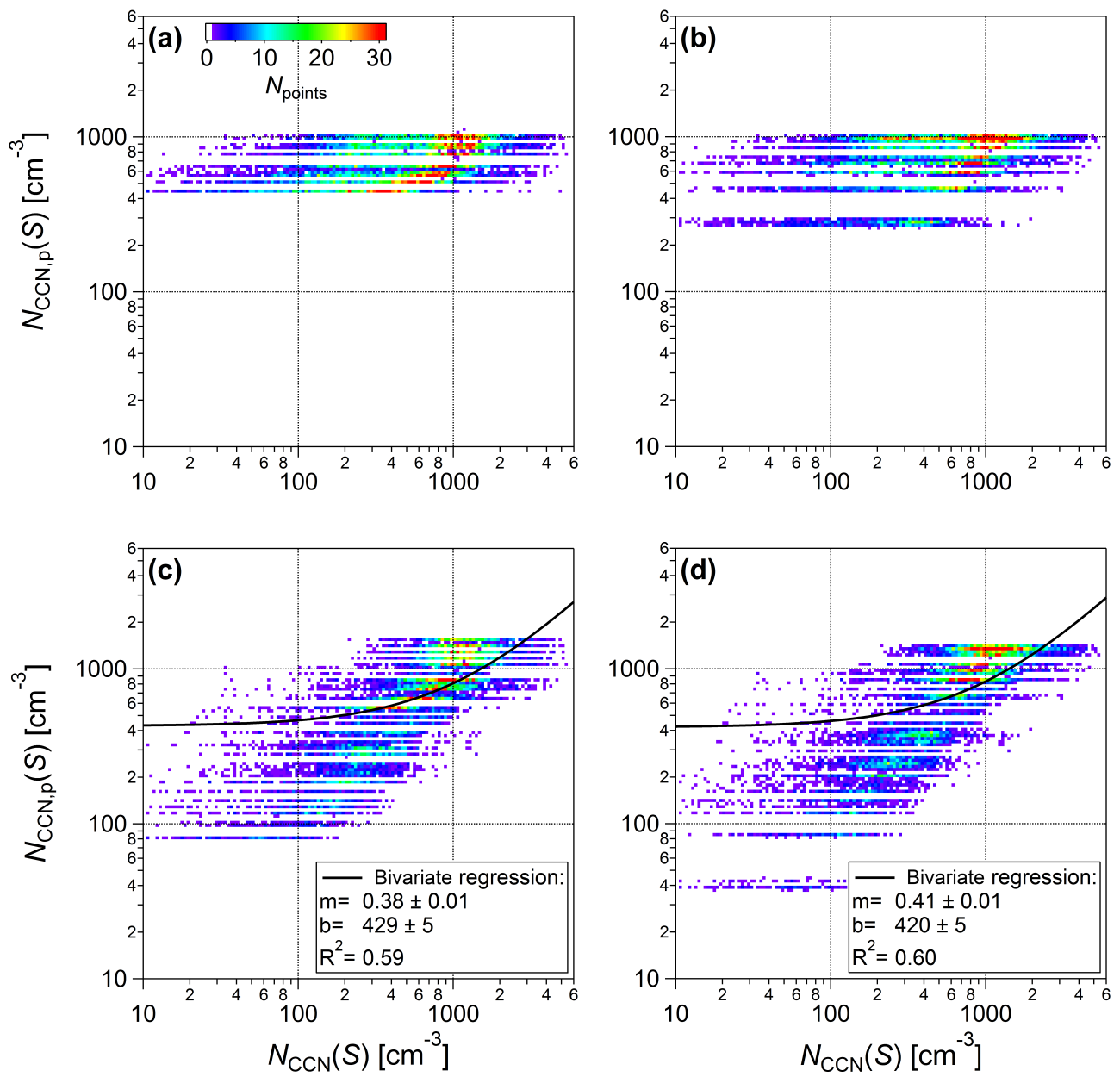

Figure 11. Predicted vs. measured CCN number concentrations based on the classical Twomey power-law fit (a, c) and an alternative error function fit $(\mathbf{b}, \mathbf{d})$. The top row $(\mathbf{a}, \mathbf{b})$ represents the annually averaged cases, whereas the bottom row $(\mathbf{c}, \mathbf{d})$ represents parametrizations based on seasonally resolved CCN spectra. Both predictions are based exclusively on the corresponding average fit functions (i.e., the annually averaged CCN spectra in Fig. 10 and seasonally averaged CCN spectra, as specified in Tables 5 and 6) without considering time-resolved aerosol parameters. The color code shows the number of data points falling into the pixel area, following Jurányi et al. (2011). Predicted and measured CCN concentrations deviate significantly, showing the inherent limitations of the CCN spectra approach. For the annually averaged data (a, b), no meaningful bivariate regression fit could be obtained.

in the case of annual mean and $80 \%$ vs. $75 \%$ for the seasonally resolved case), which can be explained by the fact that the erf fit represents the experimental data more appropriately (compare to Fig. 10). Overall, however, the powerlaw fit and the erf fit approaches give rather poor correlations due to the missing representation of the aerosol's temporal variability. This is particularly obvious for the annual mean case, since the total aerosol abundance varies significantly between wet and dry season conditions. Accordingly, the CCN spectra parametrization, which operates with constants, predictably underestimates the dry season conditions and overestimates the wet season conditions. In addition to the analytical fit approaches for the annual mean spectrum (Fig. 11a and b), we conducted an analogous CCN prediction based on seasonally resolved CCN spectra (Fig. 11c and d). The prediction accuracy clearly improves (e.g., deviation of erf fit for annual mean case equals $215 \%$ vs. $75 \%$ for seasonally resolved case; see Table 3). Figure 11 illustrates that the prediction accuracy of parametrizations that rely on analytical fit functions of CCN spectra (i.e., Twomey, erf, and related functions) improves with decreasing variability of the aerosol population (e.g., for shorter periods with less variable aerosol properties). However, the missing representation of the aerosol's temporal variability remains an inherent limitation of the $\mathrm{CCN}$ spectra parametrization. It can be concluded that this parametrization requires a minimum of aerosol input data (i.e., only the parameters of the corresponding fit function), which explains its wide use in various modeling studies. However, Fig. 11 and Table 3 show that this simplicity is clearly at the expense of the prediction accuracy. 


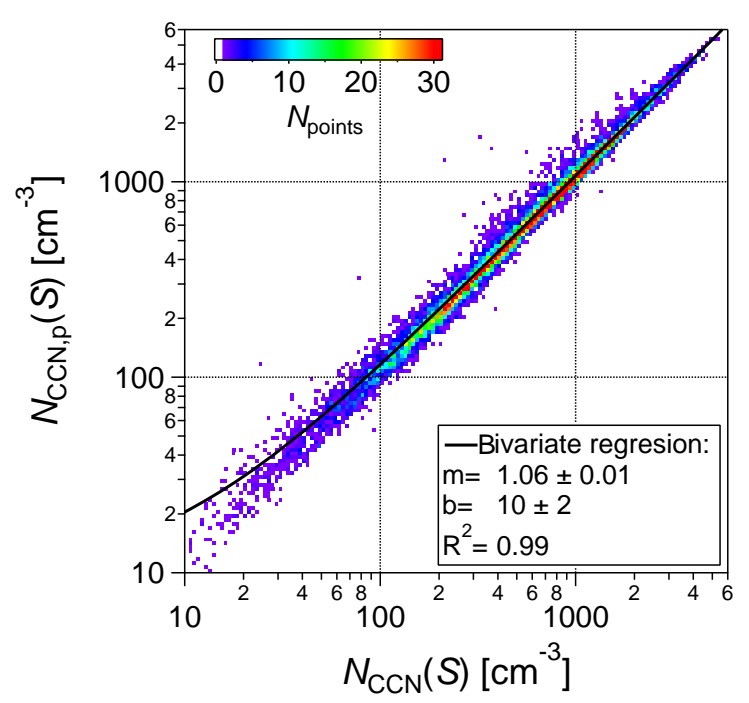

Figure 12. Predicted vs. measured CCN number concentrations using the $\kappa$-Köhler model approach. This approach requires the following time-resolved aerosol input data: (i) time-resolved aerosol size spectra spanning the CCN-relevant range (e.g., SMPS) and (ii) annual average $\kappa$ values for the Aitken and accumulation size range ( $\kappa_{\mathrm{Ait}}=0.14$ and $\left.\kappa_{\mathrm{Acc}}=0.22\right)$. The color code shows the number of data points falling into the pixel area, following Jurányi et al. (2011). The black line represents a bivariate regression fit of the data.

\subsection{4 $\kappa$-Köhler parametrization}

The $\kappa$-Köhler model approach has been used in previous studies and gave good CCN predictions (e.g., Gunthe et al., 2009; Rose et al., 2010). For the present data set, the $N_{\mathrm{CCN}, \mathrm{p}}(S)$ concentrations were calculated according to Rose et al. (2010). ${ }^{7}$ Here, the annually averaged values $\kappa_{\text {Ait }}=0.14$ and $\kappa_{\mathrm{Acc}}=0.22$ were used for the $\mathrm{CCN}$ prediction, since they accurately represent the stable $\kappa$ levels in the central Amazon. Figure 12 shows the corresponding $N_{\mathrm{CCN}, \mathrm{p}}(S)$ vs. $N_{\mathrm{CCN}}(S)$ scatterplot, in which the areas with the highest density of data points precisely follow the one-to-one line. Table 3 underlines this good agreement, as the observed deviation of around $10 \%$ between $N_{\mathrm{CCN}, \mathrm{p}}(S)$ and $N_{\mathrm{CCN}}(S)$ is the smallest among all tested parametrizations. Accordingly, the $\kappa$-Köhler model approach turns out to be a very accurate parametrization. However, it requires a time series of $N_{\mathrm{CN}}$ size distributions as input data and is therefore the most "data demanding" strategy in this regard.

\subsubsection{CCN efficiency spectra parametrization}

It has to be kept in mind that CCN spectra strongly depend on the total aerosol concentration and thus predominantly reflect

\footnotetext{
${ }^{7}$ Briefly, for every SMPS scan, the $N_{\mathrm{CN}}$ size distribution has been integrated above the critical diameter $D_{a}$, in which $D_{a}$ has been obtained based on a given $\kappa$ and $S$.
}

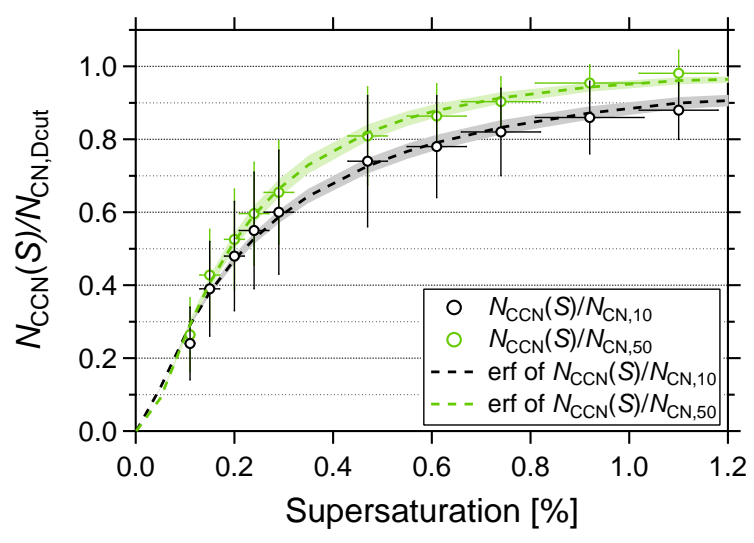

Figure 13. CCN efficiency spectra averaged over the entire measurement period for the reference concentrations, $N_{\mathrm{CN}, 10}$ and $N_{\mathrm{CN}, 50}$. The fit functions are error function fits (the dashed line with shading represents the uncertainty of the fit). The error bars at the markers represent the measurement error in $S$ and 1 standard deviation (not the standard error as in Fig. 10) in $N_{\mathrm{CCN}}(S) / N_{\mathrm{CN}, D_{\text {cut }}}$.

the specific (temporary) aerosol population during the period of the study. The shape of CCN spectra provides some information on the aerosol activation behavior as a function of $S$. However, the strong variability in the total aerosol abundance makes it difficult to compare the $\mathrm{CCN}$ efficiency behavior between different locations and/or periods of interest with specific (e.g., seasonal) conditions. For the present data set, Fig. 13 shows annually averaged CCN efficiency spectra $\left(N_{\mathrm{CCN}}(S) / N_{\mathrm{CN}, D_{\text {cut }}}\right.$ plotted against $\left.S\right)$ for two different reference aerosol concentrations $N_{\mathrm{CN}, 10}$ and $N_{\mathrm{CN}, 50}{ }^{8}$ The corresponding fit parameters are summarized in Table 7 . The $\mathrm{CCN}$ efficiency spectra are independent of the total aerosol load and instead reflect the fraction of activated particles for the relevant $S$ range. Here, we also use an erf fit,

$$
\frac{N_{\mathrm{CCN}}(S)}{N_{\mathrm{CN}, D_{\mathrm{cut}}}}=\frac{1}{2}+\frac{1}{2} \cdot \operatorname{erf}\left(\frac{\ln \left(\frac{S}{S_{1}}\right)}{w_{1}}\right),
$$

to describe the data for the same reasons as outlined in Sect. 3.5.3. The fits yield high coefficients of determination $\left(R^{2}=0.99\right)$. Per definition, $N_{\mathrm{CCN}}(S) / N_{\mathrm{CN}, D_{\text {cut }}}$ spans from zero to unity. Therefore, the offset $y_{0}$ of the function as well as the pre-factor $A$ have been set to 0.5 . For the atmospherically relevant $S$ range - typically $S<0.6 \%$ (see Andreae, 2009) - aerosol sizes around $50-60 \mathrm{~nm}$ are considered the onset of the CCN size range (see also Fig. 4). Accordingly, if $D_{\text {cut }}$ is chosen close to this activation threshold, the corresponding $N_{\mathrm{CCN}}(S) / N_{\mathrm{CN}, D_{\text {cut }}}$ approaches unity, which can be seen in Fig. 13. The free variable $S_{1}$ (e.g., $S_{1}=0.22 \pm 0.01 \%$ for $N_{\mathrm{CN}, 10}$ and $S_{1}=0.19 \pm 0.01 \%$ for $\left.N_{\mathrm{CN}, 50}\right)$ represents the

\footnotetext{
${ }^{8}$ The use of aerosol number concentrations with $D_{\text {cut }}=50 \mathrm{~nm}$ has been suggested by Paramonov et al. (2015) as a reference value to ensure comparability of CCN efficiencies from different studies.
} 
Table 7. Erf fit parameters describing CCN efficiency spectra $N_{\mathrm{CCN}}(S) / N_{\mathrm{CN}, D_{\text {cut }}}$ vs. $S$ as model input data (compare to Figs. 13 and 14). Fit parameters are provided for (i) annually averaged efficiency spectra with five different aerosol number reference concentrations $N_{\mathrm{CN}, D_{\text {cut }}}$ and (ii) resolved by seasons for $N_{\mathrm{CN}, 10}$ and $N_{\mathrm{CN}, 50}$.

\begin{tabular}{llccc}
\hline$N_{\mathrm{CN}, D_{\text {cut }}}$ & Time period & $S_{1}(\%)$ & $w_{1}$ & $R^{2}$ \\
\hline$N_{\mathrm{CN}, 10}$ & & $0.22 \pm 0.01$ & $1.78 \pm 0.08$ & 0.99 \\
$N_{\mathrm{CN}, 20}$ & Annual & $0.22 \pm 0.01$ & $1.78 \pm 0.08$ & 0.99 \\
$N_{\mathrm{CN}, 30}$ & & $0.22 \pm 0.01$ & $1.72 \pm 0.07$ & 0.99 \\
$N_{\mathrm{CN}, 50}$ & & $0.19 \pm 0.01$ & $1.41 \pm 0.05$ & 0.99 \\
\hline \multirow{3}{*}{$N_{\mathrm{CN}, 10}$} & Wet season & $0.35 \pm 0.01$ & $1.80 \pm 0.06$ & 0.99 \\
& LRT period & $0.22 \pm 0.01$ & $2.39 \pm 0.10$ & 0.98 \\
& Transition & $0.28 \pm 0.01$ & $1.70 \pm 0.05$ & 0.99 \\
& Dry season & $0.18 \pm 0.01$ & $1.57 \pm 0.11$ & 0.98 \\
\hline \multirow{3}{*}{$N_{\mathrm{CN}, 50}$} & Wet season & $0.26 \pm 0.01$ & $1.37 \pm 0.12$ & 0.99 \\
& LRT period & $0.17 \pm 0.01$ & $1.58 \pm 0.10$ & 0.99 \\
& Transition & $0.23 \pm 0.01$ & $1.38 \pm 0.04$ & 0.99 \\
& Dry season & $0.17 \pm 0.01$ & $1.31 \pm 0.06$ & 0.92 \\
\hline
\end{tabular}

$S$ value where half of the aerosol particles are activated into cloud droplets. A monodisperse aerosol with a defined composition would yield a steep step-like CCN efficiency spectrum, while the complex Amazonian aerosol results in a wide and rather smooth "step". In other words, the width of the erf fit (here $w_{1}=1.78 \pm 0.08$ for $N_{\mathrm{CN}, 10}$ and $w_{1}=1.41 \pm 0.05$ for $N_{\mathrm{CN}, 50}$ ) is an (indirect) measure for the diversity (i.e., size and composition) of the aerosol population.

Figure 14 shows a direct comparison of the $\mathrm{CCN}$ efficiency spectra resolved by seasonal periods of interest (compare also to Sect. 3.3), which reveals characteristic differences in the curve's shape (i.e., its "steepness"). The corresponding fit parameters are summarized in Table 7. A good numeric indicator for the differences in "steepness" is the fit parameter $S_{1}$, which specifies the $50 \%$ activation supersaturation of the total aerosol population. The largest contrast in shape and $S_{1}$ can be seen between the dry and wet season scenario: during the dry season, the CCN efficiency increases steeply with $S$, and $S_{1}$ is reached at $0.18 \%$ for $N_{\mathrm{CN}, 10}$, whereas during the wet season, the increase of the CCN efficiency is rather gradual and $S_{1}$ is reached only at $0.35 \%$ for $N_{\mathrm{CN}, 10}$. The transition period represents (once more) an intermediate state between the dry and wet season extremes $\left(S_{1}=0.28 \%\right.$ for $\left.N_{\mathrm{CN}, 10}\right)$. For transition period conditions, Kuhn et al. (2010) reported $N_{\mathrm{CCN}}(0.6 \%) / N_{\mathrm{CN}}=0.66 \pm 0.15$, which is in good agreement with Fig. $14 \mathrm{c}\left(N_{\mathrm{CCN}}(0.61 \%) / N_{\mathrm{CN}, 10}=0.72 \pm 0.10\right)$.

The observed differences among the $\mathrm{CCN}$ efficiency spectra in Fig. 14 reflect some of the major trends in the aerosol seasonality in Amazonia. A closer look at Fig. 6 helps to understand those. Overall, the key parameters in the $\mathrm{CCN}$ activation behavior are (primarily) the aerosol number size distribution and, in a secondary role, the particles' chemical composition, represented by $\kappa\left(S, D_{a}\right)$ (Dusek et al., 2006). Thus, the seasonally averaged number size distributions and the seasonally averaged $\kappa\left(S, D_{a}\right)$ size distribution in Fig. 6 have to be considered to explain the different shapes in Fig. 14. Focusing on the contrasting wet and dry season plots, it can be stated that (i) while the $\kappa\left(S, D_{a}\right)$ size distributions for wet and dry seasons appear to be very similar (same size trend and same values), the number size distributions (i.e., the ratio of Aitken and accumulation modes) differ substantially. (ii) With increasing $S$, the diameter $D_{a}(S)$ decreases and is shifted from the accumulation-mode towards the Aitken-mode size range. (iii) Thus, under dry season conditions, comparatively small $S$ levels $(S=0.11-0.2 \%)$ can already activate most particles of the pronounced accumulation mode. (iv) In contrast, under wet season conditions, while the same $S$ levels still activate the accumulationmode particles, the comparatively strong Aitken mode remains unactivated. This means that the ratio of Aitken- and accumulation-mode particles $\left(N_{\mathrm{CN}, \mathrm{Ait}} / N_{\mathrm{CN}, \mathrm{Acc}}(\right.$ wet $)=1.7$; $N_{\mathrm{CN}, \mathrm{Ait}} / N_{\mathrm{CN}, \mathrm{Acc}}(\mathrm{dry})=0.4$; compare to Table 2$)$ determines the activated fraction as a function of $S$ and thus also the steepness of the CCN efficiency spectra in Fig. 14.

While size appears as the dominant parameter in the $\mathrm{CCN}$ activation behavior, in certain cases variability in chemical composition also matters (Dusek et al., 2006). In Fig. 14, this can be seen for the wet season cases with and without LRT influence: in the presence of LRT aerosol, the $50 \%$ activation occurs already at $S_{1}=0.22 \%$ for $N_{\mathrm{CN}, 10}$, which is much closer to the dry $\left(S_{1}=0.18 \%\right.$ for $\left.N_{\mathrm{CN}, 10}\right)$ than to the wet season $\left(S_{1}=0.35 \%\right.$ for $\left.N_{\mathrm{CN}, 10}\right)$ behavior. While Fig. 6 shows that the number size distributions for both cases are similar, the observed difference in Fig. 14 can be explained by the deviations in the corresponding $\kappa\left(S, D_{a}\right)$ size distributions. In other words, the elevated $\kappa\left(S, D_{a}\right)$ levels during the intrusion of LRT aerosols allows the activation of particle sizes that remain inactivated at the lower $\kappa\left(S, D_{a}\right)$ levels in the absence of LRT aerosol. Therefore, the differences in chemical composition can explain the decreased $S_{1}$ in these cases.

In Fig. 14, single-erf fits have been used as analytical descriptions of the CCN efficiency spectra. Overall, this approach provides a good representation of the experimental data (see high coefficients of determination in Table 5). However, the single-erf fit is merely an approximation, assuming that the aerosol size distribution is monomodal. This is a valid assumption for the dry season (see Fig. 6) and corresponds to a good agreement between fit and data points in Fig. 14d. In contrast, the wet season shows pronounced and prevailing bimodal size distributions (see Fig. 6), which corresponds to a clear discrepancy between the fit and data points in Fig. 14b (i.e., for $S>0.3 \%$ ). For a bimodal size distribution, a double-erf fit is the physically more appropriate description (see also discussion in Sect. 3.5.3). Figure 15 illustrates the contrast between a single- and a double-erf fit 

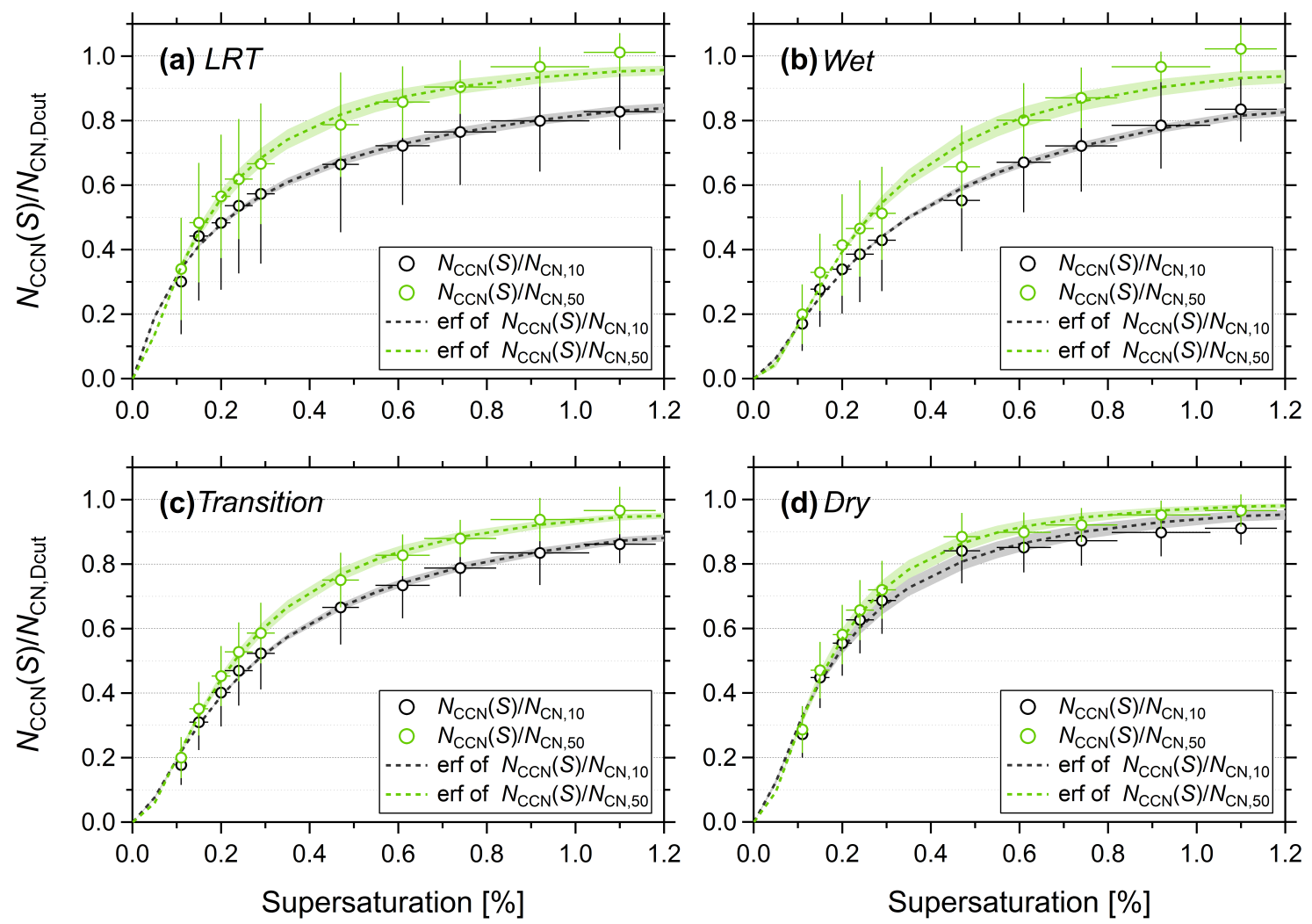

Figure 14. CCN efficiency spectra averaged over the entire measurement period for reference concentrations, $N_{\mathrm{CN}, 10}$ and $N_{\mathrm{CN}, 50}$, and subdivided into seasonal periods of interest as specified in Sect. 3.3. The fit functions are error function fits (the dashed line with shading represents the uncertainty of the fit). The error bars at the markers represent the measurement error in $S$ and 1 standard deviation (not the standard error, as in Fig. 10) in $N_{\mathrm{CCN}}(S) / N_{\mathrm{CN}, D_{\text {cut }}}$.

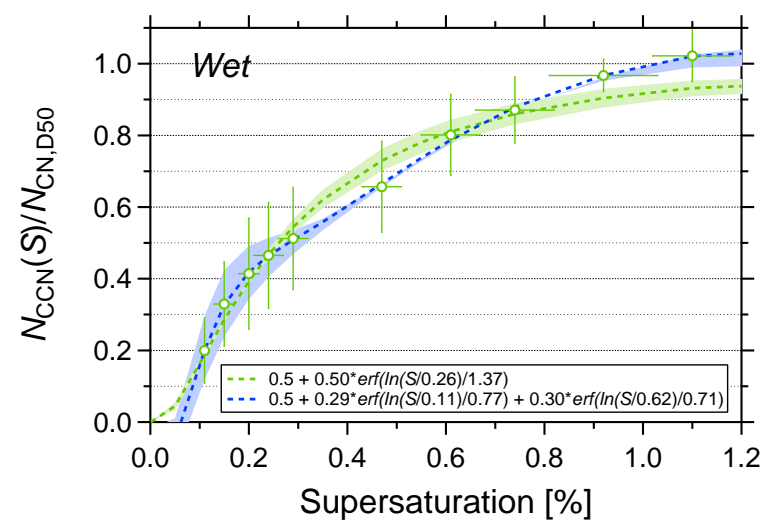

Figure 15. CCN efficiency spectrum for the wet season scenario (Fig. 14b) with $N_{\mathrm{CN}, 50}$ as reference concentration. The experimental data have been fitted with single- and double-erf fits (dashed lines with shading as uncertainty of the fits). The error bars at the markers represent the measurement error in $S$ and 1 standard deviation in $N_{\mathrm{CCN}}(S) / N_{\mathrm{CN}, 50}$. of the wet season $\mathrm{CCN}$ efficiency spectrum for $N_{\mathrm{CN}, 50}$. As expected, the double-erf fit is clearly a better representation of the data across the entire $S$ range. However, in the context of this study, the double-erf fit of CCN spectra merely serves as proof of concept. It will be discussed in more detail in a follow-up study (M. L. Pöhlker et al., 2017b). Thus, in the context of the following $\mathrm{CCN}$ parametrization, we will work exclusively with the single-erf fit approach for the following reasons: (i) the single-erf fit represents the simpler parametrization scheme (two fit parameters instead of six) and (ii) the difference in the $\mathrm{CCN}$ prediction accuracy of single- vs. double-erf fit turns out to be insignificant.

Figure 16 explores the applicability of the CCN efficiency spectra parametrization (single-erf fits) to calculate $\mathrm{CCN}$ concentrations. The following four modifications of the parametrization scheme are compared: annually averaged CCN efficiency spectra with (i) $D_{\text {cut }}=10 \mathrm{~nm}$ and (ii) $D_{\text {cut }}=50 \mathrm{~nm}$ (compare to Fig. 13) as well as seasonally resolved CCN efficiency spectra with (iii) $D_{\text {cut }}=10 \mathrm{~nm}$, and (iv) $D_{\text {cut }}=50 \mathrm{~nm}$ (compare to Fig. 14). All cases in Fig. 16 show rather tight correlations, which prove the high prediction accuracy of the CCN efficiency spectra parametrization. The corresponding deviations between $N_{\mathrm{CCN}}(S)$ and 

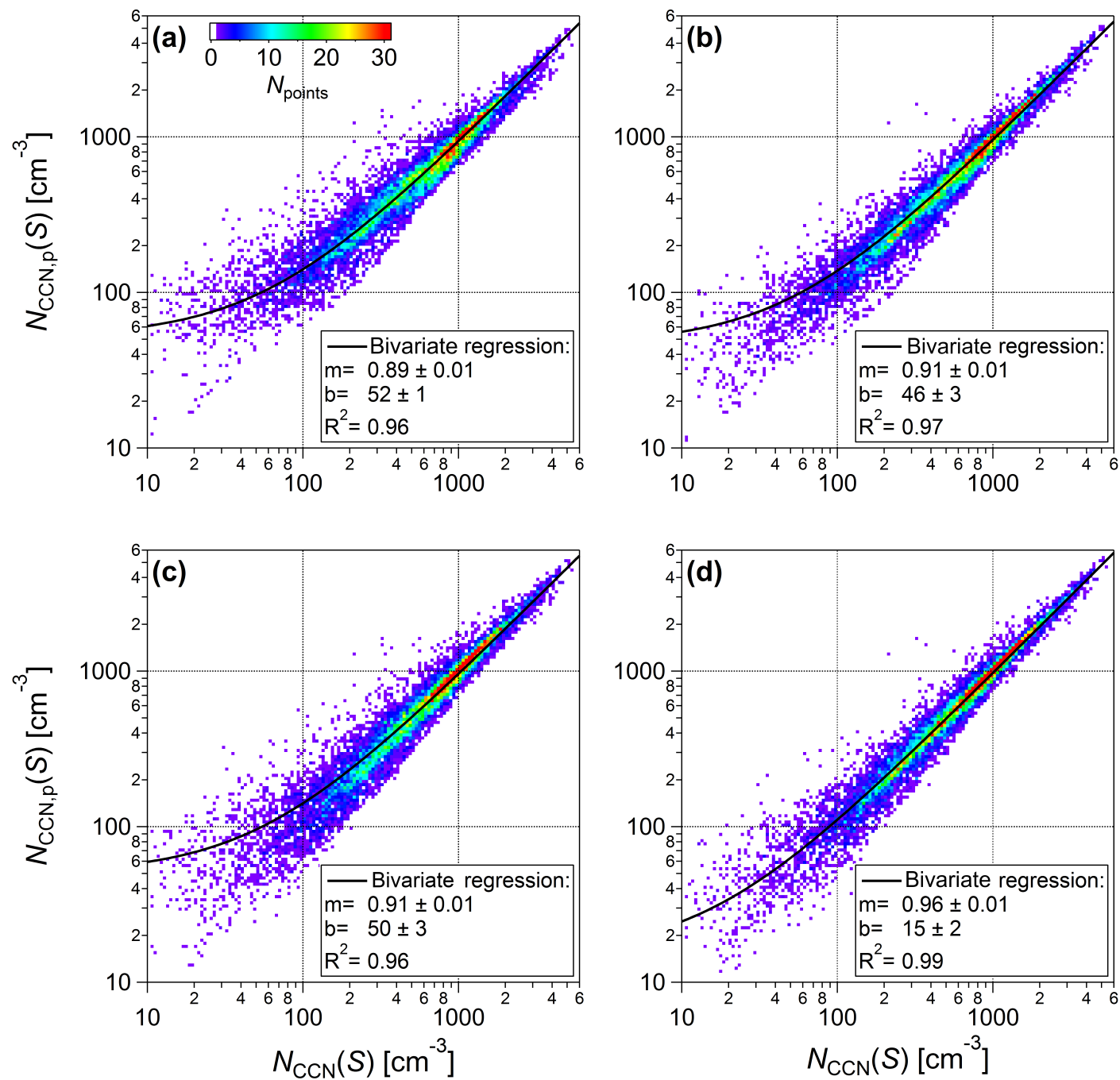

Figure 16. Predicted vs. measured CCN number concentrations, based on our novel parametrization using time-resolved aerosol number concentrations and average error function fits of $\mathrm{CCN}$ efficiency spectra. The panels show the following four variations of the parametrization: (a) erf fit of the annually averaged $N_{\mathrm{CCN}}(S) / N_{\mathrm{CN}, 10}$ vs. $S$ efficiency plot, (b) erf fit of the annually averaged $N_{\mathrm{CCN}}(S) / N_{\mathrm{CN}, 50}$ vs. $S$ efficiency plot, (c) erf fits of the $N_{\mathrm{CCN}}(S) / N_{\mathrm{CN}, 10}$ vs. $S$ efficiency plot, resolved by seasons, and (d) erf fits of the $N_{\mathrm{CCN}}(S) / N_{\mathrm{CN}, 50}$ vs. $S$ efficiency plot, resolved by seasons. This approach requires the following as input data: (i) a time series of total aerosol concentration (e.g., $N_{\mathrm{CN}, 10}$ from a CPC measurement or $N_{\mathrm{CN}, 50}$ as model output) and (ii) the parameters of the erf fit (e.g., as provided in Table 7). The color code shows the number of data points falling into the pixel area, following Jurányi et al. (2011). The black line represents a bivariate regression fit of the data.

$N_{\mathrm{CCN}, \mathrm{p}}(S)$ are summarized in Table 3. The comparison confirms that the cases with $D_{\text {cut }}=50 \mathrm{~nm}$ perform better than $D_{\text {cut }}=10 \mathrm{~nm}$. Moreover, the seasonally resolved cases show higher prediction accuracies than the annually averaged scenarios. Thus, the highest deviation of $33 \%$ is observed for the case of Fig. 16a and the lowest deviation (and therefore best performance) with $17 \%$ for the case of Fig. 16d (see Table 3).

In a way, the $\mathrm{CCN}$ efficiency spectra parametrization represents a "compromise" between the previously introduced parametrization strategies: it operates with a comparatively small set of input data and still provides good prediction ac- curacies. The input data require the fit parameters $S_{1}$ and $w_{1}$ of the single-erf fit, which reflects the "shape" of the fit functions. This part conveys the specific $\mathrm{CCN}$ activation behavior of the given aerosol population (e.g., the wet season scenario). In addition, a time series of $N_{\mathrm{CN}, D_{\text {cut }}}$ is required, which accounts for the temporal variability of the aerosol population. The new parametrization approach is currently extended and applied to further data sets worldwide (M. L. Pöhlker et al., 2017b). 


\section{Conclusions}

Size-resolved CCN measurements have been conducted at the remote ATTO site in the central Amazon, spanning a full seasonal cycle from March 2014 to February 2015. These measurements represent the first long-term study on $\mathrm{CCN}$ concentrations and hygroscopicity in this unique and globally important ecosystem. The reported measurements span the aerosol size range of $20-245 \mathrm{~nm}$ and therefore cover the Aitken and accumulation modes, which dominate the aerosol burden in the Amazon throughout the year (Andreae et al., 2015). The supersaturation in the CCN counter was cycled through 10 levels from $S=0.11 \%$ to $S=1.10 \%$. Overall, this study presents an in-depth analysis of the key CCN parameters, based on a continuous sequence of more than $10000 \mathrm{CCN}$ activation curves with a temporal resolution of $4.5 \mathrm{~h}$ and therefore allows a detailed analysis of the $\mathrm{CCN}$ cycling in the central Amazon Basin.

The Amazonian atmosphere reveals a characteristic bimodal aerosol size distribution, which is dominated by pronounced Aitken and accumulation modes $\left(D_{\text {Ait }} \sim 70 \mathrm{~nm}\right.$ vs. $\left.D_{\text {Acc }} \sim 150 \mathrm{~nm}\right)$ as well as the sparse occurrence of nucleation-mode particles $(<30 \mathrm{~nm})$. This size distribution closely relates to the observed $\mathrm{CCN}$ properties, as its entire size range - and thus the majority of particles - fall into the $\mathrm{CCN}$-active range. Accumulation-mode particles are $\mathrm{CCN}$ active at supersaturations between 0.11 and $0.29 \%$, while supersaturations between 0.47 and $1.10 \%$ activate both the Aitken and accumulation modes. The absence of nucleation-mode particles further explains the high activated fractions $N_{\mathrm{CCN}}(S) / N_{\mathrm{CN}, 10}$ that were observed throughout all seasons, with $N_{\mathrm{CCN}}(0.11 \%) / N_{\mathrm{CN}, 10}$ reaching up to 0.4 and $N_{\mathrm{CCN}}(1.10 \%) / N_{\mathrm{CN}, 10}$ constantly exceeding 0.9 . These values are substantially higher than corresponding activated fractions at other continental background sites worldwide (Jurányi et al., 2011; Levin et al., 2012; Paramonov et al., 2013). Overall, the CCN concentrations $N_{\mathrm{CCN}}(S)$ for all $S$ levels closely follow the pronounced pollution-related seasonal cycle in $N_{\mathrm{CN}}$ that is typical for the Amazon region.

The hygroscopicity parameter $\kappa\left(S, D_{a}\right)$, which reflects the chemical composition of the particles, appears to be remarkably stable throughout the entire measurement period with only a weak seasonal cycle and no perceptible diurnal trends. Numerically, the $\kappa\left(S, D_{a}\right)$ values lie within a rather narrow range from 0.1 to 0.3 for most of the time. The mean hygroscopicity averaged over the entire period and size range and its corresponding standard deviation is $\kappa_{\text {mean }}=0.17 \pm 0.06$. In terms of particle size, $\kappa\left(S, D_{a}\right)$ reveals a clear size dependence with lower values for the Aitken mode $\left(\kappa_{\text {Ait }}=\right.$ $0.14 \pm 0.03)$ and elevated levels in the accumulation-mode range $\left(\kappa_{\mathrm{Acc}}=0.22 \pm 0.05\right)$. Previous studies showed that the Amazonian aerosol population is dominated by organic aerosols throughout the seasons (Talbot et al., 1988, 1990; Graham et al., 2003; Gunthe et al., 2009; Martin et al., 2010b; Chen et al., 2015). The comparatively low $\kappa\left(S, D_{a}\right)$ values in this study underline this observation. However, the observed difference between $\kappa_{\mathrm{Ait}}$ and $\kappa_{\mathrm{Acc}}$ shows that the Aitken mode is almost purely organic (close to $\kappa=0.1$ ), while the accumulation mode is somewhat enriched in inorganic constituents.

Focusing on seasonal differences, substantial changes in the aerosol concentrations and the shape of the size distribution have been observed. During the (clean) wet season, equally strong Aitken and accumulation modes were observed, while during the (polluted) dry season the accumulation mode overwhelms the Aitken mode. The transition periods represent intermediate states between these extremes. Interestingly, the strong seasonal variability in aerosol abundance and sources does not correspond to noticeable changes in $\kappa\left(S, D_{a}\right)$. In other words, $\kappa_{\text {Ait }}$ and $\kappa_{\text {Acc }}$ are almost identical for dry and wet season conditions. The only seasonal period where $\kappa\left(S, D_{a}\right)$ deviates from its typical range is the LRT season when out-of-basin dust, marine sulfate, and sea salt are transported into the Amazon Basin. During this period, a significant increase in $\kappa_{\text {Acc }}$ up to 0.28 is observed. In summary, the seasonally averaged CCN populations (represented by the $\mathrm{CCN}$ efficiency spectra) are mostly defined by particle size (i.e., shape of aerosol size distribution). The only episodes when (besides size) chemical variability also matters are the LRT periods with their enhanced $\kappa\left(S, D_{a}\right)$ values.

Based on the $\mathrm{CCN}$ key parameters that have been obtained in the present study, we show that the $\mathrm{CCN}$ population over Amazonia can be modeled very effectively. Different approaches to infer a $\mathrm{CCN}$ concentration from basic aerosol parameters have been compared and it turns out that a remarkably good correlation between modeled and measured data can be obtained based on continuous SMPS time series as well as the annually averaged $\kappa_{\text {Ait }}$ and $\kappa_{\text {acc }}$ values from this study. Alternatively, CCN concentration can effectively be calculated based on our novel parametrization, which is based on fitted $\mathrm{CCN}$ efficiency spectra and continuous time series of total aerosol number concentrations. These efficient approaches to infer the Amazonian CCN population are expected to help improve future modeling studies.

\section{Data availability}

The CCN data of this study has been deposited as a Supplement. The data is provided in NASA Ames format (see British Atmospheric Data Centre (BADC), 2008). For specific data requests or detailed information on the deposited data, please refer to the corresponding author m.pohlker@mpic.de. 


\section{Appendix A}

Table A1. List of symbols.

\begin{tabular}{|c|c|}
\hline Symbol & Quantity and unit \\
\hline$A$ & $\mathrm{CN}$ number concentration derived from erf fit of $\mathrm{CCN}$ spectra, $\mathrm{cm}^{-3}$ \\
\hline$a\left(S, D_{i}\right)$ & cumulative Gaussian fit of multi-charge $\mathrm{CCN}$ activation fraction at a given $D$ and $S$ \\
\hline$a(S, D)$ & cumulative Gaussian fit of CCN activation fraction at a given $S$ \\
\hline$c_{\mathrm{CO}}$ & CO mole fraction, $\mathrm{ppb}$ \\
\hline$D$ & mobility equivalent particle diameter, $\mathrm{nm}$ \\
\hline$D_{a}(S)$ & midpoint activation diameter determined from $\mathrm{CCN}$ activation curve, $\mathrm{nm}$ \\
\hline$D_{\text {Ait }}$ & position of Aitken-mode maximum, nm \\
\hline$D_{\text {Acc }}$ & position of accumulation-mode maximum, $\mathrm{nm}$ \\
\hline$D_{\text {cut }}$ & lower cutoff diameter in aerosol number reference concentration $N_{C N, D c u t}, \mathrm{~nm}$ \\
\hline$D_{\mathrm{H}}$ & position of Hoppel minimum, $\mathrm{nm}$ \\
\hline$f\left(D_{i}\right)$ & multiple-charged fraction at a given $D$ \\
\hline$f_{\text {org }}$ & organic mass fraction \\
\hline$f_{\text {inorg }}$ & inorganic mass fraction \\
\hline$I$ & number of charges \\
\hline$\kappa$ & hygroscopicity parameter \\
\hline$\kappa\left(S, D_{a}\right)$ & hygroscopicity parameter determined from $\mathrm{CCN}$ activation curve \\
\hline$\kappa_{\text {Acc }}$ & mean hygroscopicity parameter for accumulation-mode particles \\
\hline$\kappa_{\text {Ait }}$ & mean hygroscopicity parameter for Aitken-mode particles \\
\hline$\kappa$ mean & mean hygroscopicity parameter for all measured $S$ \\
\hline $\operatorname{MAF}(S)$ & maximum activated fraction determined by $\mathrm{CCN}$ activation curve \\
\hline$N$ & number of data points \\
\hline$N_{\mathrm{CCN}}(S)$ & $\mathrm{CCN}$ number concentration at a given $S, \mathrm{~cm}^{-3}$ \\
\hline$N_{\mathrm{CCN}, \mathrm{p}}(S)$ & predicted CCN number concentration at a given $S, \mathrm{~cm}^{-3}$ \\
\hline$N_{\mathrm{CCN}}\left(S, D_{a}\right)$ & $\mathrm{CCN}$ number concentration determined from $\mathrm{CCN}$ activation curve, $\mathrm{cm}^{-3}$ \\
\hline$N_{\mathrm{CCN}}(S, D) / N_{\mathrm{CN}}(D)$ & $\mathrm{CCN}$ activation fraction \\
\hline$N_{\mathrm{CCN}}(S) / N_{\mathrm{CN}, D_{\mathrm{cut}}}$ & $\mathrm{CCN}$ efficiency for aerosol reference concentration $N_{\mathrm{CN}, D_{\text {cut }}}$ \\
\hline$N_{\mathrm{CN}, D_{\text {cut }}}$ & aerosol number reference concentration $\left(>D_{\text {cut }}\right), \mathrm{cm}^{-3}$ \\
\hline$N_{\mathrm{CN}, 10}$ & aerosol number reference concentration $(>10 \mathrm{~nm}), \mathrm{cm}^{-3}$ \\
\hline$N_{\mathrm{CN}, 50}$ & aerosol number reference concentration $(>50 \mathrm{~nm}), \mathrm{cm}^{-3}$ \\
\hline$N_{\mathrm{CN}, \mathrm{Acc}}$ & $\mathrm{CN}$ number concentration for accumulation-mode particles, $\mathrm{cm}^{-3}$ \\
\hline$N_{\mathrm{CN}, \text { Ait }}$ & $\mathrm{CN}$ number concentration for Aitken-mode particles, $\mathrm{cm}^{-3}$ \\
\hline$P_{\text {ATTO }}$ & precipitation rate at ATTO site, mm day $^{-1}$ \\
\hline$P_{\text {TRMM }}$ & precipitation rate from TRMM mission, $\mathrm{mm}$ day $^{-1}$ \\
\hline$S$ & water vapor supersaturation, $\%$ \\
\hline$S_{\mathrm{c}}$ & critical supersaturation for $\mathrm{CCN}$ activation, $\%$ \\
\hline$S_{\text {cloud }}\left(D_{\mathrm{H}}, \kappa\right)$ & average cloud peak supersaturation, $\%$ \\
\hline$s(D)$ & SMPS size distribution, $\mathrm{cm}^{-3}$ \\
\hline$s\left(D_{i}\right)$ & multi-charge size distribution of $D, \mathrm{~cm}^{-3}$ \\
\hline$S_{0}$ & abscissa transect of erf fit of CCN spectra, \% \\
\hline$S_{1}$ & midpoint activation supersaturation determined from $\mathrm{CCN}$ efficiency spectra, $\%$ \\
\hline$w_{0}$ & width of erf fit of CCN spectra \\
\hline$w_{1}$ & width of erf fit of CCN efficiency spectra \\
\hline$x_{0}$ & position of mobility equivalent particle diameter, $\mathrm{nm}$ \\
\hline$\sigma$ & width of log-normal fit of Aitken and accumulation modes \\
\hline$\sigma(S)$ & width of $\mathrm{CCN}$ activation curve, $\mathrm{nm}$ \\
\hline$\sigma(S) / D_{a}(S)$ & heterogeneity parameter \\
\hline
\end{tabular}


Table A2. List of abbreviations.

\begin{tabular}{|c|c|}
\hline Abbreviation & Description \\
\hline ACSM & aerosol chemical speciation monitor \\
\hline AOT & aerosol optical thickness \\
\hline ATTO & Amazon Tall Tower Observatory \\
\hline ACRIDICON & aerosol, cloud, precipitation, and radiation interactions and dynamics of convective cloud systems \\
\hline BUNIAACIC & Brazil-UK network for investigation of Amazonian atmospheric composition and impacts on climate \\
\hline $\mathrm{BC}$ & black carbon \\
\hline $\mathrm{CCN}$ & cloud condensation nuclei \\
\hline CCNC & cloud condensation nuclei counter \\
\hline $\mathrm{CN}$ & condensation nuclei \\
\hline CHUVA & $\begin{array}{l}\text { cloud processes of the main precipitation systems in Brazil: a contribution to cloud resolving modeling } \\
\text { and to the GPMs (global precipitation measurements) }\end{array}$ \\
\hline $\mathrm{CPC}$ & condensation particle counter \\
\hline $\mathrm{CO}$ & carbon monoxide \\
\hline DMA & differential mobility analyzer \\
\hline ENSO & El Niño-Southern Oscillation \\
\hline Erf & log-normal error function \\
\hline GCMs & global climate models \\
\hline GoAmazon $14 / 5$ & green ocean Amazon 2014/5 \\
\hline HALO & high-altitude and long-range research aircraft \\
\hline HTDMA & hygroscopicity tandem differential mobility analyzer \\
\hline IN & ice nuclei \\
\hline IOP & intensive observation period \\
\hline LES & large eddy simulation \\
\hline LRT & long-range transport \\
\hline NPF & new particle formation \\
\hline ONI & Oceanic Niño Index \\
\hline OPC & optical particle counter \\
\hline PSL & polystyrene latex \\
\hline RH & relative humidity \\
\hline SE & standard error \\
\hline SMPS & scanning mobility particle sizer \\
\hline SOA & secondary organic aerosol \\
\hline SST & sea surface temperature \\
\hline TRMM & tropical rainfall measuring mission \\
\hline UTC & coordinated universal time \\
\hline
\end{tabular}




\section{The Supplement related to this article is available online at doi:10.5194/acp-16-15709-2016-supplement.}

Acknowledgements. This work has been supported by the Max Planck Society (MPG) and the Max Planck Graduate Center with the Johannes Gutenberg University Mainz (MPGC). For the operation of the ATTO site, we acknowledge the support by the German Federal Ministry of Education and Research (BMBF contract 01LB1001A) and the Brazilian Ministério da Ciência, Tecnologia e Inovação (MCTI/FINEP contract 01.11.01248.00) and the Amazon State University (UEA), FAPEAM, LBA/INPA and SDS/CEUC/RDS-Uatumã, and the St. Petersburg state University, Russia (project 11.37.220.2016) as well as the EU FP7 project BACCHUS (project no. 603445). This paper contains results of research conducted under the Technical/Scientific Cooperation Agreement between the National Institute for Amazonian Research, the State University of Amazonas, and the Max Planck Gesellschaft e.V.; the opinions expressed are the entire responsibility of the authors and not of the participating institutions. We highly acknowledge the support by the Instituto Nacional de Pesquisas da Amazônia (INPA). We would like to especially thank all the people involved in the technical, logistical, and scientific support of the ATTO project, in particular Matthias Sörgel, Thomas Disper, Andrew Crozier, Uwe Schulz, Steffen Schmidt, Antonio Ocimar Manzi, Alcides Camargo Ribeiro, Hermes Braga Xavier, Elton Mendes da Silva, Nagib Alberto de Castro Souza, Adi Vasconcelos Brandão, Amaury Rodrigues Pereira, Antonio Huxley Melo Nascimento, Thiago de Lima Xavier, Josué Ferreira de Souza, Roberta Pereira de Souza, Bruno Takeshi, and Wallace Rabelo Costa. Further, we thank the GoAmazon2014/5 team for the fruitful collaboration and discussions. We acknowledge technical support by the DMT and Grimm Aerosol Technik teams in the course of the experiments. Moreover, we thank Qiaoqiao Wang, Bettina Weber, Nina Ruckteschler, Bruna Amorim Holanda, Kathrin Reinmuth-Selzle, J. Alex Huffman, Ramon Braga, and Daniel Rosenfeld for support and stimulating discussions.

The article processing charges for this open-access publication were covered by the Max Planck Society.

Edited by: G. Fisch

Reviewed by: two anonymous referees

\section{References}

Almeida, G. P., Borrmann, S., and Leal Junior, J. B. V.: Cloud condensation nuclei $(\mathrm{CCN})$ concentration in the Brazilian northeast semi-arid region: the influence of local circulation, Meteorol. Atmos. Phys., 125, 159-176, doi:10.1007/s00703-014-0329-1, 2014.

Andreae, M. O.: Aerosols before pollution, Science, 315, 50-51, doi:10.1126/science.1136529, 2007.

Andreae, M. O.: Correlation between cloud condensation nuclei concentration and aerosol optical thickness in remote and polluted regions, Atmos. Chem. Phys., 9, 543-556, doi:10.5194/acp-9-543-2009, 2009.
Andreae, M. O. and Rosenfeld, D.: Aerosol-cloudprecipitation interactions. Part 1 . The nature and sources of cloud-active aerosols, Earth-Sci. Rev., 89, 13-41, doi:10.1016/j.earscirev.2008.03.001, 2008.

Andreae, M. O., Artaxo, P., Brandao, C., Carswell, F. E., Ciccioli, P., da Costa, A. L., Culf, A. D., Esteves, J. L., Gash, J. H. C., Grace, J., Kabat, P., Lelieveld, J., Malhi, Y., Manzi, A. O., Meixner, F. X., Nobre, A. D., Nobre, C., Ruivo, M., SilvaDias, M. A., Stefani, P., Valentini, R., von Jouanne, J., and Waterloo, M. J.: Biogeochemical cycling of carbon, water, energy, trace gases, and aerosols in Amazonia: The LBA-EUSTACH experiments, J. Geophys. Res.-Atmos., 107, LBA 33-1-BA 33-25 doi:10.1029/2001jd000524, 2002.

Andreae, M. O., Artaxo, P., Beck, V., Bela, M., Freitas, S., Gerbig, C., Longo, K., Munger, J. W., Wiedemann, K. T., and Wofsy, S. C.: Carbon monoxide and related trace gases and aerosols over the Amazon Basin during the wet and dry seasons, Atmos. Chem. Phys., 12, 6041-6065, doi:10.5194/acp-12-6041-2012, 2012.

Andreae, M. O., Rosenfeld, D., Artaxo, P., Costa, A. A., Frank, G. P., Longo, K. M., and Silva-Dias, M. A. F.: Smoking rain clouds over the Amazon, Science, 303, 1337-1342, doi:10.1126/science.1092779, 2004.

Andreae, M. O., Acevedo, O. C., Araùjo, A., Artaxo, P., Barbosa, C. G. G., Barbosa, H. M. J., Brito, J., Carbone, S., Chi, X., Cintra, B. B. L., da Silva, N. F., Dias, N. L., Dias-Júnior, C. Q., Ditas, F., Ditz, R., Godoi, A. F. L., Godoi, R. H. M., Heimann, M., Hoffmann, T., Kesselmeier, J., Könemann, T., Krüger, M. L., Lavric, J. V., Manzi, A. O., Lopes, A. P., Martins, D. L., Mikhailov, E. F., Moran-Zuloaga, D., Nelson, B. W., Nölscher, A. C., Santos Nogueira, D., Piedade, M. T. F., Pöhlker, C., Pöschl, U., Quesada, C. A., Rizzo, L. V., Ro, C.-U., Ruckteschler, N., Sá, L. D. A., de Oliveira Sá, M., Sales, C. B., dos Santos, R. M. N., Saturno, J., Schöngart, J., Sörgel, M., de Souza, C. M., de Souza, R. A. F., Su, H., Targhetta, N., Tóta, J., Trebs, I., Trumbore, S., van Eijck, A., Walter, D., Wang, Z., Weber, B., Williams, J., Winderlich, J., Wittmann, F., Wolff, S., and Yáñez-Serrano, A. M.: The Amazon Tall Tower Observatory (ATTO): overview of pilot measurements on ecosystem ecology, meteorology, trace gases, and aerosols, Atmos. Chem. Phys., 15, 10723-10776, doi:10.5194/acp-15-10723-2015, 2015.

Ansmann, A., Baars, H., Tesche, M., Muller, D., Althausen, D., Engelmann, R., Pauliquevis, T., and Artaxo, P.: Dust and smoke transport from Africa to South America: Lidar profiling over Cape Verde and the Amazon rainforest, Geophys. Res. Lett., 36, L11802, doi:10.1029/2009g1037923, 2009.

Asner, G. P., Townsend, A. R., and Braswell, B. H.: Satellite observation of El Nino effects on Amazon forest phenology and productivity, Geophys. Res. Lett., 27, 981-984, doi:10.1029/1999gl011113, 2000.

Bony, S., Stevens, B., Frierson, D. M. W., Jakob, C., Kageyama, M., Pincus, R., Shepherd, T. G., Sherwood, S. C., Siebesma, A. P., Sobel, A. H., Watanabe, M., and Webb, M. J.: Clouds, circulation and climate sensitivity, Nat. Geosci., 8, 261-268, doi:10.1038/ngeo2398, 2015.

Boucher, O., Randall, D., Artaxo, P., Bretherton, C., Feingold, G., Forster, P., Kerminen, V. M., Kondo, Y., Liao, H., Lohmann, U., Rasch, P., Satheesh, S. K., Sherwood, S., B., S., and Zhang, X. Y.: Clouds and Aerosols, Cambridge, United Kingdom and New York, NY, US, 571-658, 2013. 
Boulon, J., Sellegri, K., Venzac, H., Picard, D., Weingartner, E., Wehrle, G., Collaud Coen, M., Bütikofer, R., Fl"uckiger, E., Baltensperger, U., and Laj, P.: New particle formation and ultrafine charged aerosol climatology at a high altitude site in the Alps (Jungfraujoch, 3580 m a.s.l., Switzerland), Atmos. Chem. Phys., 10, 9333-9349, doi:10.5194/acp-10-9333-2010, 2010.

Brienen, R. J. W., Phillips, O. L., Feldpausch, T. R., Gloor, E., Baker, T. R., Lloyd, J., Lopez-Gonzalez, G., MonteagudoMendoza, A., Malhi, Y., Lewis, S. L., Martinez, R. V., Alexiades, M., Davila, E. A., Alvarez-Loayza, P., Andrade, A., Aragao, L., Araujo-Murakami, A., Arets, E., Arroyo, L., Aymard, G. A., Banki, O. S., Baraloto, C., Barroso, J., Bonal, D., Boot, R. G. A., Camargo, J. L. C., Castilho, C. V., Chama, V., Chao, K. J., Chave, J., Comiskey, J. A., Valverde, F. C., da Costa, L., de Oliveira, E. A., Di Fiore, A., Erwin, T. L., Fauset, S., Forsthofer, M., Galbraith, D. R., Grahame, E. S., Groot, N., Herault, B., Higuchi, N., Coronado, E. N. H., Keeling, H., Killeen, T. J., Laurance, W. F., Laurance, S., Licona, J., Magnussen, W. E., Marimon, B. S., Marimon, B. H., Mendoza, C., Neill, D. A., Nogueira, E. M., Nunez, P., Camacho, N. C. P., Parada, A., Pardo-Molina, G., Peacock, J., Pena-Claros, M., Pickavance, G. C., Pitman, N. C. A., Poorter, L., Prieto, A., Quesada, C. A., Ramirez, F., Ramirez-Angulo, H., Restrepo, Z., Roopsind, A., Rudas, A., Salomao, R. P., Schwarz, M., Silva, N., Silva-Espejo, J. E., Silveira, M., Stropp, J., Talbot, J., ter Steege, H., Teran-Aguilar, J., Terborgh, J., ThomasCaesar, R., Toledo, M., Torello-Raventos, M., Umetsu, R. K., Van der Heijden, G. M. F., Van der Hout, P., Vieira, I. C. G., Vieira, S. A., Vilanova, E., Vos, V. A., and Zagt, R. J.: Longterm decline of the Amazon carbon sink, Nature, 519, p. 344, doi:10.1038/nature14283, 2015.

British Atmospheric Data Centre (BADC): NASA Ames Format for Data Exchange, available at: http://cedadocs.badc.rl.ac.uk/73/4/ index.html (last access: 19 December 2016), 2008.

Cantrell, C. A.: Technical Note: Review of methods for linear leastsquares fitting of data and application to atmospheric chemistry problems, Atmos. Chem. Phys., 8, 5477-5487, doi:10.5194/acp8-5477-2008, 2008.

Chen, Q., Farmer, D. K., Rizzo, L. V., Pauliquevis, T., Kuwata, M., Karl, T. G., Guenther, A., Allan, J. D., Coe, H., Andreae, M. O., Pöschl, U., Jimenez, J. L., Artaxo, P., and Martin, S. T.: Submicron particle mass concentrations and sources in the Amazonian wet season (AMAZE-08), Atmos. Chem. Phys., 15, 3687-3701, doi:10.5194/acp-15-3687-2015, 2015.

Coe, M. T., Marthews, T. R., Costa, M. H., Galbraith, D. R., Greenglass, N. L., Imbuzeiro, H. M. A., Levine, N. M., Malhi, Y., Moorcroft, P. R., Muza, M. N., Powell, T. L., Saleska, S. R., Solorzano, L. A., and Wang, J.: Deforestation and climate feedbacks threaten the ecological integrity of southsoutheastern Amazonia, Philos. T. Roy. Soc. B, 368, 1-9, doi:10.1098/rstb.2012.0155, 2013.

Cohard, J. M., Pinty, J. P., and Bedos, C.: Extending Twomey's analytical estimate of nucleated cloud droplet concentrations from CCN spectra, J. Atmos. Sci., 55, 3348-3357, doi:10.1175/15200469(1998)055<3348:etsaeo>2.0.co;2, 1998.

Cotton, W. R. and Anthes, R. A.: Storm and cloud dynamics, San Diego, Academic Press, 833 pp., 1989.

Davidson, E. A., de Araujo, A. C., Artaxo, P., Balch, J. K., Brown, I. F., Bustamante, M. M. C., Coe, M. T., DeFries, R. S., Keller, M., Longo, M., Munger, J. W., Schroeder, W., Soares-Filho, B.
S., Souza Jr., C. M., and Wofsy, S. C.: The Amazon basin in transition, Nature, 481, 321-328, doi:10.1038/nature10717, 2012.

Deng, Z. Z., Zhao, C. S., Ma, N., Ran, L., Zhou, G. Q., Lu, D. R., and Zhou, X. J.: An examination of parameterizations for the $\mathrm{CCN}$ number concentration based on in situ measurements of aerosol activation properties in the North China Plain, Atmos. Chem. Phys., 13, 6227-6237, doi:10.5194/acp-13-62272013, 2013.

Dusek, U., Frank, G. P., Hildebrandt, L., Curtius, J., Schneider, J., Walter, S., Chand, D., Drewnick, F., Hings, S., Jung, D., Borrmann, S., and Andreae, M. O.: Size matters more than chemistry for cloud-nucleating ability of aerosol particles, Science, 312, 1375-1378, doi:10.1126/science.1125261, 2006.

Engelhart, G. J., Asa-Awuku, A., Nenes, A., and Pandis, S. N.: CCN activity and droplet growth kinetics of fresh and aged monoterpene secondary organic aerosol, Atmos. Chem. Phys., 8, 39373949, doi:10.5194/acp-8-3937-2008, 2008.

Fernandes, K., Giannini, A., Verchot, L., Baethgen, W., and Pinedo-Vasquez, M.: Decadal covariability of Atlantic SSTs and western Amazon dry-season hydroclimate in observations and CMIP5 simulations, Geophys. Res. Lett., 42, 6793-6801, doi:10.1002/2015g1063911, 2015.

Frank, G. P., Dusek, U., and Andreae, M. O.: Technical note: A method for measuring size-resolved $\mathrm{CCN}$ in the atmosphere, Atmos. Chem. Phys. Discuss., 6, 4879-4895, doi:10.5194/acpd-64879-2006, 2006.

Freud, E., Rosenfeld, D., Andreae, M. O., Costa, A. A., and Artaxo, P.: Robust relations between $\mathrm{CCN}$ and the vertical evolution of cloud drop size distribution in deep convective clouds, Atmos. Chem. Phys., 8, 1661-1675, doi:10.5194/acp-8-1661-2008, 2008.

Fu, R., Dickinson, R. E., Chen, M. X., and Wang, H.: How do tropical sea surface temperatures influence the seasonal distribution of precipitation in the equatorial Amazon?, J. Climate, 14, 40034026, doi:10.1175/1520-0442(2001)014<4003:hdtsst>2.0.co;2, 2001.

Gloor, M., Barichivich, J., Ziv, G., Brienen, R., Schongart, J., Peylin, P., Cintra, B. B. L., Feldpausch, T., Phillips, O., and Baker, J.: Recent Amazon climate as background for possible ongoing and future changes of Amazon humid forests, Global Biogeochem. Cy., 29, 1384-1399, doi:10.1002/2014gb005080, 2015.

Graham, B., Guyon, P., Maenhaut, W., Taylor, P. E., Ebert, M., Matthias-Maser, S., Mayol-Bracero, O. L., Godoi, R. H. M., Artaxo, P., Meixner, F. X., Moura, M. A. L., Rocha, C., Van Grieken, R., Glovsky, M. M., Flagan, R. C., and Andreae, M. O.: Composition and diurnal variability of the natural Amazonian aerosol, J. Geophys. Res.-Atmos., 108, 4765, doi:10.1029/2003jd004049, 2003.

Gunthe, S. S., King, S. M., Rose, D., Chen, Q., Roldin, P., Farmer, D. K., Jimenez, J. L., Artaxo, P., Andreae, M. O., Martin, S. T., and Pöschl, U.: Cloud condensation nuclei in pristine tropical rainforest air of Amazonia: size-resolved measurements and modeling of atmospheric aerosol composition and CCN activity, Atmos. Chem. Phys., 9, 7551-7575, doi:10.5194/acp-9-75512009, 2009.

Hamilton, D. S., Lee, L. A., Pringle, K. J., Reddington, C. L., Spracklen, D. V., and Carslaw, K. S.: Occurrence of pristine 
aerosol environments on a polluted planet, P. Natl. Acad. Sci. USA, 111, 18466-18471, doi:10.1073/pnas.1415440111, 2014.

Hoppel, W. A., Frick, G. M., and Fitzgerald, J. W.: Deducing droplet concentration and supersaturation in marine boundary layer clouds from surface aerosol measurements, J. Geophys. Res.-Atmos., 101, 26553-26565, doi:10.1029/96jd02243, 1996.

Junk, W. J.: Current state of knowledge regarding South America wetlands and their future under global climate change, Aquat. Sci., 75, 113-131, doi:10.1007/s00027-012-0253-8, 2013.

Jurányi, Z., Gysel, M., Weingartner, E., Bukowiecki, N., Kammermann, L., and Baltensperger, U.: A 17 month climatology of the cloud condensation nuclei number concentration at the high alpine site Jungfraujoch, J. Geophys. Res.-Atmos., 116, D10204, doi:10.1029/2010JD015199, 2011.

Khain, A., Ovtchinnikov, M., Pinsky, M., Pokrovsky, A., and Krugliak, H.: Notes on the state-of-the-art numerical modeling of cloud microphysics, Atmos. Res., 55, 159-224, doi:10.1016/s0169-8095(00)00064-8, 2000.

King, S. M., Rosenoern, T., Shilling, J. E., Chen, Q., and Martin, S. T.: Cloud condensation nucleus activity of secondary organic aerosol particles mixed with sulfate, Geophys. Res. Lett., 34, 2007GL030390, doi:10.1029/2007GL030390, 2007.

Köhler, H.: The nucleus in and the growth of hygroscopic droplets, T. Faraday Soc., 32, 1152-1161, doi:10.1039/tf9363201152, 1936.

Koren, I., Kaufman, Y. J., Remer, L. A., and Martins, J. V.: Measurement of the effect of Amazon smoke on inhibition of cloud formation, Science, 303, 1342-1345, doi:10.1126/science.1089424, 2004.

Koren, I., Altaratz, O., Remer, L. A., Feingold, G., Martins, J. V., and Heiblum, R. H.: Aerosol-induced intensification of rain from the tropics to the mid-latitudes, Nat. Geosci., 5, 118-122, doi:10.1038/ngeo1364, 2012.

Krüger, M. L., Mertes, S., Klimach, T., Cheng, Y. F., Su, H., Schneider, J., Andreae, M. O., Pöschl, U., and Rose, D.: Assessment of cloud supersaturation by size-resolved aerosol particle and cloud condensation nuclei (CCN) measurements, Atmos. Meas. Tech., 7, 2615-2629, doi:10.5194/amt-7-2615-2014, 2014.

Kuhn, U., Ganzeveld, L., Thielmann, A., Dindorf, T., Schebeske, G., Welling, M., Sciare, J., Roberts, G., Meixner, F. X., Kesselmeier, J., Lelieveld, J., Kolle, O., Ciccioli, P., Lloyd, J., Trentmann, J., Artaxo, P., and Andreae, M. O.: Impact of Manaus City on the Amazon Green Ocean atmosphere: ozone production, precursor sensitivity and aerosol load, Atmos. Chem. Phys., 10, 9251-9282, doi:10.5194/acp-10-9251-2010, 2010.

Kulmala, M., Vehkamaki, H., Petaja, T., Dal Maso, M., Lauri, A., Kerminen, V. M., Birmili, W., and McMurry, P. H.: Formation and growth rates of ultrafine atmospheric particles: a review of observations, J. Aerosol Sci., 35, 143-176, doi:10.1016/j.jaerosci.2003.10.003, 2004.

Lawrence, D. and Vandecar, K.: Effects of tropical deforestation on climate and agriculture, Nature Climate Change, 5, 27-36, doi:10.1038/nclimate2430, 2015.

Lawson, S. J., Keywood, M. D., Galbally, I. E., Gras, J. L., Cainey, J. M., Cope, M. E., Krummel, P. B., Fraser, P. J., Steele, L. P., Bentley, S. T., Meyer, C. P., Ristovski, Z., and Goldstein, A. H.: Biomass burning emissions of trace gases and particles in marine air at Cape Grim, Tasmania, Atmos. Chem. Phys., 15, 1339313411, doi:10.5194/acp-15-13393-2015, 2015.
Levin, E. J. T., Prenni, A. J., Petters, M. D., Kreidenweis, S. M., Sullivan, R. C., Atwood, S. A., Ortega, J., DeMott, P. J., and Smith, J. N.: An annual cycle of size-resolved aerosol hygroscopicity at a forested site in Colorado, J. Geophys. Res.-Atmos., 117, D06201, doi:10.1029/2011JD016854, 2012.

Lohmann, U. and Feichter, J.: Global indirect aerosol effects: a review, Atmos. Chem. Phys., 5, 715-737, doi:10.5194/acp-5-7152005, 2005.

Machado, L. A. T., Silva Dias, M. A. F., Morales, C., Fisch, G., Vila, D., Albrecht, R., Goodman, S. J., Calheiros, A. J. P., Biscaro, T., Kummerow, C., Cohen, J., Fitzjarrald, D., Nascimento, E. L., Sakamoto, M. S., Cunningham, C., Chaboureau, J.-P., Petersen, W. A., Adams, D. K., Baldini, L., Angelis, C. F., Sapucci, L. F., Salio, P., Barbosa, H. M. J., Landulfo, E., Souza, R. A. F., Blakeslee, R. J., Bailey, J., Freitas, S., Lima, W. F. A., and Tokay, A.: THE CHUVA PROJECT How Does Convection Vary across Brazil?, B. Am. Meteorol. Soc., 95, 1365-1380, doi:10.1175/bams-d-13-00084.1, 2014.

Martin, S. T., Andreae, M. O., Althausen, D., Artaxo, P., Baars, H., Borrmann, S., Chen, Q., Farmer, D. K., Guenther, A., Gunthe, S. S., Jimenez, J. L., Karl, T., Longo, K., Manzi, A., Müller, T., Pauliquevis, T., Petters, M. D., Prenni, A. J., Pöschl, U., Rizzo, L. V., Schneider, J., Smith, J. N., Swietlicki, E., Tota, J., Wang, J., Wiedensohler, A., and Zorn, S. R.: An overview of the Amazonian Aerosol Characterization Experiment 2008 (AMAZE08), Atmos. Chem. Phys., 10, 11415-11438, doi:10.5194/acp10-11415-2010, 2010a.

Martin, S. T., Andreae, M. O., Artaxo, P., Baumgardner, D., Chen, Q., Goldstein, A. H., Guenther, A., Heald, C. L., Mayol-Bracero, O. L., McMurry, P. H., Pauliquevis, T., Pöschl, U., Prather, K. A., Roberts, G. C., Saleska, S. R., Dias, M. A. S., Spracklen, D. V., Swietlicki, E., and Trebs, I.: Sources and properties of Amazonian aerosol particles, Rev. Geophys., 48, RG2002, doi:10.1029/2008rg000280, 2010b.

Martin, S. T., Artaxo, P., Machado, L. A. T., Manzi, A. O., Souza, R. A. F., Schumacher, C., Wang, J., Andreae, M. O., Barbosa, H. M. J., Fan, J., Fisch, G., Goldstein, A. H., Guenther, A., Jimenez, J. L., Pöschl, U., Silva Dias, M. A., Smith, J. N., and Wendisch, M.: Introduction: Observations and Modeling of the Green Ocean Amazon (GoAmazon2014/5), Atmos. Chem. Phys., 16, 47854797, doi:10.5194/acp-16-4785-2016, 2016.

Martins, J. A., Dias, M., and Goncalves, F. L. T.: Impact of biomass burning aerosols on precipitation in the Amazon: A modeling case study, J. Geophys. Res.-Atmos., 114, 83-93, doi:10.1029/2007jd009587, 2009a.

Martins, J. A., Goncalves, F. L. T., Morales, C. A., Fisch, G. F., Pinheiro, F. G. M., Leal, J. B. V., Jr., Oliveira, C. J., Silva, E. M., Oliveira, J. C. P., Costa, A. A., and Silva Dias, M. A. F.: Cloud condensation nuclei from biomass burning during the Amazonian dry-to-wet transition season, Meteorol. Atmos. Phys., 104, 83-93, doi:10.1007/s00703-009-0019-6, 2009b.

McFiggans, G., Artaxo, P., Baltensperger, U., Coe, H., Facchini, M. C., Feingold, G., Fuzzi, S., Gysel, M., Laaksonen, A., Lohmann, U., Mentel, T. F., Murphy, D. M., O’Dowd, C. D., Snider, J. R., and Weingartner, E.: The effect of physical and chemical aerosol properties on warm cloud droplet activation, Atmos. Chem. Phys., 6, 2593-2649, doi:10.5194/acp-6-2593-2006, 2006.

Mikhailov, E., Vlasenko, S., Martin, S. T., Koop, T., and Pöschl, U.: Amorphous and crystalline aerosol particles interacting with 
water vapor: conceptual framework and experimental evidence for restructuring, phase transitions and kinetic limitations, Atmos. Chem. Phys., 9, 9491-9522, doi:10.5194/acp-9-9491-2009, 2009.

Mikhailov, E., Vlasenko, S., Rose, D., and Pöschl, U.: Mass-based hygroscopicity parameter interaction model and measurement of atmospheric aerosol water uptake, Atmos. Chem. Phys., 13, $717-$ 740, doi:10.5194/acp-13-717-2013, 2013.

Mikhailov, E. F., Mironov, G. N., Pöhlker, C., Chi, X., Krüger, M. L., Shiraiwa, M., Förster, J.-D., Pöschl, U., Vlasenko, S. S., Ryshkevich, T. I., Weigand, M., Kilcoyne, A. L. D., and Andreae, M. O.: Chemical composition, microstructure, and hygroscopic properties of aerosol particles at the Zotino Tall Tower Observatory (ZOTTO), Siberia, during a summer campaign, Atmos. Chem. Phys., 15, 8847-8869, doi:10.5194/acp-15-88472015, 2015.

Mishra, A. K., Lehahn, Y., Rudich, Y., and Koren, I.: Co-variability of smoke and fire in the Amazon basin, Atmos. Environ., 109, 97-104, doi:10.1016/j.atmosenv.2015.03.007, 2015.

Moran-Zuloaga, D., Ditas, F., Walter, D., Araùjo, A., Brito, J., Carbone, S., Chi, X., Hrabe de Angelis, I., Lavric, J. V., Ming, J., Pöhlker, M. L., Ruckteschler, N., Saturno, J., Wang, Y., Wang, Q., Weber, B., Wolff, S., Artaxo, P., Andreae, M. O., and Pöhlker, C.: Coarse mode aerosols in the Amazon rainforest, Atmos. Chem. Phys. Discuss., in preparation, 2017.

Nenes, A. and Seinfeld, J. H.: Parameterization of cloud droplet formation in global climate models, J. Geophys. Res.-Atmos., 108, AAC 7-1-ACC 7-14, doi:10.1029/2002jd002911, 2003.

Ng, N. L., Canagaratna, M. R., Zhang, Q., Jimenez, J. L., Tian, J., Ulbrich, I. M., Kroll, J. H., Docherty, K. S., Chhabra, P. S., Bahreini, R., Murphy, S. M., Seinfeld, J. H., Hildebrandt, L., Donahue, N. M., DeCarlo, P. F., Lanz, V. A., Prévôt, A. S. H., Dinar, E., Rudich, Y., and Worsnop, D. R.: Organic aerosol components observed in Northern Hemispheric datasets from Aerosol Mass Spectrometry, Atmos. Chem. Phys., 10, 46254641, doi:10.5194/acp-10-4625-2010, 2010.

Ng, N. L., Herndon, S. C., Trimborn, A., Canagaratna, M. R., Croteau, P. L., Onasch, T. B., Sueper, D., Worsnop, D. R., Zhang, Q., Sun, Y. L., and Jayne, J. T.: An Aerosol Chemical Speciation Monitor (ACSM) for Routine Monitoring of the Composition and Mass Concentrations of Ambient Aerosol, Aerosol Sci. Tech., 45, 780-794, doi:10.1080/02786826.2011.560211, 2011.

Olivares, I., Svenning, J. C., van Bodegom, P. M., and Balslev, H.: Effects of Warming and Drought on the Vegetation and Plant Diversity in the Amazon Basin, Bot. Rev., 81, 42-69, doi:10.1007/s12229-014-9149-8, 2015.

Ortega, J., Turnipseed, A., Guenther, A. B., Karl, T. G., Day, D. A., Gochis, D., Huffman, J. A., Prenni, A. J., Levin, E. J. T., Kreidenweis, S. M., DeMott, P. J., Tobo, Y., Patton, E. G., Hodzic, A., Cui, Y. Y., Harley, P. C., Hornbrook, R. S., Apel, E. C., Monson, R. K., Eller, A. S. D., Greenberg, J. P., Barth, M. C., CampuzanoJost, P., Palm, B. B., Jimenez, J. L., Aiken, A. C., Dubey, M. K., Geron, C., Offenberg, J., Ryan, M. G., Fornwalt, P. J., Pryor, S. C., Keutsch, F. N., DiGangi, J. P., Chan, A. W. H., Goldstein, A. H., Wolfe, G. M., Kim, S., Kaser, L., Schnitzhofer, R., Hansel, A., Cantrell, C. A., Mauldin, R. L., and Smith, J. N.: Overview of the Manitou Experimental Forest Observatory: site description and selected science results from 2008 to 2013, Atmos. Chem. Phys., 14, 6345-6367, doi:10.5194/acp-14-6345-2014, 2014.
Paramonov, M., Aalto, P. P., Asmi, A., Prisle, N., Kerminen, V.M., Kulmala, M., and Petäjä, T.: The analysis of size-segregated cloud condensation nuclei counter (CCNC) data and its implications for cloud droplet activation, Atmos. Chem. Phys., 13, 10285-10301, doi:10.5194/acp-13-10285-2013, 2013.

Paramonov, M., Kerminen, V.-M., Gysel, M., Aalto, P. P., Andreae, M. O., Asmi, E., Baltensperger, U., Bougiatioti, A., Brus, D., Frank, G. P., Good, N., Gunthe, S. S., Hao, L., Irwin, M., Jaatinen, A., Jurányi, Z., King, S. M., Kortelainen, A., Kristensson, A., Lihavainen, H., Kulmala, M., Lohmann, U., Martin, S. T., McFiggans, G., Mihalopoulos, N., Nenes, A., O’Dowd, C. D., Ovadnevaite, J., Petäjä, T., Pöschl, U., Roberts, G. C., Rose, D., Svenningsson, B., Swietlicki, E., Weingartner, E., Whitehead, J., Wiedensohler, A., Wittbom, C., and Sierau, B.: A synthesis of cloud condensation nuclei counter (CCNC) measurements within the EUCAARI network, Atmos. Chem. Phys., 15, 12211-12229, doi:10.5194/acp-15-12211-2015, 2015.

Petters, M. D. and Kreidenweis, S. M.: A single parameter representation of hygroscopic growth and cloud condensation nucleus activity, Atmos. Chem. Phys., 7, 1961-1971, doi:10.5194/acp-71961-2007, 2007.

Pinsky, M., Khain, A., Mazin, I., and Korolev, A.: Analytical estimation of droplet concentration at cloud base, J. Geophys. Res.Atmos., 117, D18211, doi:10.1029/2012jd017753, 2012.

Pöhlker, C., Wiedemann, K. T., Sinha, B., Shiraiwa, M., Gunthe, S. S., Smith, M., Su, H., Artaxo, P., Chen, Q., Cheng, Y. F., Elbert, W., Gilles, M. K., Kilcoyne, A. L. D., Moffet, R. C., Weigand, M., Martin, S. T., Pöschl, U., and Andreae, M. O.: Biogenic Potassium Salt Particles as Seeds for Secondary Organic Aerosol in the Amazon, Science, 337, 10751078, doi:10.1126/science.1223264, 2012.

Pöhlker, M. L., Pöhlker, C., Ditas, F., Klimach, T., Hrabe de Angelis, I., Araujo, A., Brito, J., Carbone, S., Chi, X., Cheng, Y., Ditz, R., Gunthe, S. S., Kesselmeier, J., Könemann, T., Lavric, J. V., Martin, S. T., Moran, D., Rose, D., Saturno, J., Su, H., Thalman, R., Walter, D., Wang, J., Wolff, S., Barbosa, H. M. J., Artaxo, P., Andreae, M. O., and Pöschl, U.: Long-term observations of cloud condensation nuclei in the Amazon rain forest - Part 2: Near-pristine episodes, ultrafine particle bursts, biomass burning and long range transport events, in preparation, 2017a.

Pöhlker, M. L., Rose, D., Pöhlker, C., Klimach, T., Hrabe de Angelis, I., Ditas, F., Cheng, Y., Gunthe, S. S., Su, H., Andreae, M. O., and Pöschl, U.: Parameterizations for model predictions of cloud condensation nuclei $(\mathrm{CCN})$ concentration and hygroscopicity from tropical to polar environments, in preparation, $2017 \mathrm{~b}$.

Pöschl, U.: Atmospheric aerosols: Composition, transformation, climate and health effects, Angew. Chem.-Int. Edit., 44, 75207540, doi:10.1002/anie.200501122, 2005.

Prenni, A. J., Petters, M. D., Kreidenweis, S. M., DeMott, P. J., and Ziemann, P. J.: Cloud droplet activation of secondary organic aerosol, J. Geophys. Res.-Atmos., 112, 402-405, doi:10.1029/2006jd007963, 2007.

Reutter, P., Su, H., Trentmann, J., Simmel, M., Rose, D., Gunthe, S. S., Wernli, H., Andreae, M. O., and Pöschl, U.: Aerosol- and updraft-limited regimes of cloud droplet formation: influence of particle number, size and hygroscopicity on the activation of cloud condensation nuclei (CCN), Atmos. Chem. Phys., 9, 70677080, doi:10.5194/acp-9-7067-2009, 2009. 
Rissler, J., Swietlicki, E., Zhou, J., Roberts, G., Andreae, M. O., Gatti, L. V., and Artaxo, P.: Physical properties of the submicrometer aerosol over the Amazon rain forest during the wetto-dry season transition - comparison of modeled and measured CCN concentrations, Atmos. Chem. Phys., 4, 2119-2143, doi:10.5194/acp-4-2119-2004, 2004.

Rissler, J., Vestin, A., Swietlicki, E., Fisch, G., Zhou, J., Artaxo, P., and Andreae, M. O.: Size distribution and hygroscopic properties of aerosol particles from dry-season biomass burning in Amazonia, Atmos. Chem. Phys., 6, 471-491, doi:10.5194/acp6-471-2006, 2006.

Roberts, G. C. and Nenes, A.: A continuous-flow streamwise thermal-gradient $\mathrm{CCN}$ chamber for atmospheric measurements, Aerosol Sci. Technol., 39, 206-221, doi:10.1080/027868290913988, 2005.

Roberts, G. C., Artaxo, P., Zhou, J. C., Swietlicki, E., and Andreae, M. O.: Sensitivity of CCN spectra on chemical and physical properties of aerosol: A case study from the Amazon Basin, J. Geophys. Res.-Atmos., 107, LBA 37-1-LBA 37-18 doi:10.1029/2001jd000583, 2002.

Roberts, G. C., Nenes, A., Seinfeld, J. H., and Andreae, M. O.: Impact of biomass burning on cloud properties in the Amazon Basin, J. Geophys. Res.-Atmos., 108, ACC 9-1-ACC 9-19., doi:10.1029/2001jd000985, 2003.

Roberts, M. C., Andreae, M. O., Zhou, J. C., and Artaxo, P.: Cloud condensation nuclei in the Amazon Basin: "Marine" conditions over a continent?, Geophys. Res. Lett., 28, 2807-2810, 2001.

Ronchail, J., Cochonneau, G., Molinier, M., Guyot, J. L., Chaves, A. G. D., Guimaraes, V., and de Oliveira, E.: Interannual rainfall variability in the Amazon basin and sea-surface temperatures in the equatorial Pacific and the tropical Atlantic Oceans, Int. J. Climatol., 22, 1663-1686, doi:10.1002/joc.815, 2002.

Rose, D., Gunthe, S. S., Mikhailov, E., Frank, G. P., Dusek, U., Andreae, M. O., and Pöschl, U.: Calibration and measurement uncertainties of a continuous-flow cloud condensation nuclei counter (DMT-CCNC): CCN activation of ammonium sulfate and sodium chloride aerosol particles in theory and experiment, Atmos. Chem. Phys., 8, 1153-1179, doi:10.5194/acp-8-11532008, 2008a.

Rose, D., Gunthe, S. S., Mikhailov, E., Frank, G. P., Dusek, U., Andreae, M. O., and Pöschl, U.: Calibration and measurement uncertainties of a continuous-flow cloud condensation nuclei counter (DMT-CCNC): CCN activation of ammonium sulfate and sodium chloride aerosol particles in theory and experiment, Atmos. Chem. Phys., 8, 1153-1179, doi:10.5194/acp-8-11532008, 2008b.

Rose, D., Nowak, A., Achtert, P., Wiedensohler, A., Hu, M., Shao, M., Zhang, Y., Andreae, M. O., and Pöschl, U.: Cloud condensation nuclei in polluted air and biomass burning smoke near the mega-city Guangzhou, China - Part 1: Size-resolved measurements and implications for the modeling of aerosol particle hygroscopicity and CCN activity, Atmos. Chem. Phys., 10, 33653383, doi:10.5194/acp-10-3365-2010, 2010.

Rose, D., Gunthe, S. S., Su, H., Garland, R. M., Yang, H., Berghof, M., Cheng, Y. F., Wehner, B., Achtert, P., Nowak, A., Wiedensohler, A., Takegawa, N., Kondo, Y., Hu, M., Zhang, Y., Andreae, M. O., and Pöschl, U.: Cloud condensation nuclei in polluted air and biomass burning smoke near the mega-city Guangzhou, China - Part 2: Size-resolved aerosol chemical composition, di- urnal cycles, and externally mixed weakly $\mathrm{CCN}$-active soot particles, Atmos. Chem. Phys., 11, 2817-2836, doi:10.5194/acp-112817-2011, 2011.

Rosenfeld, D., Lohmann, U., Raga, G. B., O’Dowd, C. D., Kulmala, M., Fuzzi, S., Reissell, A., and Andreae, M. O.: Flood or drought: How do aerosols affect precipitation?, Science, 321, 1309-1313, doi:10.1126/science.1160606, 2008.

Salvador, P., Almeida, S. M., Cardoso, J., Almeida-Silva, M., Nunes, T., Cerqueira, M., Alves, C., Reis, M. A., Chaves, P. C., Artíñano, B., and Pio, C.: Composition and origin of $\mathrm{PM}_{10}$ in Cape Verde: Characterization of longrange transport episodes, Atmos. Environ., 127, 326-339, doi:10.1016/j.atmosenv.2015.12.057, 2016.

Stevens, B., Farrell, D., Hirsch, L., Jansen, F., Nuijens, L., Serikov, I., Brügmann, B., Forde, M., Linne, H., Lonitz, K., and Prospero, J. M.: The Barbados Cloud Observatory - Anchoring Investigations of Clouds and Circulation on the Edge of the ITCZ, B. Am. Meteorol. Soc., 0, 787-801, doi:10.1175/BAMS-D-14-00247.1, 2016.

Su, H., Rose, D., Cheng, Y. F., Gunthe, S. S., Massling, A., Stock, M., Wiedensohler, A., Andreae, M. O., and Pöschl, U.: Hygroscopicity distribution concept for measurement data analysis and modeling of aerosol particle mixing state with regard to hygroscopic growth and CCN activation, Atmos. Chem. Phys., 10, 7489-7503, doi:10.5194/acp-10-7489-2010, 2010.

Talbot, R. W., Andreae, M. O., Andreae, T. W., and Harriss, R. C.: Regional aerosol chemistry of the amazon basin during the dry season, J. Geophys. Res.-Atmos., 93, 1499-1508, doi:10.1029/JD093iD02p01499, 1988.

Talbot, R. W., Andreae, M. O., Berresheim, H., Artaxo, P., Garstang, M., Harriss, R. C., Beecher, K. M., and Li, S. M.: Aerosol chemistry during the wet season in central amazonia - the influence of long-range transport, J. Geophys. Res.-Atmos., 95, 1695516969, doi:10.1029/JD095iD10p16955, 1990.

Thalman, R., de Sá, S. S., Palm, B. B., Barbosa, H. M. J., Plker, M. L., Alexander, M. L., Carbone, S., Day, D. A., Kuang, C., Manzi, A. O., Ng, N. L., Sedlacek, A., Souza, R. A. F., Springston, S., Watson, T., Pöhlker, C., Pöschl, U., Andreae, M. O., Artaxo, P., Jimenez, J. L., Martin, S. T., and Wang, J.: CCN activity and organic hygroscopicity of Amazonian aerosols - seasonal and diel variations and impact of anthropogenic emissions, in preparation, 2017.

Twomey, S.: The nuclei of natural cloud formation-part II: The supersaturation in natural clouds and the variation of cloud droplet concentration, Geofis Pura e Appl, 43, 243-249, 1959.

Twomey, S. and Wojciechowski, T. A.: Observations of the geographical variation of cloud nuclei, J. Atmos. Sci., 26, 684-688, 1969.

Vestin, A., Rissler, J., Swietlicki, E., Frank, G. P., and Andreae, M. O.: Cloud-nucleating properties of the Amazonian biomass burning aerosol: Cloud condensation nuclei measurements and modeling, J. Geophys. Res.-Atmos., 112, D14201, doi:10.1029/2006jd8104, 2007.

Wendisch, M., Pöschl, U., Andreae, M. O., Machado, L. A. T., Albrecht, R., Schlager, H., Rosenfeld, D., Martin, S. T., Abdelmonem, A., Afchine, A., Araùjo, A., Artaxo, P., Aufmhoff, H., Barbosa, H. M. J., Borrmann, S., Braga, R., Buchholz, B., Cecchini, M. A., Costa, A., Curtius, J., Dollner, M., Dorf, M., Dreiling, V., Ebert, V., Ehrlich, A., Ewald, F., Fisch, G., Fix, A., Frank, 
F., Fütterer, D., Heckl, C., Heidelberg, F., Hüneke, T., Jäkel, E., Järvinen, E., Jurkat, T., Kanter, S., Kästner, U., Kenntner, M., Kesselmeier, J., Klimach, T., Knecht, M., Kohl, R., Kölling, T., Krämer, M., Krüger, M., Krisna, T. C., Lavric, J. V., Longo, K., Mahnke, C., Manzi, A. O., Mayer, B., Mertes, S., Minikin, A., Molleker, S., Münch, S., Nillius, B., Pfeilsticker, K., Pöhlker, C., Roiger, A., Rose, D., Rosenow, D., Sauer, D., Schnaiter, M., Schneider, J., Schulz, C., de Souza, R. A. F., Spanu, A., Stock, P., Vila, D., Voigt, C., Walser, A., Walter, D., Weigel, R., Weinzierl, B., Werner, F., Yamasoe, M. A., Ziereis, H., Zinner, T., and Zöger, M.: ACRIDICON-CHUVA Campaign: Studying Tropical Deep Convective Clouds and Precipitation over Amazonia Using the New German Research Aircraft HALO, B. Am. Meteorol. Soc., 97, 1885-1908, doi:10.1175/bams-d-14-00255.1, 2016.

Wex, H., Petters, M. D., Carrico, C. M., Hallbauer, E., Massling, A., McMeeking, G. R., Poulain, L., Wu, Z., Kreidenweis, S. M., and Stratmann, F.: Towards closing the gap between hygroscopic growth and activation for secondary organic aerosol: Part $1-$ Evidence from measurements, Atmos. Chem. Phys., 9, 3987-3997, doi:10.5194/acp-9-3987-2009, 2009.
Whitehead, J. D., Darbyshire, E., Brito, J., Barbosa, H. M. J., Crawford, I., Stern, R., Gallagher, M. W., Kaye, P. H., Allan, J. D., Coe, H., Artaxo, P., and McFiggans, G.: Biogenic cloud nuclei in the central Amazon during the transition from wet to dry season, Atmos. Chem. Phys., 16, 9727-9743, doi:10.5194/acp-16-97272016, 2016.

Winderlich, J., Chen, H., Gerbig, C., Seifert, T., Kolle, O., Lavric, J. V., Kaiser, C., Höfer, A., and Heimann, M.: Continuous lowmaintenance $\mathrm{CO}_{2} / \mathrm{CH}_{4} / \mathrm{H}_{2} \mathrm{O}$ measurements at the Zotino Tall Tower Observatory (ZOTTO) in Central Siberia, Atmos. Meas. Tech., 3, 1113-1128, doi:10.5194/amt-3-1113-2010, 2010.

Yáñez-Serrano, A. M., Nölscher, A. C., Williams, J., Wolff, S., Alves, E., Martins, G. A., Bourtsoukidis, E., Brito, J., Jardine, K., Artaxo, P., and Kesselmeier, J.: Diel and seasonal changes of biogenic volatile organic compounds within and above an Amazonian rainforest, Atmos. Chem. Phys., 15, 3359-3378, doi:10.5194/acp-15-3359-2015, 2015.

Zhou, J., Swietlicki, E., Hansson, H. C., and Artaxo, P.: Submicrometer aerosol particle size distribution and hygroscopic growth measured in the Amazon rain forest during the wet season, J. Geophys. Res., 107, 8055, doi:10.1029/2000jd000203, 2002. 